\title{
UNIVERSIDADE DE SÃO PAULO \\ ESCOLA DE EDUCAÇÃO FÍSICA E ESPORTE
}

\section{PAPEL DO TREINAMENTO FÍSICO AERÓBICO NA PLASTICIDADE MUSCULAR EM MODELO EXPERIMENTAL DE INSUFICIÊNCIA CARDÍACA POR HIPERTENSÃO PULMONAR}

JANAINA DA SILVA VIEIRA

São Paulo 


\section{PAPEL DO TREINAMENTO FÍSICO AERÓBICO NA PLASTICIDADE MUSCULAR EM MODELO EXPERIMENTAL DE INSUFICIÊNCIA CARDÍACA POR HIPERTENSÃO PULMONAR}

Dissertação apresentada à Escola de Educação Física e Esporte da Universidade de São Paulo como requisito parcial para obtenção do título de Mestre em Ciências

Área de Concentração: Estudos Biodinâmicos da Educação Física e Esporte

Orientadora: Prof ${ }^{\mathrm{a}}$ Dr $^{\mathrm{a}}$ Patricia Chakur Brum 
Catalogação da Publicação

Serviço de Biblioteca

Escola de Educação Física e Esporte da Universidade de São Paulo

Vieira, Janaina da Silva

Papel do treinamento físico aeróbio na plasticidade muscular em modelo experimental de insuficiência cardíaca por hipertensão pulmonar / Janaina da Silva Vieira. - São Paulo : [s.n.], 2020. 100 p.

Dissertação (Mestrado) - Escola de Educação Física e Esporte da Universidade de São Paulo.

Orientadora Profa. Dra Patricia Chakur Brum

1. Insuficiência cardíaca 2. Treinamento físico 3. Hipertensão Pulmonar I. Título. 


\section{FOLHA DE APROVAÇÃO}

Autor: DA SILVA VIEIRA, Janaina

Título: Papel do treinamento físico aeróbico na plasticidade muscular em modelo experimental de insuficiência cardíaca por hipertensão pulmonar

Dissertação apresentada à Escola de Educação Física e Esporte da Universidade de São Paulo como requisito parcial para obtenção do título de Mestre em Ciências

Data:

Banca examinadora

Prof. Dr.:

Instituição: Julgamento:

Prof. Dr.:

Instituição: Julgamento:

Prof. Dr.:

Instituição: Julgamento: 
Dedico esse trabalho aos meus pais, Josefa e Amadeu, por sempre me incentivarem a buscar conhecimento e ser um ser humano melhor. 


\section{AGRADECIMENTOS}

À minha família, por todo amor, carinho, paciência e incentivo ao longo da minha vida, que contribuíram e contribuem a todo momento para meu crescimento no âmbito profissional e pessoal. Especialmente aos meus pais, meus maiores e melhores exemplos, sem vocês jamais teria chegado até aqui.

À Patricia Brum, pela oportunidade de fazer parte do seu grupo. Por ser um exemplo de ser humano e de pesquisadora que me serve de inspiração cada dia mais. Obrigada pelos ensinamentos, respeito, apoio e carinho.

À Aline Villa Nova Bacurau, minha primeira orientadora e grande companheira de trabalho ao longo desses anos. Foi quem me apresentou à vida científica e quem primeiro me inspirou com seu amor à ciência.

Aos meus colaboradores, Paulo Magno, Marcele, Lucas Carrascoza, pela disposição, dedicação e por sempre trabalharem ao meu lado com alegria.

Ao Luciano, Telma e Nathalie, companheiros de trabalho que muito me ensinaram e se tornaram grandes amigos.

Aos meus amigos, por todo o apoio, incentivo e momentos de alegria compartilhados ao longo dos anos.

Aos funcionários da EEFE, por toda a ajuda e por contribuírem com a manutenção e segurança da escola, tornando-a um ambiente de trabalho prazeroso.

Aos colegas e técnicos dos laboratórios de Fisiologia e Bioquímica, por toda a ajuda com meu trabalho e por tornar o ambiente de trabalho mais agradável e divertido.

À FAPESP (2016/24284-6), CAPES e CNPq, pelo apoio financeiro. 
"A vida sem ciência é uma espécie de morte." Sócrates 


\section{RESUMO}

VIEIRA, Janaina da Silva. Papel do treinamento físico aeróbico na plasticidade muscular em modelo experimental de insuficiência cardíaca por hipertensão pulmonar. $100 \mathrm{f}$. Dissertação (Mestrado em Ciências). Escola de Educação Física e Esporte, Universidade de São Paulo, São Paulo. 2020.

A hipertensão pulmonar (HP) é uma síndrome crônica, sendo a maior causa de insuficiência cardíaca direita (ICD) não relacionada à disfunção do ventrículo esquerdo (VE), com prevalência de 50\% em pacientes com ICD (IC com fração de ejeção do ventrículo esquerdo preservada). A ICD pode culminar em atrofia muscular que está diretamente relacionada com o mau prognóstico de pacientes com insuficiência cardíaca (IC) e contribui para a intolerância ao esforço físico apresentada por pacientes com ICD induzida por HP. No entanto, existe uma lacuna na literatura sobre em que fase da ICD o quadro de miopatia esquelética se estabelece e estratégias eficientes para minimizar a perda de massa e função muscular na ICD induzida por HP. Nas últimas décadas vem crescendo o número de evidências que apontam o treinamento físico aeróbico (TFA) como um importante coadjuvante no tratamento da IC, trazendo benefícios metabólicos e estruturais para os indivíduos portadores desta síndrome. De fato, trabalhos prévios do nosso grupo demonstraram que o TFA minimiza a miopatia esquelética tanto em pacientes como em modelos experimentais de IC com disfunção do VE. Contudo, o potencial efeito do treinamento físico sobre a fisiopatologia ICD ainda não está completamente esclarecido, uma vez que tal intervenção deixou de ser proscrita há poucos anos nesta síndrome. Existem diversos modelos de IC utilizados para a melhor compreensão da IC esquerda em camundongos, contudo, para estudo de ICD, ainda há uma escassez de modelos já caracterizados. Desta forma foi objetivo desse projeto padronizar um modelo robusto de ICD induzido por monocrotalina (MCT), bem como avaliar o impacto do TFA sobre a musculatura esquelética e cardíaca em camundongos com disfunção do ventrículo direito. Nós utilizamos camundongos C57BL6/J, tratados com (MCT) ou salina. O tratamento com MCT por 2 meses causou hipertrofia e disfunção do ventrículo direito acompanhada de edema pulmonar sem afetar o VE ou a tolerância ao esforço dos animais comparado aos animais tratados com salina, caracterizando um quadro de ICD isolada induzida por HP. Já aos 4 meses de tratamento com MCT, observou-se disfunção dos ventrículos direito e esquerdo acompanhada de edema pulmonar, associados à intolerância ao esforço e à atrofia de fibras do tipo II comparado ao tratamento com salina. Portanto, nessa fase da doença, há uma ICD grave que compromete a função do VE associada à intolerância aos esforços e à miopatia esquelética. Para estudar o 
efeito do TFA no tratamento da IC induzida por HP, animais tratados com MCT por 4 meses foram submetidos ao TFA nas últimas 4 semanas de tratamento. O TFA foi eficiente em melhorar a função do VE e a tolerância ao esforço físico em animais tratados com MCT, bem como reestabelecer o trofismo do músculo cardíaco e esquelético sendo, assim, uma estratégia interessante para tratamento da miopatia esquelética na ICD induzida por HP.

Palavras-chave: insuficiência cardíaca direita, músculo esquelético, treinamento físico aeróbico. 


\begin{abstract}
VIEIRA, Janaina da Silva. Role of aerobic exercise training in muscle plasticity in experimental model of heart failure induced by pulmonary hypertension. $100 \mathrm{f}$.
\end{abstract} Dissertação (Mestrado em Ciências). Escola de Educação Física e Esporte, Universidade de São Paulo, São Paulo. 2020.

Pulmonary hypertension $(\mathrm{PH})$ is a chronic syndrome and the major cause of right heart failure non-related with left ventricular dysfunction, with a prevalence of $50 \%$ in patients with right heart failure (HF) (HF with preserved left ventricular ejection fraction). Right HF can culminate in muscle atrophy that is directly related to the poor prognosis of HF patients as it contributes to exercise intolerance. However, there is a gap in the literature regarding the right HF phase that skeletal myopathy is stablished and effective strategies to minimize the loss of muscle mass and function on $\mathrm{PH}$-induced right $\mathrm{HF}$. In recent decades, the number of evidences supporting aerobic exercise training (AET) as an important secondary treatment for HF has increased. In fact, previous work of our group has shown that AET minimizes skeletal myopathy in both patients and experimental models of HF with left ventricular dysfunction. However, the potential effect of AET on the pathophysiology of HF is not yet fully understood, as this intervention has been prescribed only a few years ago for right HF. There are several HF models used to better understand left HF in mice, but there is still a lack of good models to study right HF in mice. Thus, the aim of this project was to characterize a robust model of monocrotaline (MCT)-induced right HF, as well as to evaluate the impact of AET on skeletal and cardiac muscle of mice with right HF. We have used C57BL6 / J mice treated with (MCT) or saline. The treatment with MCT for two months induced right ventricular dysfunction paralleled by pulmonary edema, hypertrophy without affecting left ventricle or exercise tolerance compared with saline treated group, which characterizes an isolated right HF at this stage of the syndrome. Four months of MCT treatment caused right and left ventricular dysfunction with pulmonary edema associated with exercise intolerance and atrophy of type II fibers compared with saline group. Therefore, at this stage, the right HF is severe and compromises left ventricle function leading to exercise intolerance and skeletal myopathy. To better understand the effects AET on PH-induced right HF, animals treated with MCT for 4 months were submitted to AET in the last 4 weeks of treatment. AET was effective in improving left ventricular function and exercise tolerance on MCT group, as well as restoring cardiac and skeletal muscle trophicity, being an interesting strategy for the treatment of skeletal myopathy in PH-induced right HF.

Keywords: right heart failure, skeletal muscle, aerobic exercise training. 


\section{LISTA DE SIGLAS, ABREVIATURAS E SÍMBOLOS}

\begin{tabular}{|c|c|}
\hline ANOVA & Análise de variância \\
\hline AST & Área de secção transversa \\
\hline $\mathrm{Ca}^{2+}$ & Íon $\mathrm{Ca}^{2+}$ \\
\hline cDNA & Ácido desoxirribonucleico cópia \\
\hline CS & Células satélites \\
\hline EDL & Extensor digitorum longus \\
\hline FGF & Fator de crescimento fibroblástico \\
\hline $\mathrm{HGF}$ & Fator de crescimento tipo hepatócitos \\
\hline IGF-I & Fator de crescimento similar à insulina-I \\
\hline HP & Hipertensão pulmonar \\
\hline $\mathrm{IC}$ & Insuficiência cardíaca \\
\hline $\mathrm{ICD}$ & Insuficiência cardíaca direita \\
\hline MCT & Monocrotalina \\
\hline MCTP & Monocrotalinapirrol \\
\hline MHC & Miosina de cabeça pesada \\
\hline MRF4 & Fator regulador miogênico 4 \\
\hline Myf-5 & Fator miogênico 5 \\
\hline MyoD & Proteína de determinação de mioblasto-1 \\
\hline
\end{tabular}




$\begin{array}{ll}\text { Pax7 } & \text { Paired box protein } 7 \\ \text { qRT-PCR } & \begin{array}{l}\text { técnica de reação em cadeia da polimerase quantitativa em tempo } \\ \text { real }\end{array} \\ \text { RNA } & \text { Ácido ribonucleico } \\ \text { TF } & \text { Treinamento físico aeróbico } \\ \text { TFA } & \text { Fator de transformação do crescimento beta } \\ \text { TGF- } \beta & \text { Fator de necrose tumoral } \alpha \\ \text { TNF } \alpha & \text { Ventrículo direito } \\ \text { VD } & \text { Ventrículo esquerdo } \\ \text { VE } & \end{array}$

\section{Unidades}

$\begin{array}{ll}\mathrm{mmHg} & \text { Milímetros de mercúrio } \\ \mathrm{L} & \text { Litro } \\ \mu \mathrm{L} & \text { Microlitro } \\ \mathrm{m} & \text { Metro } \\ \mathrm{cm} & \text { Centímetro } \\ \mathrm{mm} & \text { Milímetro } \\ \mu \mathrm{m} & \text { Micrometro }\left(10^{-6}\right) \\ \mathrm{min} & \text { Minuto } \\ \mathrm{ms} & \text { Milissegundo }\end{array}$


g

mg

M

$\mathrm{mM}$

$\mu \mathrm{M}$
Grama

Miligrama

Molar

Milimolar

Micromolar 


\section{LISTA DE FIGURAS}

Página

FIGURA 1 Mecanismo de ação da monocrotalina. Adaptado de http://www.sw.org/HealthLibrary/Pulmonary_Hypertension. MCT, Monocrotalina; MCTP, Monocrotalinapirrol

FIGURA 2 Desenhos experimentais da etapa I. Protocolo de tratamento com monocrotalina $(80 \mathrm{mg} / \mathrm{kg}$ ) por 2 meses (A). Protocolo de tratamento com monocrotalina $(80 \mathrm{mg} / \mathrm{kg})$ por 4 meses (B). MCT, monocrotalina

FIGURA 3 Desenho experimental da etapa II. Protocolo de treinamento físico aeróbico por 4 semanas em esteira rolante (A). MCT, monocrotalina

FIGURA 4 Camundongos tratados com alta dose de monocrotalina (600 $\mathrm{mg} / \mathrm{kg}$ ) apresentam menor sobrevida. Curva de sobrevida (A) e massa corporal (B) de camundongos tratados com salina (linha preta ou círculos pretos) ou monocrotalina (doses semanais de $600 \mathrm{mg} / \mathrm{kg}$, representados pela linha tracejada ou quadrados vermelhos). Os dados estão representados na forma de média \pm erro padrão da média. * diferença significante vs. salina, $\mathrm{p}<0,05$. Para a curva de sobrevida, os dados foram comparados entre os grupos pelo teste Mantel-Haenszel logrank. Para o acompanhamento ponderal, os dados foram comparados entre os grupos pela ANOVA de um caminho com medidas repetidas 
FIGURA 5 80mg/kg dose de monocrotalina não altera a massa corporal e a ingestão alimentar de camundongos. Massa corporal durante a primeira semana de tratamento com monocrotalina (A) e ao longo de 15 semanas do protocolo experimental (B) de camundongos tratados com salina (círculos pretos) ou monocrotalina (doses a cada 20 dias de $80 \mathrm{mg} / \mathrm{kg}$, representados pelos quadrados cinzas). Ingestão alimentar (C) ao longo do tratamento nos grupos supracitados. Os dados estão representados na forma de média \pm erro padrão da média. Os dados foram comparados entre os grupos pela ANOVA de um caminho com medidas repetidas

FIGURA 6 Tratamento por 2 meses com monocrotalina induz edema pulmonar disfunção do VD, sem induzir intolerância ao esforço ou comprometimento da função muscular. Esquema do desenho experimental (A), coloração por hematoxilina eosina em cortes transversais do pulmão (as setas indicam área de edema pulmonar) (B) e o número de eventos de edema pulmonar (C). Fração de encurtamento por ecocardiograma (D) e espessura da parede livre por histologia do VD (E). Fração de encurtamento $(F)$, fração de ejeção $(G)$ e diâmetro de cardiomiócitos $(\mathrm{H})$ do VE. Distância percorrida em teste de tolerância ao esforço (I), tempo até a queda no teste de rotarod (J) e força máxima de contração isométrica (K) em camundongos tratados com salina (barras brancas) ou monocrotalina (doses a cada 20 dias de $80 \mathrm{mg} / \mathrm{kg}$, representados pelas barras vermelhas). Os dados estão representados na forma de média \pm erro padrão da média. Os dados foram analisados pelo teste $\mathrm{t}$ de Student para dados não pareados. * diferença significante vs. salina, $\mathrm{p}<0.05$; ** diferença significante vs. salina, $\mathrm{p}<0,01$. MCT, monocrotalina; VD, ventrículo direito; VE, ventrículo esquerdo 
FIGURA 7 Mudanças funcionais e estruturais desencadeadas pelo tratamento por 4 meses com monocrotalina. Esquema do desenho experimental (A), coloração por hematoxilina eosina em cortes transversais do pulmão (as setas indicam área de edema pulmonar) (B) e o número de eventos de edema pulmonar (C). Fração de encurtamento por ecocardiograma (D) e espessura da parede livre por histologia do VD (E). Fração de encurtamento $(\mathrm{F})$, fração de ejeção $(\mathrm{G})$ e diâmetro de cardiomiócitos $(\mathrm{H})$ do VE de camundongos tratados com salina (barras brancas) ou monocrotalina (doses a cada 20 dias de $80 \mathrm{mg} / \mathrm{kg}$, representados pelas barras vermelhas). Os dados estão representados na forma de média \pm erro padrão da média. Os dados foram analisados pelo teste $\mathrm{t}$ de Student para dados não pareados. $*$ diferença significante vs. salina, $\mathrm{p}<0.05 ; * *$ diferença significante vs. salina, $\mathrm{p}<0,01$. MCT, monocrotalina; VD, ventrículo direito; VE, ventrículo esquerdo 
FIGURA 8 Alterações funcionais e estruturais desencadeadas pelo tratamento com monocrotalina no músculo esquelético. Distância percorrida em teste de tolerância ao esforço (A), tempo até a queda no teste de rotarod (B) e força máxima de contração isométrica (C). Painel representativo com as marcações por imunofluorescência para fibras do tipo I (MHC I, vermelho) no músculo sóleo, fibras do tipo IIA (MHC IIa, verde) nos músculos EDL e tibial anterior, e laminina (marcação do sarcolema, verde no sóleo e vermelha no EDL e tibial anterior) (D). Área de secção transversa (AST) das fibras do tipo I e II do músculo sóleo (E) e AST fibras do tipo II e IIA dos músculos EDL (F) e tibial anterior (G) em camundongos tratados com salina (barras brancas) ou monocrotalina (doses a cada 20 dias de $80 \mathrm{mg} / \mathrm{kg}$, representados pelas barras vermelhas). Os dados estão representados na forma de média \pm erro padrão da média. Os dados foram analisados pelo teste $t$ de Student para dados não pareados. * diferença significante vs. salina, $\mathrm{p}<0.05 ; * *$ diferença significante vs. salina, $\mathrm{p}<0,01$. AST, área de secção transversa; EDL, extensor digitorum longus; MCT, monocrotalina

FIGURA 9 Tipagem de fibras e razão capilar por fibra do músculo EDL de animais tratados com monocrotalina. Painel representativo com as marcações por imunofluorescência para fibras do tipo IIA (MHC IIa, verde) e laminina (marcação do sarcolema, vermelha) (A). Percentual de fibras tipo I e IIA do músculo EDL (B). Painel representativo com as marcações por imunofluorescência para marcação de vasos (CD31, vermelho) e laminina (marcação do sarcolema, verde) (C). Razão capilar por fibra do músculo EDL (D) de camundongos 
tratados com salina (círculos ou barras pretas) ou monocrotalina (doses a cada 20 dias de $80 \mathrm{mg} / \mathrm{kg}$, representados pelos quadrados ou barras cinzas). Os dados estão representados na forma de média \pm erro padrão da média. Os dados foram analisados pelo teste $\mathrm{t}$ de Student para dados não pareados. *diferença significante vs. salina, $\mathrm{p}<0.05$. As setas brancas indicam as fibras positivas para MHC IIA. EDL, extensor digitorum longus. MCT, monocrotalina

FIGURA 10 Efeito do treinamento físico aeróbico nas mudanças funcionais e estruturais desencadeadas pelo tratamento com monocrotalina no músculo cardíaco e tecido pulmonar. Esquema do desenho experimental (A), coloração por hematoxilina eosina em cortes transversais do pulmão (as setas indicam área de edema pulmonar) (B) e o número de eventos de edema pulmonar (C). Fração de encurtamento por ecocardiograma (D) e espessura da parede livre por histologia do VD (E). Fração de encurtamento (F), fração de ejeção $(G)$ e diâmetro de cardiomiócitos $(\mathrm{H})$ do ventrículo esquerdo de camundongos tratados com salina (barras brancas) ou monocrotalina (doses a cada 20 dias de $80 \mathrm{mg} / \mathrm{kg}$, representados pelas barras vermelhas), sedentários (barras brancas e vermelhas) e após 1 mês de treinamento físico aeróbico (barras azuis e salmão) (do 3o ao 4o mês do período experimental). Os dados foram comparados pela ANOVA de dois caminhos. * diferença significante vs. grupo indicado pelo traço, $\mathrm{p}<0.05$. MCT, monocrotalina; TF, treinamento físico; VD, ventrículo direito; VE, ventrículo esquerdo 
FIGURA 11 Efeito do treinamento físico aeróbico nas mudanças funcionais e estruturais desencadeadas pelo tratamento com monocrotalina no músculo esquelético. Distância percorrida em teste de tolerância ao esforço (A). Painel representativo com as marcações por imunofluorescência para fibras do tipo IIA (MHC IIa, verde) e laminina (marcação do sarcolema, vermelha) no músculo tibial anterior (C). Área de secção transversa (AST) das fibras do tipo IIX/B (D) e IIA (E) do músculo tibial anterior em camundongos tratados com salina (barras brancas) ou monocrotalina (doses a cada 20 dias de $80 \mathrm{mg} / \mathrm{kg}$, representados pelas barras vermelhas), sedentários (barras brancas e vermelhas) e após 1 mês de treinamento físico aeróbico (barras azuis e salmão) (do 3o ao 4o mês do período experimental). Os dados foram comparados pela ANOVA de dois caminhos. * diferença significante vs. grupo indicado pelo traço, $\mathrm{p}<0.05$. AST, área de secção transversa; MCT, monocrotalina; TF, treinamento físico

FIGURA 12 Efeito do treinamento físico aeróbico nas células satélites e nos indicadores de lesão/regeneração do músculo tibial anterior no quadro de miopatia muscular após tratamento com monocrotalina. Coloração por hematoxilina-eosina para análise do número de eventos de infiltrado inflamatório (A; indicado pelas setas); Imunofluorescência para laminina (vermelha) e mionúcleo (azul) para quantificação do percentual de células com núcleo centralizado (B; indicado pelas setas); Imunofluorescência para laminina (vermelha), mionúcleo (azul) e Pax7 (verde) para quantificação do percentual de fibras divididas ( $\mathrm{C}$; indicado pela seta); Painel ilustrativo para imunofluorescência para mionúcleo (azul), 
Pax7 (verde), e merge de laminina (vermelha) núcleo e Pax7 (D; indicado pelas setas) e quantificação do percentual de células satélites (E) no músculo tibial anterior anterior em camundongos tratados com salina (barras brancas) ou monocrotalina (doses a cada 20 dias de $80 \mathrm{mg} / \mathrm{kg}$, representados pelas barras vermelhas), sedentários (barras brancas e vermelhas) e após 1 mês de treinamento físico aeróbico (barras azuis e salmão) (do 3o ao 4o mês do período experimental). Os dados foram comparados pela ANOVA de dois caminhos. * diferença significante vs. grupo indicado pelo traço, $\mathrm{p}<0.05$. MCT, monocrotalina; PAX7, Paired box protein $7, \mathrm{TF}$, treinamento físico

FIGURA 13 Efeito do treinamento físico aeróbico na expressão gênica de reguladores miogênicos, atrogenes e indicadores de lesão/regeneração muscular. Expressão dos genes para Atrogin (A), MuRF (B), TNF- $\alpha$ (C), Colágeno tipo I (D), Colágeno tipo III (E), Miostatina (F), Myf-5 (G), MyoD (H), Pax7 (I), Desmina (J), Miogennina (K), MRF4 (L) do músculo tibial anterior anterior em camundongos tratados com salina (barras brancas) ou monocrotalina (doses a cada 20 dias de $80 \mathrm{mg} / \mathrm{kg}$, representados pelas barras vermelhas), sedentários (barras brancas e vermelhas) e após 1 mês de treinamento físico aeróbico (barras azuis e salmão) (do 30 ao 40 mês do período experimental). Os resultados são expressos utilizando o método de limiar comparativo de ciclos (2- $\Delta \Delta \mathrm{Ct})$ como descrito pelo produtor do sistema. Os dados foram comparados entre os grupos pela ANOVA de dois caminhos com medidas repetidas. TNF- $\alpha$, Tumor Necrosis Factor $\alpha$; Myf-5, Myogenic Factor 1; MyoD, Myoblast Determination Protein 1; Pax7, Paired box protein 7; MRF4, Myogenic factor 6; MCT, monocrotalina 
FIGURA 14 Sumário dos resultados da padronização do modelo de IC induzida por MCT em camundongos, bem como o efeito do TF nos tecidos pulmonar, cardíaco e muscular esquelético. Diferentes fases do tratamento com MCT, 2 meses (seta amarela) e 4 meses (seta verde). O TF compreendeu em uma duração de 1 mês, do 3o ao 4o mês, do período experimental. A variáveis e setas em vermelho indicam o efeito do tratamento com MCT. As variáveis e setas em azul indicam o efeito contrarregulador do TF. MCT, monocrotalina; TF, treinamento físico; P.L., parede livre; EDL, extensor digitorum longus; Fr., fração

FIGURA 15 Aparelho Vevo 2100 utilizado para avaliação ecocardiográfica de roedores de pequeno porte

FIGURA 16 Esteira rolante para determinar tolerância ao esforço e treinamento físico

FIGURA 17 Aparelho Rotarod AVS Projetos (C) para determinar função muscular 66

FIGURA 18 Sistema de banho de órgãos (A) e cuba com o músculo EDL (B) para avaliação de função contrátil 


\section{LISTA DE TABELAS}

Página

TABELA 1 Massa corporal e de tecidos (corrigidos pelo comprimento da tíbia) de camundongos tratados por 2 e 4 meses com salina ou monocrotalina, sedentários e treinados (MCT, $80 \mathrm{mg} / \mathrm{kg}$ a cada 20 dias). VD, ventrículo direito; VE, ventrículo esquerdo; EDL, extensor digitorum longus; MCT, monocrotalina; TR, treinamento físico aeróbico. Os dados estão representados na forma de média \pm erro padrão da média e foram analisados pelo teste $\mathrm{t}$ de Student para dados não pareados ou pela ANOVA de dois caminho com medidas repetidas.

TABELA 2 Sequência dos oligonucleotídeos iniciadores (primers) utilizados na expressão gênica por meio de PCR 


\section{LISTA DE ANEXOS}

Página

ANEXO I Aprovação do projeto de pesquisa na Comissão de Ética no Uso de Animais (CEUA) da Escola de Educação Física e

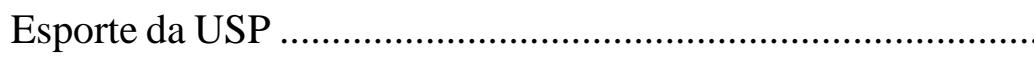




\section{SUMÁRIO}

Página

RESUMO

ABSTRACT

LISTA DE SIGLAS, ABREVIATURAS E SÍMBOLOS

LISTA DE FIGURAS

LISTA DE TABELAS

LISTA DE ANEXOS

1. INTRODUÇÃ

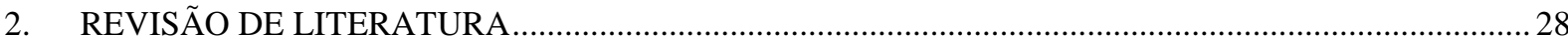

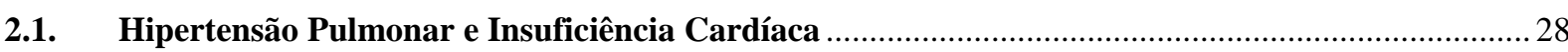

2.2. Modelo de insuficiência cardíaca direita induzida por hipertensão pulmonar (monocrotalina) ....29

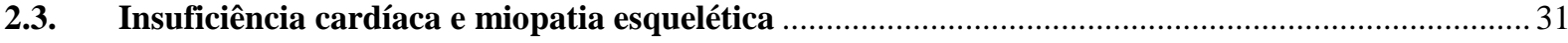

2.4. Contribuição das alterações no processo lesão/regeneração muscular para a miopatia esquelética na

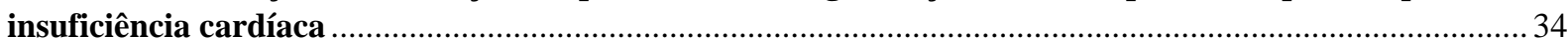

2.5. Treinamento Físico Aeróbico: estratégia não farmacológica no tratamento da IC ........................37

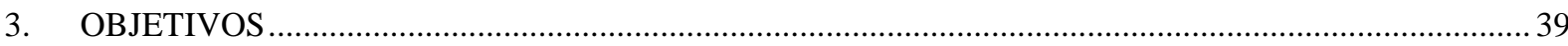

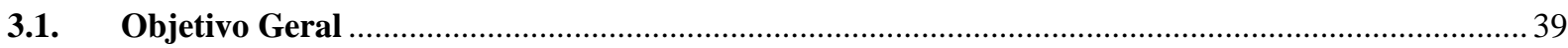

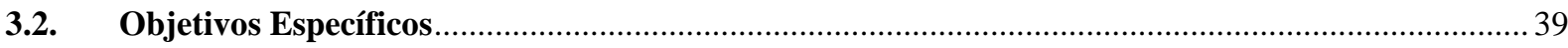

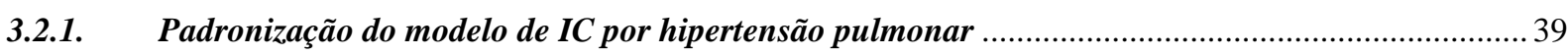

3.2.2. Efeito do treinamento físico aeróbico em animais com IC por HP ........................................... 41

3.2.2.1. Efeito do treinamento físico aeróbico nos marcadores de lesão/regeneração ................................ 42

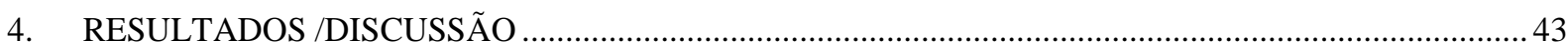

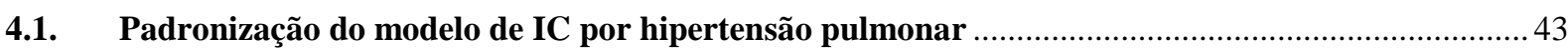

4.2. Efeito do treinamento físico aeróbico nos sistemas cardiovascular e muscular esquelético em modelo de IC induzida por MCT

4.3. Papel do treinamento físico aeróbico na modulação de marcadores de lesão/regeneração durante a miopatia esquelética em modelo de IC por monocrotalina ............................................................. 55

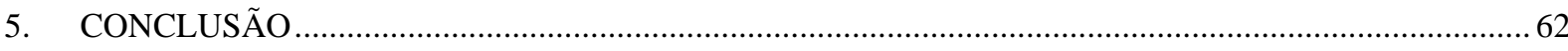

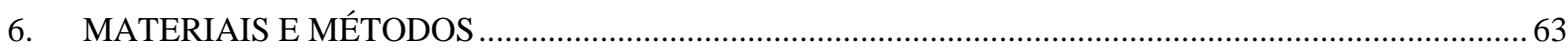

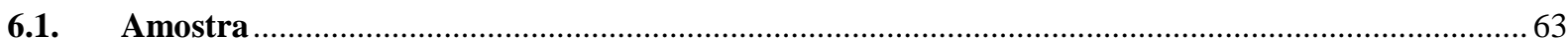

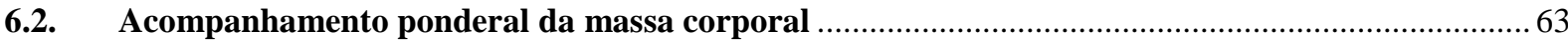

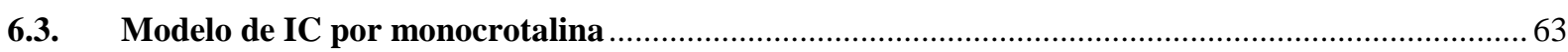

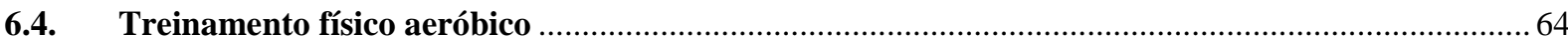

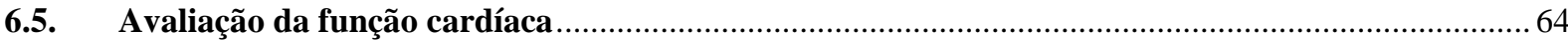

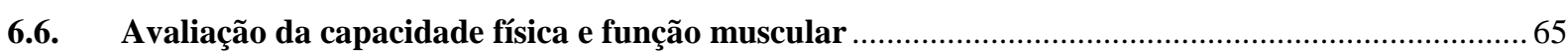

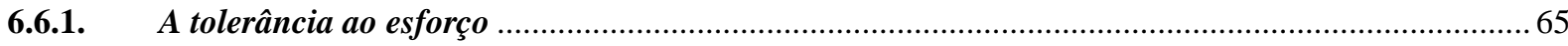




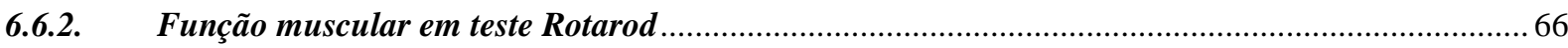

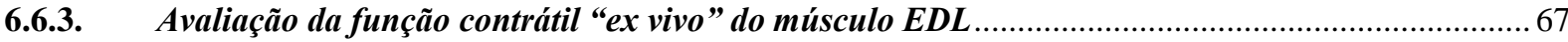

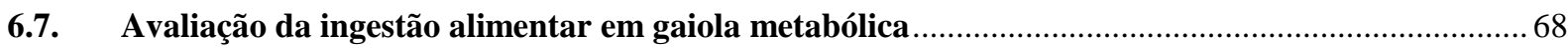

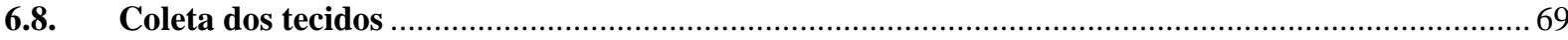

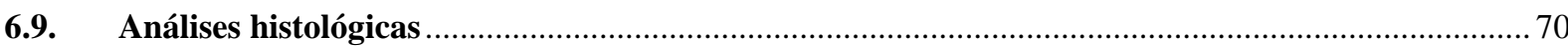

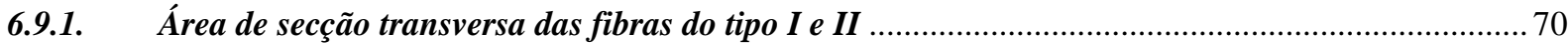

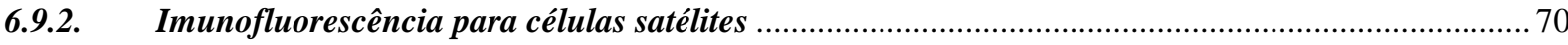

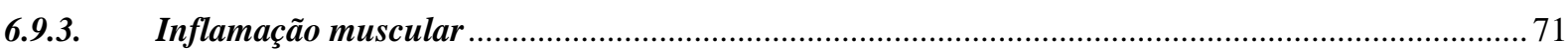

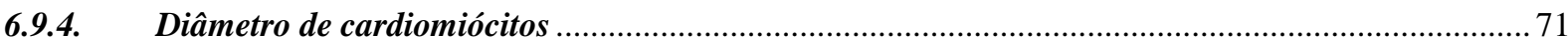

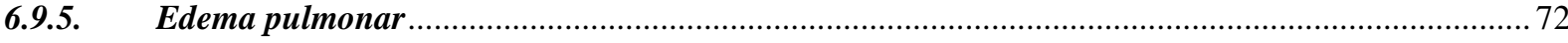

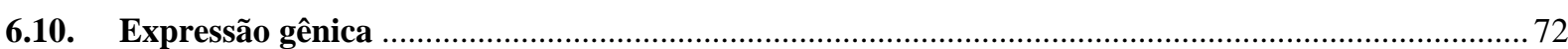

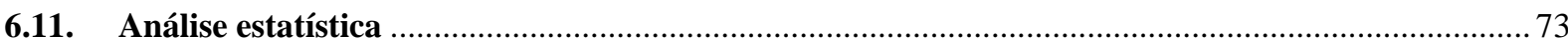

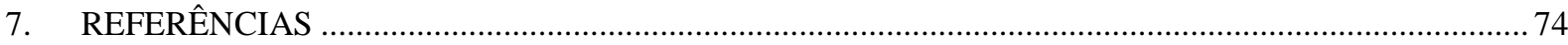

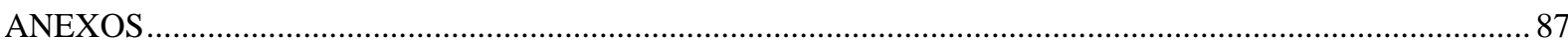




\section{INTRODUÇÃO}

Hoje a importância da disfunção ventricular direita para a mortalidade em doenças cardiovasculares já está bem estabelecida e, nas últimas décadas tem crescido o número de estudos que buscam entender melhor a participação do ventrículo direito na evolução da IC (Ghio et al., 2001; Redington et al., 2014).

Entre as etiologias mais comuns que levam à insuficiência cardíaca direita (ICD) está a hipertensão pulmonar, doença caracterizada por uma elevação da pressão interna das artérias pulmonares acima de $25 \mathrm{mmHg}$ em repouso e $30 \mathrm{mmHg}$ durante o exercício físico (Ghio et al., 2001; Mahmud e Champion, 2007; Ryan et al., 2015). A ICD por HP, ocorre devido ao aumento crônico da pós-carga do ventrículo direito, fazendo com que o ventrículo perca a capacidade de compensação (hipertrofia e aumento da contratilidade), o que reduz a fração de ejeção ventricular, favorecendo o surgimento de sinais de IC (Mahmud e Champion, 2007; Ryan et $a l ., 2015)$.

Embora os principais órgãos responsáveis pelo mau prognóstico dos pacientes sejam o pulmão e o coração, a ICD por HP também afeta outros tecidos, como o músculo esquelético (Tran et al., 2018). Alterações no tecido muscular esquelético incluem diminuição da massa muscular, rarefação capilar, densidade e função mitocondrial reduzida, transição de tipo de fibra (oxidativa para glicolítica) e aumento de espécies reativas de oxigênio (Wust et al., 2012). Em conjunto, essas alterações levam à intolerância ao exercício e à diminuição da qualidade de vida em pacientes com ICD induzida por HP (Ghio et al., 2001).

Dentre os mecanismos responsáveis pela atrofia muscular, o aumento na incidência de lesão muscular e/ou a menor eficiência regenerativa, vêm sendo associados ao declínio da massa muscular. Dessa forma, no presente projeto a participação do processo lesão/regeneração muscular na atrofia muscular promovida pela ICD induzida por HP foi analisada. Como a progressão da disfunção muscular esquelética não é totalmente compreendida na HP, um dos objetivos do nosso trabalho foi analisar a função cardíaca e muscular, bem como a tolerância ao exercício em diferentes momentos da HP induzida por monocrotalina.

A monocrotalina (MCT), alcaloide extraído de plantas do gênero crotalaria, age nos pulmões causando HP. A HP por sua vez, gera aumento de pós-carga no VD, acarretando 
disfunção ventricular e, posteriormente, ICD (Meyrick et al., 1980). Este é um modelo bem estabelecido em ratos (Doggrell e Brown, 1998; Wust et al., 2012), porém são poucos os estudos que o utilizaram para estudo de ICD em camundongos. Desta forma, foi também parte deste projeto a padronização do modelo de IC induzido por MCT em camundongos, uma vez que esta espécie tem sido muito usada em pesquisa devido a grande quantidade de modelos transgênicos e ou com outra manipulação genética.

Sabe-se que o TFA é benéfico na IC esquerda, que é semelhante à ICD em muitos fatores, como alterações nos sistemas neuro-humorais, função endotelial, efeitos antiinflamatórios, efeitos cardiovasculares e alterações nos músculos esqueléticos. Parte dos benefícios do TFA é composta por adaptações no controle neuro-hormonal (Roveda et al., 2003) e função cardíaca (Erbs et al., 2003; Medeiros et al., 2007; Rolim et al., 2007), enquanto outra parte resulta de seus efeitos no músculo esquelético (Hambrecht et al., 1995). Na ICD induzida por HP, pouco se sabe sobre os efeitos da TFA nas anormalidades da estrutura muscular esquelética induzidas pela doença. Esse fato se torna relevante, pois a intolerância ao exercício de pacientes com ICD não é totalmente explicada pela disfunção cardíaca (Batt et al., 2014; Breda et al., 2014; Marra et al., 2015).

Entre as adaptações induzidas pelo TFA no músculo esquelético na IC esquerda estão: vasodilatação dependente do endotélio (Adamopoulos et al., 2003), aumento da área de secção transversa (AST) das fibras musculares, aumento da densidade capilar e densidade mitocondrial associada ao aumento da atividade de enzimas oxidativas (Bacurau A.V., 2015). A compreensão das adaptações estruturais induzidas pelo TFA torna-se essencial pelo impacto que a perda muscular tem sobre o mau prognóstico da IC (Anker et al., 1997). Nesse sentido, vale ressaltar que o treinamento físico é a principal abordagem terapêutica para minimizar a perda de massa muscular (Anker et al., 2013; Bacurau A.V., 2015). No entanto, o papel do treinamento físico na HP precisa ser melhor elucidado.

Assim, também foi objetivo do nosso estudo avaliar os efeitos terapêuticos do TFA na capacidade física de animais com ICD induzida por monocrotalina, bem como no trofismo muscular e em marcadores de lesão/regeneração muscular esquelética. 


\section{REVISÃO DE LITERATURA}

\subsection{Hipertensão Pulmonar e Insuficiência Cardíaca}

As doenças cardiovasculares são a maior causa de morte em mulheres e homens no Brasil. A incidência dessas doenças tem aumentado ao longo dos anos, especialmente em países em desenvolvimento, mesmo com a criação de novas estratégias terapêuticas para combatê-las (Bocchi, 2012; Mandic et al., 2012; Mansur Ade, 2012). Isto pode ser atribuído ao fato de que os fatores de risco como sedentarismo e obesidade também têm aumentado ao longo do tempo (Mandic et al., 2012).

A IC é a via final comum da maioria das doenças cardiovasculares, sendo considerada um problema de saúde pública devido à grande mortalidade associada a ela, bem como o número de internações, especialmente em pacientes idosos. De maneira geral, a IC pode envolver só um dos ventrículos (esquerdo ou direito) ou ambos, sendo a IC esquerda mais comum na população (Friedberg e Redington, 2014). Embora menos estudada que a IC esquerda, a ICD é uma síndrome grave, originada principalmente como um agravamento da HP e que ainda carece de estratégias eficientes de tratamento (Mckenna et al., 2006).

A HP e uma síndrome caracterizada por uma elevação da pressão interna das artérias pulmonares acima de $25 \mathrm{mmHg}$ em repouso e $30 \mathrm{mmHg}$ durante o exercício físico (Ghio et al., 2001; Mahmud e Champion, 2007; Ryan et al., 2015). A HP leva à disfunção endotelial, com persistente vasoconstrição e remodelamento estrutural de artérias pulmonares, o que leva a redução da área de secção transversa microvascular e aumento da resistência vascular. Como consequência, a elevação da pressão arterial pulmonar reflete em aumento na sobrecarga (póscarga) no VD, induzindo hipertrofia do VD (Stenmark et al., 2009), o que posteriormente culmina em disfunção ventricular direita, originando assim, a ICD (Gaine, 2000). Embora as alterações iniciais da HP sejam em relação às artérias pulmonares, a sobrevivência de pacientes 
portadores dessa síndrome em fase avançada está intimamente relacionada com a função do VD (Mahmud e Champion, 2007; Vonk-Noordegraaf et al., 2013).

Apesar da ICD ter origem diferente da IC esquerda, parte das alterações causadas por essa síndrome são semelhantes às observadas na IC esquerda. Dentre elas destacam-se o aumento na inflamação sistêmica e as modificações no tecido muscular esquelético, como a redução da massa muscular, rarefação capilar, diminuição da densidade e função mitocondrial, transição do tipo de fibras (oxidativa para glicolítica) e aumento de espécies reativas de oxigênio (Wust et al., 2012). De fato, portadores de ICD apresentam intolerância ao esforço físico e diminuição na qualidade de vida (Ghio et al., 2001; Arena et al., 2015).

\subsection{Modelo de insuficiência cardíaca direita induzida por hipertensão}

\section{pulmonar (monocrotalina)}

Estudos sobre os mecanismos pelos quais a IC se desenvolve e progride são conduzidos em animais há décadas (Patten e Hall-Porter, 2009). Dentre os animais utilizados em protocolos de pesquisa, os roedores são mais usados, em especial os camundongos, uma vez que este modelo permite o uso de manipulação genética (Zaragoza et al., 2011; Haidara et al., 2015). Hoje existem diversos modelos de IC utilizados para a melhor compreensão dessa síndrome em camundongos. Dentre eles, temos os modelos cirúrgicos, modelos por indução farmacológica e modelos por modificação genética (Brum et al., 2002; Zaragoza et al., 2011). Porém, para estudo de ICD, ainda há uma escassez de modelos já caracterizados quando comparados à IC esquerda. Nesse sentido, o modelo de ICD induzido por MCT parece ser uma estratégia interessante para estudar o estabelecimento e a progressão desta síndrome, uma vez que a HP desenvolvida pelos animais não é tão agressiva, possibilitando diferentes intervenções nesses animais. 
A MCT é o principal alcaloide encontrado nas plantas do gênero Crotalaria. Este alcalóide requer a bioativação em monocrotalinapirrol (MCTP) pelo citocromo P450 3A4 no fígado, uma reação bifuncional de um agente alcalínico que se liga ao DNA celular in vivo. A MCTP, um metabólito reativo, que é transportada até os pulmões, causa lesão do leito vascular e remodelamento estrutural dos mesmos, resultando em HP, seguida de hipertrofia do VD por aumento de pós-carga e, consequentemente, ICD (Figura 1) (Meyrick et al., 1980; Li et al., 2014; Yao et al., 2014).

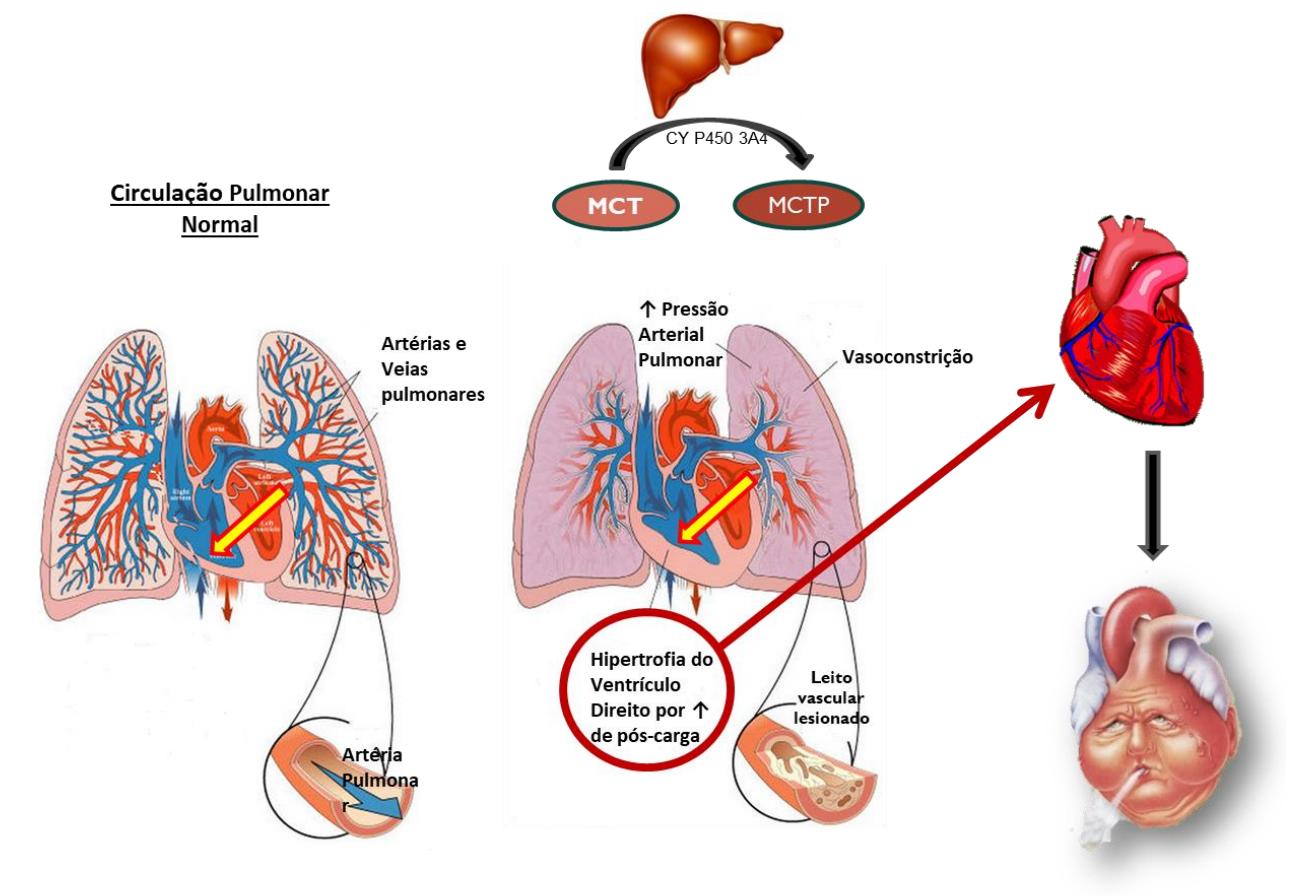

Figura 1. Mecanismo de ação da monocrotalina. Adaptado de http://www.sw.org/HealthLibrary page=Pulmonary\%20Hypertension. MCT, Monocrotalina; MCTP, Monocrotalinapirrol.

A ICD induzida por MCT já está bem estabelecida em ratos, porém, este modelo ainda apresenta algumas restrições (Doggrell e Brown, 1998; Lourenco et al., 2011), como a limitação da manipulação genética, e a alta taxa de mortalidade (50\% após 28 dias de tratamento) (Nogueira-Ferreira et al., 2016). Em camundongos, são poucos os estudos que usam a MCT como modelo de IC e ainda mais raros os que estudam alterações morfofuncionais do tecido muscular esquelético ou o efeito do TFA. Além disso, vale ressaltar que em estudo piloto, 
observamos que camundongos tratados com MCT por 4 meses não apresentaram mortalidade, mostrando que este pode ser um modelo viável para redução do número de animais utilizados em protocolos experimentais para estudo da ICD (Dados não publicados). Recentemente Ahn et al. (2013) demonstraram que 6 a 8 semanas de injeções semanais de MCT (s.c. $600 \mathrm{mg} / \mathrm{kg}$ ) em camundongos, induziam disfunção do músculo diafragma, associada à atrofia das fibras. Deste modo, foi objetivo do presente estudo avaliar se as alterações morfofuncionais observadas no músculo diafragma também se estendem a músculos locomotores de camundongos tratados com MCT.

Desta forma, foi parte do presente projeto a padronização de um modelo de ICD, que apresentasse baixa taxa de mortalidade e variabilidade na progressão da ICD, e que permitisse o estudo das alterações musculares nessa síndrome, bem como os efeitos do TFA sobre essas possíveis alterações.

\subsection{Insuficiência cardíaca e miopatia esquelética}

A musculatura esquelética representa cerca de 40-45\% da massa corporal em humanos, sendo constituída por mais de 600 músculos (Arthur et al., 2008) de fundamental importância para a manutenção do equilíbrio metabólico, além de armazenar a maior quantidade de proteínas do organismo (Zurlo et al., 1990).

Já é bem estabelecido na literatura que pacientes com IC no ventrículo direito ou esquerdo apresentam alterações na musculatura esquelética que levam à uma redução da função muscular, bem como da tolerância ao esforço (Harrington et al., 1997; Ghio et al., 2001; Kato, 2013). Estudo clássico de Sullivan e colaboradores (1991) mostrou que pacientes com IC apresentavam uma maior atividade do metabolismo anaeróbio, avaliado pelo acúmulo da lactato associado a uma redução da atividade de enzimas oxidativas (Sullivan et al., 1991). Esse perfil mais glicolítico do músculo esquelético induz um maior acúmulo de metabólitos, que 
reflexamente ativam o sistema nervoso simpático, por meio da ativação de metaborreceptores no músculo esquelético (Piepoli e Coats, 2013). Agudamente, essa ativação consiste em um importante mecanismo de compensação, pois aumenta a frequência e a contratilidade cardíaca, bem como a frequência respiratória, que ulteriormente culmina em aumento do débito cardíaco, e portanto, do suprimento adequado de nutrientes para os órgãos e tecidos do corpo. No entanto, em longo prazo, essa hiperativação simpática apresenta um efeito tóxico no tecido cardíaco, contribuindo para a progressão da IC e para as alterações na musculatura esquelética (hipótese muscular) (Velez-Roa et al., 2004; Piepoli e Coats, 2013).

Além das alterações metabólicas, o músculo esquelético de pacientes com IC também apresenta modificações estruturais, tais como a mudança do perfil dos tipos de fibras e a atrofia muscular (Ciciliot et al., 2013; Kato, 2013; Schiaffino et al., 2013). Na IC podemos observar uma transição de fibras do tipo I (oxidativas) para fibras do tipo II (glicolíticas) na musculatura esquelética. Essa transição está relacionada à uma menor resistência à fadiga, e a magnitude de transição de fibras apresenta relação direta com a gravidade da síndrome (Vescovo et al., 2001a; Schulze et al., 2002a; Mainguy et al., 2010b).

A atrofia muscular é outro fator determinante da capacidade física e da qualidade de vida desses pacientes (Mancini et al., 1992; Wust et al., 2012), caracterizada por diminuição no conteúdo proteico, redução no diâmetro das fibras e na força muscular (Jackman e Kandarian, 2004). Em quadros mais graves, a atrofia pode culminar em caquexia (do grego: kakos, má, ruim e hexis, condição do corpo). Uma condição resultante de várias doenças sistêmicas como o câncer, a síndrome da imunodeficiência adquirida (AIDS), o diabetes mellitus, a sepse, a insuficiência renal e a IC, sendo neste último caso denominada caquexia cardíaca (Pittman e Cohen, 1964; Hambrecht et al., 2002; Morley et al., 2006a).

No quadro de caquexia normalmente observa-se perda excessiva de massa corporal associada à perda das massas óssea, gorda e muscular (Anker e Sharma, 2002). A caquexia 
cardíaca foi recentemente definida por von Haehling e colaboradores como a perda $>5 \%$ de massa corporal de forma não intencional num período de 12 meses ou menos (Von Haehling e Anker, 2015). Na clínica, observa-se que cerca de $20 \%$ dos pacientes com IC desenvolvem caquexia (Morley et al., 2006b), e devido a essa condição apresentam mortalidade acentuada em comparação a pacientes não caquéticos (50\% vs. 17\%, respectivamente) (Anker e Coats, 1999). Dessa forma, a caquexia tem sido indicada como um preditor independente de mortalidade em portadores de IC grave (Anker et al., 1997) e por isso a inclusão da sua avaliação nos programas de transplantes cardíaco vem sendo proposta. Além disso, atualmente, a caquexia cardíaca é um importante alvo no tratamento da IC (Von Haehling et al., 2013), e portanto, estratégias farmacológicas e não farmacológicas que amenizem ou revertam a perda de massa muscular também se fazem necessárias (Bacurau, 2015).

Embora o estabelecimento e a progressão da miopatia esquelética já esteja bem caracterizado na IC esquerda, somente nos últimos anos à miopatia esquelética começou a receber atenção na ICD por hipertensão pulmonar ((Wust et al., 2012). Sendo assim, não está claro na literatura em que estágio da disfunção cardíaca e pulmonar a miopatia esquelética é estabelecida. Desta forma, foi parte deste projeto avaliar a função muscular cardíaca e esquelética em diferentes estágios da ICD.

A progressão e desenvolvimento da atrofia muscular na IC envolvem uma rede complexa de fatores metabólicos, imunológicos e neuro-humorais potencializados pela inatividade física e distúrbios nutricionais. Dentre estes fatores, um ainda pouco explorado na IC e que merece atenção é o processo de regeneração muscular. 


\subsection{Contribuição das alterações no processo lesão/regeneração muscular para}

a miopatia esquelética na insuficiência cardíaca

Embora estudos sugiram que o aumento da lesão muscular, bem como a redução na capacidade regenerativa possam contribuir para os quadros de sarcopenia do envelhecimento (Carlson, 2003) e caquexia do câncer (Mehl et al., 2005), pouco se sabe sobre a participação da regulação lesão/regeneração na progressão da miopatia esquelética induzida pela IC.

A capacidade de regeneração do músculo esquelético advém de células progenitoras não diferenciadas que residem na periferia da fibra muscular de indivíduos adultos, sendo este um dos poucos tecidos capazes de se regenerar completamente após uma lesão extensa (Hawke et al., 2003). O processo regenerativo é caracterizado por quatro fases distintas: I) degeneração, II) inflamação, III) regeneração e IV) remodelamento/reparo.

I) Degeneração: traumas no tecido muscular afetam a integridade do sarcômero, do sarcolema e da lâmina basal, isto facilita a entrada de cálcio extracelular, que posteriormente levará a célula à necrose. $\mathrm{O}$ aumento no influxo de $\mathrm{Ca}^{2+}$ leva a ativação das calpaínas, proteases neutras, associadas aos processos iniciais de degeneração ocorridos nos sarcômeros musculares, promovendo o desarranjo de proteínas miofibrilares e proteínas do citoesqueleto (Matsuda et al., 1995).

II) Inflamação: A participação do processo inflamatório na regeneração muscular é um fenômeno complexo e nem sempre benéfico para o tecido. A evolução do sistema imunológico de mamíferos possibilitou maior defesa contra microrganismos e facilitação do reparo tecidual pela remoção de debris celulares, no entanto, com maior prejuízo na capacidade regenerativa. Os neutrófilos são as primeiras células a migrarem para o local da lesão. Devido a rápida diminuição do seu número, são indetectáveis 3-4 dias após a lesão (Tidball e Villalta, 2010). Fatores liberados pelos neutrófilos, como espécies reativas de oxigênio e proteases, promovem a secreção de citocinas pró-inflamatórias que produzem sinais quimiotáticos responsáveis pela migração de monócitos circulantes ao local da lesão, sendo que os mesmos 
se diferenciarão em macrófagos (Fielding et al., 1993), sendo os últimos, o tipo celular mais predominante na área lesionada após 48h. Vários estudos sugerem que os macrófagos desempenham um papel direto não somente na remoção de debris celulares, mas também na ativação de células precursoras miogênicas, importantes na mediação da regeneração muscular (St Pierre e Tidball, 1994).

III) Regeneração e IV) Reparo. A capacidade de regeneração muscular é garantida por um mecanismo intrínseco que restaura o aparelho contrátil lesionado. Assim, uma reserva de células indiferenciadas (células satélite-CS) são ativadas, iniciam o ciclo celular e se fundem para formar miotúbulos multinucleados . Esse processo é seguido por uma fase de regeneração das fibras musculares, formação do tecido cicatricial e revascularização (Hawke e Garry, 2001). Durante a fase seguinte, a fase do remodelamento/reparo, ocorre contração e reorganização do tecido cicatricial, além da recuperação da capacidade funcional do músculo .

Uma vez que as fibras musculares adultas são células pós mitóticas incapazes de se dividir, essa habilidade de auto reparo tem sido atribuída às CS ou células-tronco musculares. Elas apresentam grande atividade mitótica que contribuindo para a manutenção do músculo esquelético adulto (Hawke e Garry, 2001).

As CS foram descobertas por Mauro (Mauro, 1961) em músculos de rã, sendo assim designadas devido à sua localização satélite, entre o sarcolema e a lâmina basal das fibras musculares esqueléticas. No músculo adulto, as CS encontram-se normalmente quiescentes, ou seja, na fase G0 do ciclo celular. O número de CS no estado quiescente se mantém relativamente constante após vários ciclos de degeneração/regeneração, sugerindo um mecanismo de autorrenovação pelas próprias CS (Asakura et al., 2002), também chamado de divisão assimétrica. No entanto, quando sujeitas a estímulos apropriados, as CS proliferam, diferenciam-se e fundem-se, adicionando novos mionúcleos às fibras musculares, sendo este um papel determinante no crescimento pós-natal e na regeneração muscular (Asakura et al., 2002). 
Fatores de crescimento liberados após lesão muscular, como, fator de crescimento similar a insulina-I (IGF-I), fator de crescimento tipo hepatócitos (HGF), fator de crescimento derivado de plaquetas e o fator de crescimento fibroblástico (FGF), são importantes estimuladores das CS, sendo parte desses fatores responsáveis por induzir a proliferação e inibir a diferenciação celular, potencializando o recrutamento de células precursoras miogênicas (Carlson, 2003). Resultados prévios do nosso grupo demonstram redução significante na expressão gênica e proteica de IGF-I no músculo de pacientes portadores de IC e em modelo animal, respectivamente. Vale ressaltar que essas alterações foram parcialmente contra reguladas pelo treinamento físico aeróbico (Bacurau et al., 2016).

Em contrapartida, os fatores de crescimento transformadores (TGF- $\beta$ ), são conhecidos em suprimir a diferenciação miogênica (Allen et al., 1999). Dentre esses fatores, a miostatina antagoniza a regeneração muscular, limitando a proliferação e diferenciação de CS, sendo esta uma proteína que apresenta sua expressão aumentada tanto no soro, quanto no músculo esquelético de indivíduos com insuficiência cardíaca (Breitbart et al., 2011).

As CS ativas expressam os fatores de transcrição Myf5 e MyoD e, uma vez diferenciadas, expressam Miogenina e MRF4. CS que mantêm a expressão de Pax7 (paired box transcription factors) e diminuem expressão de MyoD, reconstituem o compartimento de células satélites, promovendo sua autorrenovação (Zammit et al., 2006). A expressão destes fatores de regulação miogênica durante a ativação, proliferação e diferenciação das CS é análoga à que ocorre durante a embriogênese. As fibras regeneradas também repetem a sequência de transições de isoformas que ocorrem no músculo embrionário. Além disso, as fibras recém-formadas são basofílicas, apresentam calibre pequeno e núcleo centralizado. Em secções longitudinais e em fibras isoladas, os núcleos centralizados são observados em porções discretas ou ao longo de toda a fibra na área de regeneração sugerindo que durante a regeneração a fusão celular não é difusa, mas focal ao local da lesão. Após a completa fusão das células 
precursoras miogênicas, as fibras aumentam de tamanho e o mionúcleos se movem para a periferia da fibra (Charge e Rudnicki, 2004).

Sendo assim, foi parte desse projeto avaliar possíveis alterações no processo de lesão/regeneração muscular na ICD, bem como a contribuição das células satélites para o mesmo.

\subsection{Treinamento Físico Aeróbico: estratégia não farmacológica no tratamento}

da IC

Durante os últimos anos, tem se acumulado dados convincentes sobre os benefícios do TFA na IC, demonstrando que o mesmo é uma importante estratégia no tratamento da IC (Brum et al., 2011), melhorando a tolerância aos esforços físicos, a qualidade de vida, diminuindo as hospitalizações e a mortalidade desses pacientes (Hambrecht et al., 1997).

Parte dos benefícios do TFA é composta por adaptações no controle neuro-hormonal (Roveda et al., 2003) e na função cardíaca (Erbs et al., 2003; Medeiros et al., 2007; Rolim et al., 2007), enquanto outra parte resulta de seus efeitos sobre a musculatura esquelética (Hambrecht et al., 1997). Tal fato se torna relevante, uma vez que a intolerância ao esforço desses pacientes não é totalmente explicada pelo comprometimento da função cardíaca.

Dentre as adaptações relacionadas à musculatura esquelética, o TFA em pacientes com IC promove a vasodilatação dependente do endotélio (Adamopoulos et al., 1995), o aumento na densidade capilar e na densidade mitocondrial associado ao aumento na atividade de enzimas oxidativas (Bacurau et al., 2009; Bacurau, 2015). Com relação às adaptações estruturais induzidas pelo TFA, a importância destas é evidenciada pelo impacto que a perda de massa muscular tem no mau prognóstico da IC. Nesse sentido, vale destacar que o TFA é a principal abordagem terapêutica significativa em minimizar essa perda (Anker et al., 2013; Bacurau A.V., 2015). Curiosamente, o TFA per se não aumenta a área de secção transversa do músculo 
esquelético em indivíduos saudáveis, como observado pelo treinamento físico de força (Folland e Williams, 2007). No entanto, em animais com IC em estado hipotrófico, o TFA foi capaz de restaurar ou aumentar a massa muscular para níveis considerados eutróficos (Bacurau et al., 2009). Parte dos mecanismos que explicam essa resposta está relacionada ao efeito do TFA sobre reguladores do turnover proteico. Constituintes do sistema ubiquitina proteassoma, um importante regulador do catabolismo proteico, cuja atividade está aumentada na IC e é restabelecida tanto em modelo genético de IC, quanto em indivíduos portadores de IC (Cunha et al., 2012). Também foi observado o potencial efeito do TFA na ativação da via de síntese proteica IGF-I/Akt/mTOR, que estava reduzida no músculo sóleo de animais com IC por hiperatividade simpática (Bacurau et al., 2016). Nesse particular, a literatura é praticamente omissa quanto a investigações sobre o efeito do treinamento físico sobre a regeneração ineficaz observada na IC.

Em relação à $\mathrm{ICD}$, historicamente o treinamento físico foi proscrito para indivíduos com ICD decorrente de HP, uma vez que durante o exercício físico a sobrecarga do VD estaria aumentada, o que poderia apresentar risco ao paciente (Arena et al., 2015). No entanto, nos últimos anos estudos demonstraram que pacientes com HP que realizavam treinamento físico apresentavam melhora de tolerância ao esforço e força muscular associada à melhor qualidade de vida, no entanto, não foram encontradas evidências de que tal melhora ocorresse devido à uma melhora da função pulmonar (Mainguy et al., 2010a; Fox et al., 2011). Sendo assim, parte desses benefícios podem estar relacionados à melhora da função do VD ou mesmo reversão do quadro de miopatia esquelética. Portanto, foi objetivo presente projeto avaliar os efeitos terapêuticos do TFA sobre a capacidade física de animais com ICD induzida por HP, avaliar a participação dos sistemas cardiovascular e muscular esquelético nesta adaptação, bem como analisar se parte desses benefícios advindos do treinamento físico aeróbio resultam de uma melhora nos marcadores do processo de lesão/regeneração muscular. 


\section{OBJETIVOS}

\subsection{Objetivo Geral}

Realizar a caracterização morfofuncional do músculo esquelético em modelo de ICD induzida por HP e avaliar os efeitos do TFA nos tecidos cardíaco e muscular esquelético.

\subsection{Objetivos Específicos}

Este projeto foi dividido em duas etapas distintas. Na primeira, foi feita a padronização do modelo de IC induzida por hipertensão pulmonar. Uma vez padronizado o modelo, iniciamos o protocolo de treinamento e avaliamos o efeito do TFA na função cardíaca e muscular esquelética e em marcadores de lesão/regeneração do músculo esquelético.

\subsubsection{Padronização do modelo de IC por hipertensão pulmonar}
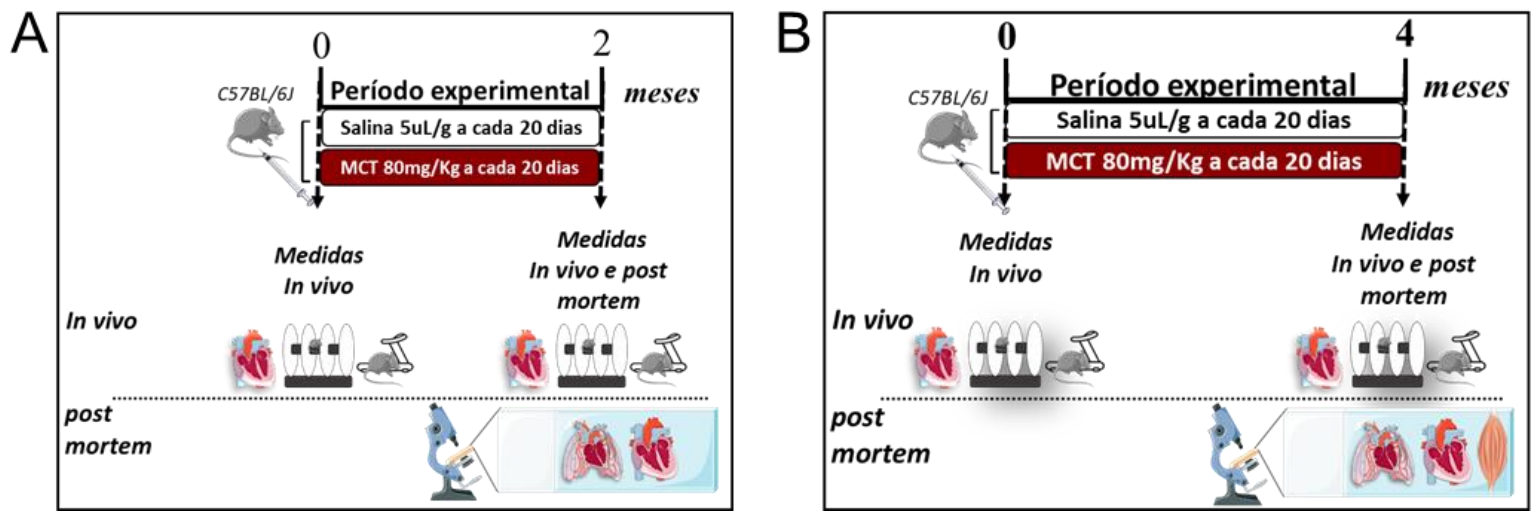

Figura 2. Desenhos experimentais da etapa I. Protocolo de tratamento com monocrotalina (80mg/kg) por 2 meses (A). Protocolo de tratamento com monocrotalina $(80 \mathrm{mg} / \mathrm{kg}$ ) por 4 meses (B). MCT, monocrotalina.

Foram avaliados em camundongos tratados com MCT ou salina:

\section{$\underline{\text { In vivo }}$}

- a curva de sobrevida ao longo do período experimental;

- $\quad$ os parâmetros ecocardiográficos; 
- $\quad$ a tolerância ao esforço;

- desempenho em teste rotarod

- $\quad$ a ingestão alimentar em gaiola metabólica;

\section{Ex vivo/Post mortem}

- a função "ex vivo" do músculo EDL em banho de órgãos;

- a área de secção transversa e distribuição de fibras nos músculos EDL, sóleo e tibial anterior;

- $\quad$ a razão massa úmida/seca do pulmão;

- a massa cardíaca e das câmaras cardíacas como indicativo de hipertrofia cardíaca direita (Índice de Fulton);

- o edema pulmonar por coloração com hematoxilina-eosina;

- a análise morfométrica de cardiomiócitos coloração com hematoxilina-eosina;

- $\quad$ fibrose miocárdica por marcação com PicroSirus Red; 


\subsubsection{Efeito do treinamento físico aeróbico em animais com IC por HP}

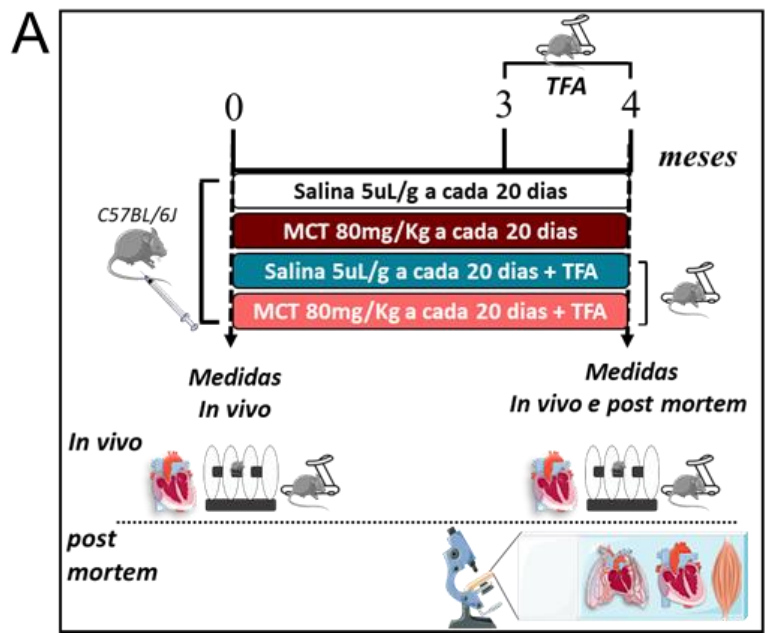

Figura 3. Desenho experimental da etapa II. Protocolo de treinamento físico aeróbico por 4 semanas em esteira rolante (A). MCT, monocrotalina.

Foram avaliados em camundongos tratados com MCT ou salina, sedentários e treinados:

\section{In vivo}

- os parâmetros ecocardiográficos;

- $\quad$ a tolerância ao esforço;

- desempenho em teste rotarod

- a curva de sobrevida ao longo do período experimental;

\section{Ex vivo/Post mortem}

- $\quad$ a área de secção transversa tibial anterior;

- $\quad$ a razão massa úmida/seca do pulmão;

- a massa cordíaca e das câmaras cardíacas como indicativo de hipertrofia cardíaca direita (Índice de Fulton);

- $\quad$ o edema pulmonar por coloração com hematoxilina-eosina;

- a análise morfométrica de cardiomiócitos coloração com hematoxilina-eosina;

- $\quad$ fibrose miocárdica por marcação com PicroSirus Red; 
3.2.2.1. Efeito do treinamento físico aeróbico nos marcadores de lesão/regeneração

- infiltrado inflamatório no músculo tibial anterior por hematoxilina-eosina;

- número de fibras com núcleo centralizado no músculo tibial anterior por imunofluorescência;

- número de fibras divididas no músculo tibial anterior por imunofluorescência;

- número de células divididas no músculo tibial anterior por imunofluorescência; 


\section{RESULTADOS /DISCUSSÃO}

\subsection{Padronizacão do modelo de IC por hipertensão pulmonar}

Atualmente diversos modelos são utilizados para o desenvolvimento de estudos com insuficiência cardíaca, contudo, tais modelos ainda apresentam diversas limitações, como alta mortalidade e variabilidade.

Sendo assim, ainda há a necessidade um modelo que desenvolva rapidamente e de forma homogênea a IC e a miopatia esquelética. Desta forma, no presente projeto de pesquisa optamos por utilizar o modelo de IC induzido por MCT.

O estudo realizado por Ahn e colaboradores (Ahn et al.) demonstrou que 6 a 8 semanas de injeções subcutâneas semanais de $600 \mathrm{mg} / \mathrm{kg}$ de MCT induzia a disfunção do músculo diafragma, associada à atrofia das fibras e diminuição da força isométrica máxima desse músculo. Com base nos resultados do estudo de Ahn e colaboradores, foi delineado o primeiro protocolo experimental do presente estudo conforme observado na Figura 4. Na Figura 6B observa-se a curva de sobrevida dos animais ao longo de 6 semanas (40 dias) de tratamento com MCT (dose semanal de $600 \mathrm{mg} / \mathrm{kg}$, via s.c.). O tratamento se mostrou muito agressivo apresentando $100 \%$ de mortalidade na sexta semana do período experimental (Figura 4A). Ainda, a toxicidade da droga levou a uma significativa perda de massa corporal (Figura 4B), principalmente no início do tratamento, sendo esse efeito semelhante ao observado em ratos tratados com MCT, cujo aumento na mortalidade está associado a uma dramática redução da massa corporal (Nogueira-Ferreira et al., 2016).

A

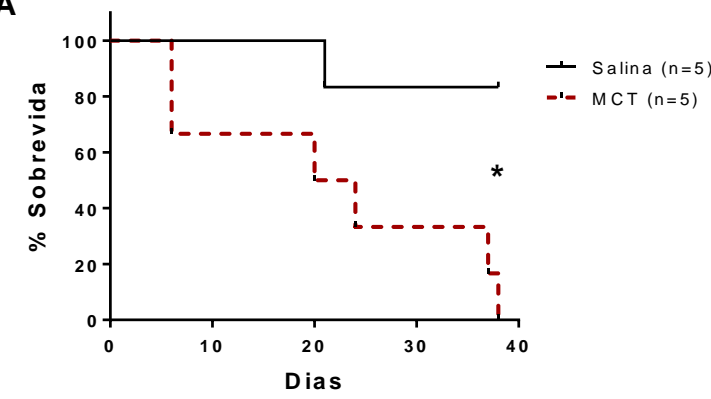

B

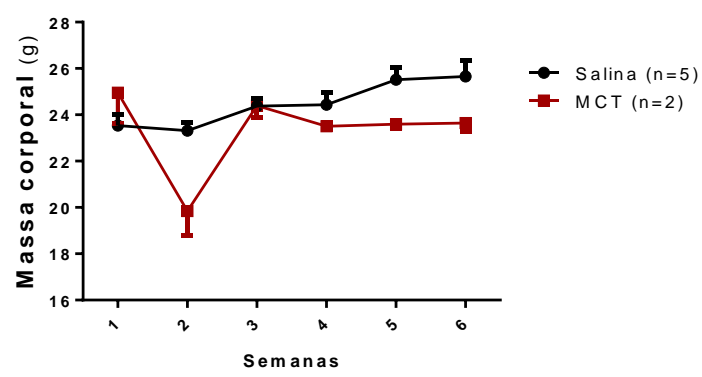

Figura 4 - Camundongos tratados com alta dose de monocrotalina $(600 \mathrm{mg} / \mathrm{kg})$ apresentam menor sobrevida. Curva de sobrevida (A) e massa corporal (B) de camundongos tratados com salina (linha preta ou círculos pretos) ou monocrotalina (doses semanais de $600 \mathrm{mg} / \mathrm{kg}$, representados pela linha tracejada ou quadrados vermelhos). Os dados estão representados na forma de média \pm erro padrão da média. * diferença significante vs. salina, $p<0,05$. Para a curva de sobrevida, os dados foram comparados entre os grupos pelo teste Mantel-Haenszel logrank. Para o acompanhamento ponderal, os dados foram comparados entre os grupos pela ANOVA de um caminho com medidas repetidas. 
Com base nos dados acima, um novo protocolo de indução de IC por monocrotalina foi conduzido, baseado no estudo realizado por Li e colaboradores (Li et al., 2014), cuja HP era observada após um período de 60 dias de tratamento. Nesse protocolo foi usada uma dose menor de MCT ( $80 \mathrm{mg} / \mathrm{kg}$ ) via intraperitoneal, com um intervalo maior entre as injeções de MCT (a cada 20 dias) e um maior período de tratamento ( 16 semanas). Em um primeiro momento, a massa corporal dos animais foi acompanhada no $3^{\circ}, 5^{\circ}$ e $7^{\circ}$ dia da primeira semana de tratamento com o intuito de avaliar o impacto agudo da dose utilizada de MCT, uma vez que evitar a perda excessiva de massa corporal com o tratamento não era interessante. De fato, não foram observadas diferenças entre os grupos salina e MCT na primeira semana de tratamento (Figura 5A). Na Figura 5B, observa-se que houve manutenção da massa corporal dos animais ao longo dos 4 meses de estudo (15 semanas), mostrando que a tolerabilidade à dose utilizada neste protocolo foi satisfatória. A manutenção da massa corporal nos animais tratados com MCT estava associada a uma manutenção da ingestão calórica ao longo dos 4 meses de tratamento quando os camundongos tratados foram comparados ao grupo salina (Figura 5C). Esse resultado é de suma importância, pois a redução da ingesta calórica com o tratamento com MCT poderia ser um fator interveniente e independente de perda de massa muscular no nosso modelo. Além disso, cabe ressaltar que esses animais apresentaram 100\% de sobrevida.
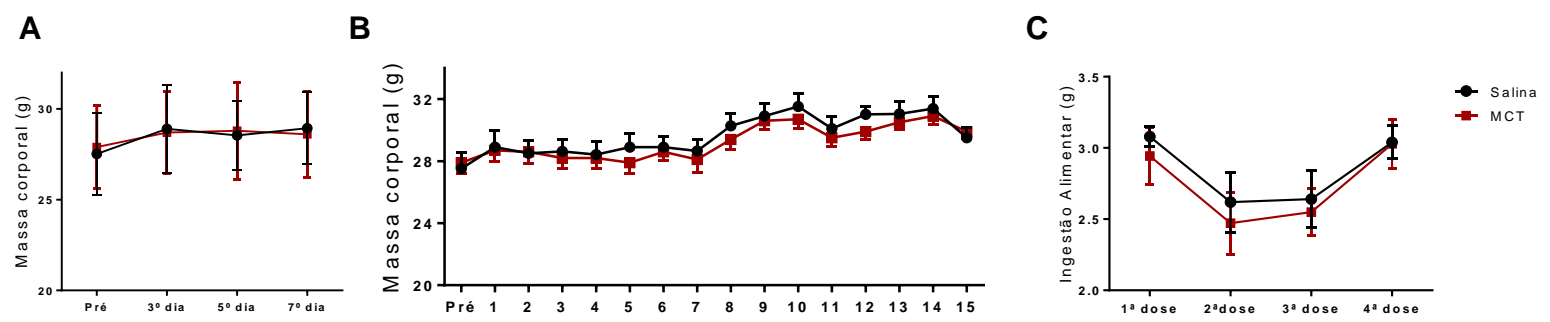

Figura $5.80 \mathrm{mg} / \mathrm{kg}$ dose de monocrotalina não altera a massa corporal e a ingestão alimentar de camundongos. Massa corporal durante a primeira semana de tratamento com monocrotalina (A) e ao longo de 15 semanas do protocolo experimental (B) de camundongos tratados com salina (círculos pretos) ou monocrotalina (doses a cada 20 dias de $80 \mathrm{mg} / \mathrm{kg}$, representados pelos quadrados cinzas). Ingestão alimentar (C) ao longo do tratamento nos grupos supracitados. Os dados estão representados na forma de média \pm erro padrão da média. Os dados foram comparados entre os grupos pela ANOVA de um caminho com medidas repetidas.

Uma vez confirmado que o tratamento com MCT era viável, não afetando a massa corpórea ou a sobrevida dos animais, o próximo passo do presente projeto foi avaliar se os animais tratados com $80 \mathrm{mg} / \mathrm{kg}$ de MCT apresentariam edema pulmonar e disfunção cardíaca. Para isso, escolhemos dois pontos para a análise, o primeiro deles com 2 meses, período no qual, de acordo com estudo desenvolvido por Li, os animais apresentariam hipertensão pulmonar e remodelamento cardíaco (Li et al., 2014). O segundo período de análise foi com 4 
meses de tratamento, no qual esperávamos que os animais apresentassem disfunção cardíaca, associada à miopatia esquelética.

Na Figura 6 (B e C), podemos observar que os animais tratados com MCT apresentam edema pulmonar quando comparados aos animais tratados com salina. Essa avaliação consiste na quantificação de áreas preenchidas (indicadas pelas setas), observadas em cortes histológicos de pulmão após coloração com hematoxilina e eosina. Esses resultados sugerem o desenvolvimento da hipertensão pulmonar após 2 meses de tratamento com MCT, além disso, os animais apresentaram disfunção cardíaca direita e remodelamento do VD (Figura 6, painéis D e E, respectivamente), indicativos de disfunção cardíaca direita. Os animais tratados com MCT não apresentaram alteração significante nos índices de função e remodelamento do VE (Figura 6 F-H). Neste período de tratamento também não foram observadas alterações de paramentos funcionais de tolerância ao esforço e função do músculo esquelético (Figura 6 I$\mathrm{K})$.

Esses resultados demonstram que apesar dos 2 meses de tratamento com MCT, não foi possível observar um grande efeito na indução da disfunção cardíaca. Nessa etapa, a hipertensão pulmonar parece levar a disfunção direita isolada ainda em estágio inicial. Ademais, o tratamento per se com MCT e o quadro de hipertensão pulmonar não apresentam efeito direto sobre a função muscular esquelética (Figura 6 e Tabela 1). 
A

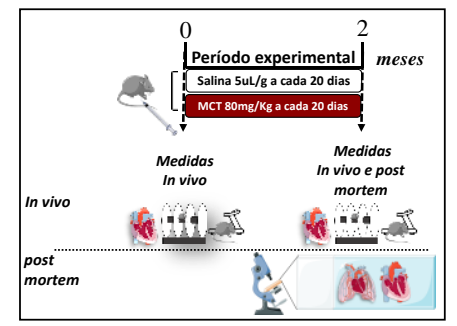

D
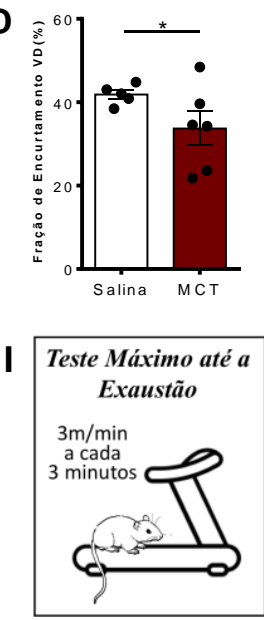

E
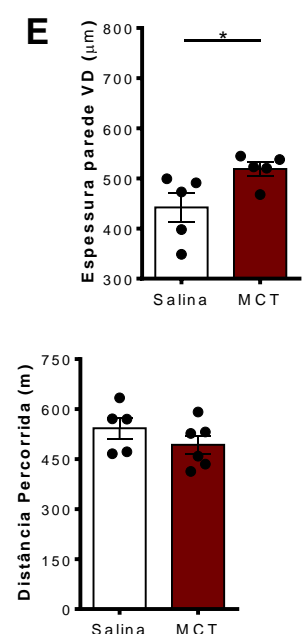

Salin a

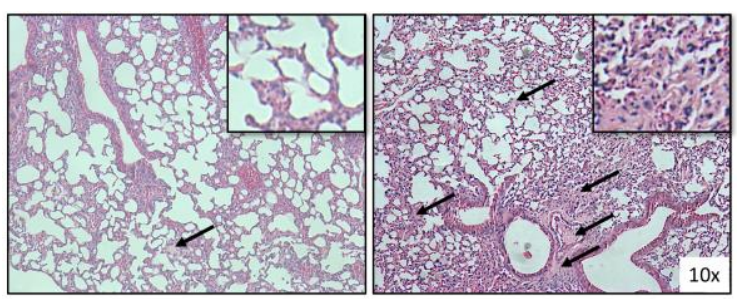

$\mathbf{F}$
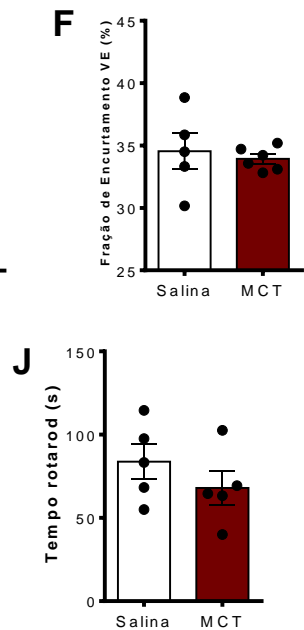

G

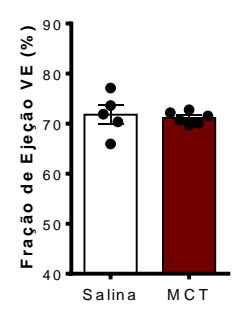

$\mathrm{K}$ Avaliação "ex vivo" músculo EDL

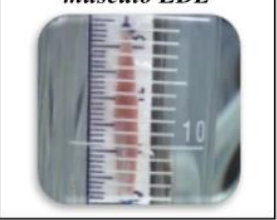

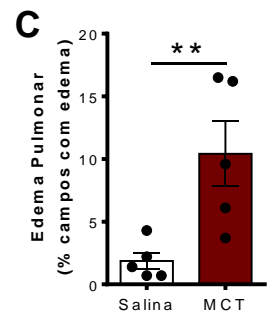
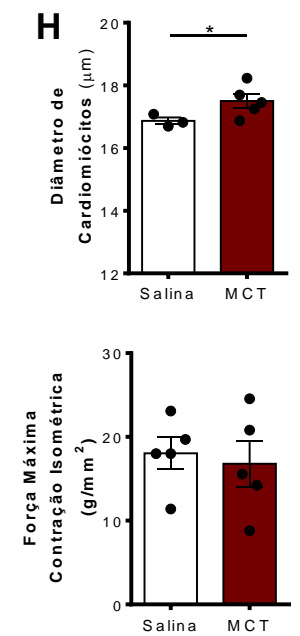

Figura 6. Tratamento por 2 meses com monocrotalina induz edema pulmonar disfunção do VD, sem induzir intolerância ao esforço ou comprometimento da função muscular. Esquema do desenho experimental (A), coloração por hematoxilina eosina em cortes transversais do pulmão (as setas indicam área de edema pulmonar) (B) e o número de eventos de edema pulmonar (C). Fração de encurtamento por ecocardiograma (D) e espessura da parede livre por histologia do VD (E). Fração de encurtamento (F), fração de ejeção $(\mathrm{G})$ e diâmetro de cardiomiócitos (H) do VE. Distância percorrida em teste de tolerância ao esforço (I), tempo até a queda no teste de rotarod (J) e força máxima de contração isométrica $(\mathrm{K})$ em camundongos tratados com salina (barras brancas) ou monocrotalina (doses a cada 20 dias de $80 \mathrm{mg} / \mathrm{kg}$, representados pelas barras vermelhas). Os dados estão representados na forma de média \pm erro padrão da média. Os dados foram analisados pelo teste $t$ de Student para dados não pareados. * diferença significante vs. salina, $\mathrm{p}<0.05$; ** diferença significante vs. salina, $\mathrm{p}<0,01$. MCT, monocrotalina; VD, ventrículo direito; $\mathrm{VE}$, ventrículo esquerdo. 


\begin{tabular}{|c|c|c|c|c|c|c|}
\hline & \multicolumn{2}{|c|}{2 MESES } & \multicolumn{4}{|c|}{4 MESES } \\
\hline & $\begin{array}{l}\text { Salina } \\
(n=5)\end{array}$ & $\begin{array}{l}\text { MCT } \\
(n=6)\end{array}$ & $\begin{array}{l}\text { Salina } \\
(n=4)\end{array}$ & $\begin{array}{l}\text { MCT } \\
(n=6)\end{array}$ & $\begin{array}{l}\text { Salina TF } \\
\qquad(n=4)\end{array}$ & $\begin{array}{l}\text { MCT TF } \\
(n=6)\end{array}$ \\
\hline Massa corporal (g) & $31,6 \pm 0,8$ & $30 \pm 0,8$ & $27,8 \pm 1$ & $30 \pm 0,4$ & $29,6 \pm 0,9$ & $29,4 \pm 0,7$ \\
\hline Pulmão $(\mathrm{mg} / \mathrm{mm})$ & $93,8 \pm 5,3$ & $101,8 \pm 4,8$ & $100,3 \pm 6,6$ & $103,5 \pm 4,4$ & $95,1 \pm 4,8$ & $98,4 \pm 5,4$ \\
\hline Fígado $(\mathrm{mg} / \mathrm{mm})$ & $1055 \pm 33,8$ & $854,9 \pm 81,1$ & $816,7 \pm 32$ & $801 \pm 57,7$ & $797,1 \pm 54,7$ & $855,7 \pm 32,9$ \\
\hline Tibial $(\mathrm{mg} / \mathrm{mm})$ & $26,7 \pm 1,2$ & $25,4 \pm 1$ & $26,9 \pm 0,6$ & $26,3 \pm 0,7$ & $26,5 \pm 0,8$ & $29 \pm 2$ \\
\hline $\begin{array}{l}\text { Gordura Epididimal } \\
\text { (mg/mm })\end{array}$ & $138,5 \pm 22,9$ & $184,6 \pm 16,8$ & $188,9 \pm 10,6$ & $266,4 \pm 30,8$ & $241,8 \pm 20,6$ & $208,7 \pm 10$ \\
\hline $\begin{array}{l}\text { Gordura Retroperitoneal } \\
\qquad(\mathrm{mg} / \mathrm{mm})\end{array}$ & $32,4 \pm 2,7$ & $64,5 \pm 21,5$ & $41,3 \pm 1,6$ & $63,1 \pm 9,8$ & $57 \pm 13,6$ & $46,5 \pm 4,5$ \\
\hline $\begin{array}{c}\text { Razão Úmido/Seco } \\
\text { Pulmão }\end{array}$ & $4,3 \pm 0,23$ & $4,2 \pm 0,15$ & $3,7 \pm 0,56$ & $3,9 \pm 0,07$ & $4,4 \pm 0,18$ & $4,5 \pm 0,09$ \\
\hline $\begin{array}{l}\text { Razão Úmido/Seco } \\
\text { Fígado }\end{array}$ & $3,0 \pm 0,05$ & $3,1 \pm 0,04$ & $3,2 \pm 0,04$ & $3,5 \pm 0,17$ & $3,1 \pm 0,06$ & $3,1 \pm 0,09$ \\
\hline
\end{tabular}

Tabela 1. Massa corporal e de tecidos (corrigidos pelo comprimento da tíbia) de camundongos tratados por 2 e 4 meses com salina ou monocrotalina, sedentários e treinados (MCT, $80 \mathrm{mg} / \mathrm{kg}$ a cada $20 \mathrm{dias}$ ). VD, ventrículo direito; VE, ventrículo esquerdo; EDL, extensor digitorum longus; MCT, monocrotalina; TF, treinamento físico aeróbico. Os dados estão representados na forma de média \pm erro padrão da média e foram analisados pelo teste $t$ de Student para dados não pareados ou pela ANOVA de dois caminho com medidas repetidas.

Na hipertensão pulmonar, o desenvolvimento de edema impede que o oxigênio seja absorvido pela corrente sanguínea, sendo uma consequência comum da doença, especialmente em fases mais avançadas, onde a ICD já está instalada (Mclaughlin e Mcgoon, 2006). Embora a razão massa úmida/seca do pulmão não tenha apresentado diferença significativa entre os grupos estudados (Tabela 1), os animais tratados por 4 meses apresentaram o quadro de edema pulmonar (Figura 7B e C).

Associado a esse edema pulmonar, podemos observar que 4 meses de tratamento com MCT induz disfunção cardíaca tanto no VD, quanto no VE (Figura 7D-H). Essa disfunção contrátil no VD do grupo MCT foi constatada pela redução de $15 \%$ na fração de encurtamento $(P<0,05$, Figura 7D) comparado ao grupo que recebeu salina. Além disso, os animais tratados com MCT também apresentaram redução da espessura do VD (Figura 7E), adaptação comum no desenvolvimento da ICD (Gaine, 2000). Interessante, a disfunção contrátil se estendeu ao VE aos 4 meses de tratamento com MCT, onde observou-se redução de $\underline{15 \% \text { na fração de }}$ encurtamento $(P<0,05$, Figura 7F) e de $14 \%$ na fração de ejeção $(P<0,02$, Figura $7 \mathrm{G})$ nos grupos tratados com MCT quando comparados ao grupo salina. Adicionalmente, observou-se 
remodelamento cardíaco com aumento no diâmetro transverso de cardiomiócitos $(P<0,05$, Figuras $7 \mathrm{H}$ ) do grupo MCT vs. grupo salina após 4 meses de tratamento. Esses resultados merecem destaque, pois a hipertrofia cardíaca é uma das formas de remodelamento que está diretamente associada com mau prognóstico na IC, aumentando o risco de óbito em pacientes (Kannel et al., 1969; Mathew et al., 2001).
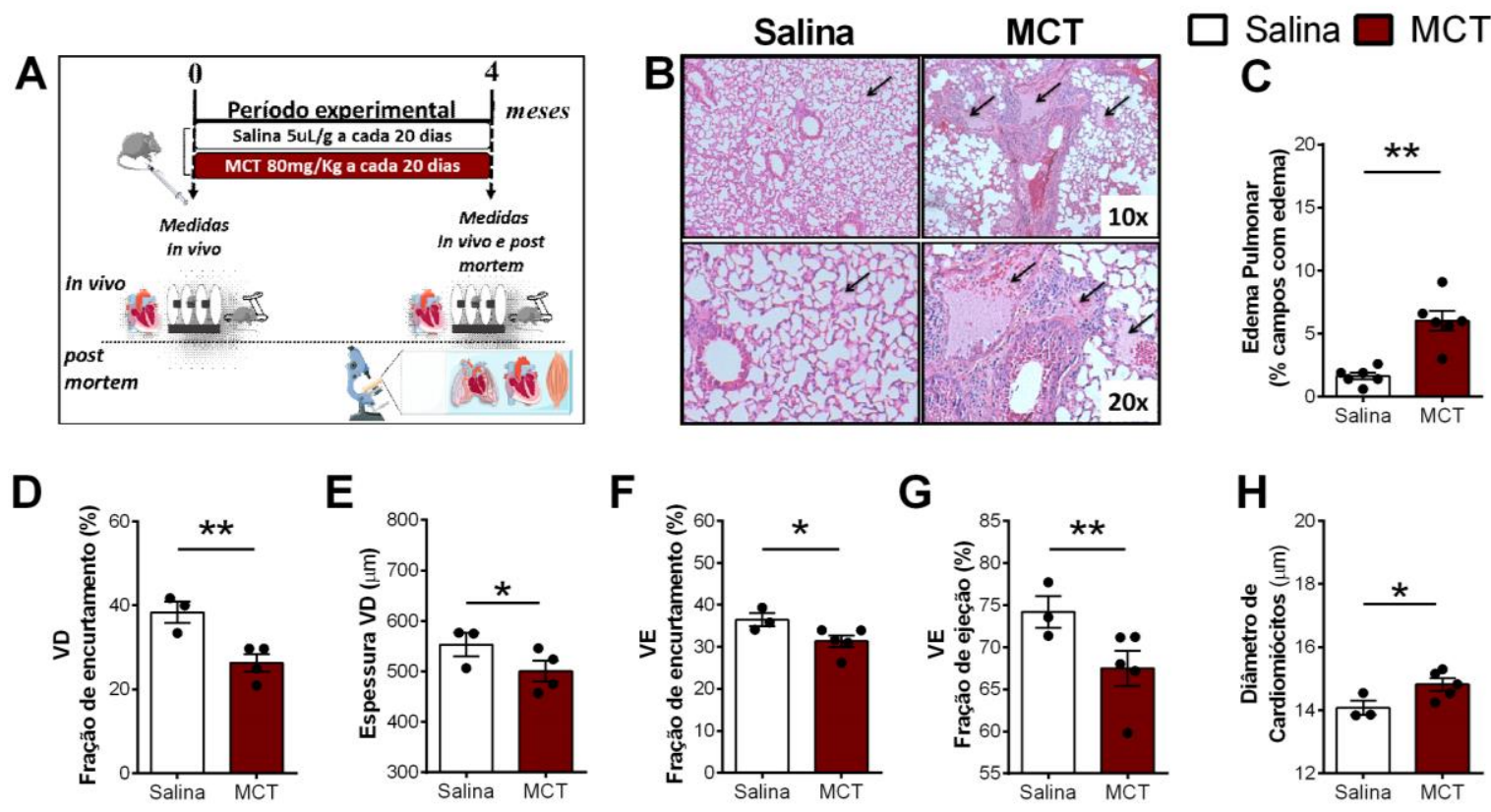

Figura 7. Mudanças funcionais e estruturais desencadeadas pelo tratamento com monocrotalina por 4 meses. Esquema do desenho experimental (A), coloração por hematoxilina eosina em cortes transversais do pulmão (as setas indicam área de edema pulmonar) (B) e o número de eventos de edema pulmonar (C). Fração de encurtamento por ecocardiograma (D) e espessura da parede livre por histologia do VD (E). Fração de encurtamento (F), fração de ejeção $(\mathrm{G})$ e diâmetro de cardiomiócitos $(\mathrm{H})$ do VE de camundongos tratados com salina (barras brancas) ou monocrotalina (doses a cada 20 dias de $80 \mathrm{mg} / \mathrm{kg}$, representados pelas barras vermelhas). Os dados estão representados na forma de média \pm erro padrão da média. Os dados foram analisados pelo teste $t$ de Student para dados não pareados. * diferença significante vs. salina, $\mathrm{p}<0.05 ; * *$ diferença significante vs. salina, $\mathrm{p}<0,01$. MCT, monocrotalina; VD, ventrículo direito; VE, ventrículo esquerdo.

Os resultados do teste de intolerância aos esforços físicos, rotarod e da avaliação da função muscular ex vivo, que caracterizam parte do quadro de miopatia esquelética na IC, se mostraram distintos entre os períodos de 2 e 4 meses de tratamento com MCT. Tal constatação se faz importante uma vez que a intolerância aos esforços físicos, observada nas doenças cardiovasculares, constitui-se em importante sinal clínico associado à gravidade da IC direita induzida por HP(Gaine, 2000). Como observado na Figura 8B, camundongos tratados por 4 meses com MCT apresentam redução de $\underline{20 \%}$ na distância total percorrida $(P<0,05)$ em comparação ao grupo salina. É importante ressaltar que os testes de tolerância ao esforço foram realizados sempre antes da administração de MCT para evitar a interferência de um possível 
efeito tóxico agudo. A intolerância aos esforços foi acompanhada pela redução no tempo até queda no teste rotarod e na produção de força pelo músculo extensor digitorum longus (EDL) do grupo tratado com MCT quando comparado com o grupo salina (Figura 8B e C). Os músculos EDL foram isolados e avaliados ex vivo em um sistema de banho de órgãos com protocolo para aferir a capacidade máxima de produção de força (protocolo de força $\mathrm{x}$ frequência). Portanto, esses resultados em conjunto, sugerem que o tratamento com MCT por 4 meses leva a intolerância aos esforços em parte devido à disfunção muscular contrátil e que essas alterações ocorrem em fases avançadas da HP, onde há um comprometimento mais acentuado da função cardíaca.

A menor tolerância ao esforço físico e produção de força muscular estão associadas ao estabelecimento do quadro de miopatia esquelética na IC (Fraga et al., 2007). Na Figura 8D-G, é possível observar que camundongos tratados com MCT por 4 meses apresentam redução na área de secção transversa das fibras do tipo II (glicolíticas) nos músculos sóleo (Figura 8E) e EDL (Figura 8F) e no músculo tibial anterior (Figura 8G). De fato, fibras do tipo II são mais sensíveis a alterações metabólicas observadas em doenças sistêmicas, como o câncer e a IC (Wing e Goldberg, 1993; Wing et al., 1995). Já as fibras do tipo I apresentam maior resistência ao estímulo atrófico por apresentarem maior defesa anti-oxidante (Schiaffino et al., 2013). Além disso, músculos com função antigravitacional como o sóleo, mantêm-se ativos durante grande parte do tempo, o que permite uma contra regulação aos estímulos atróficos. 

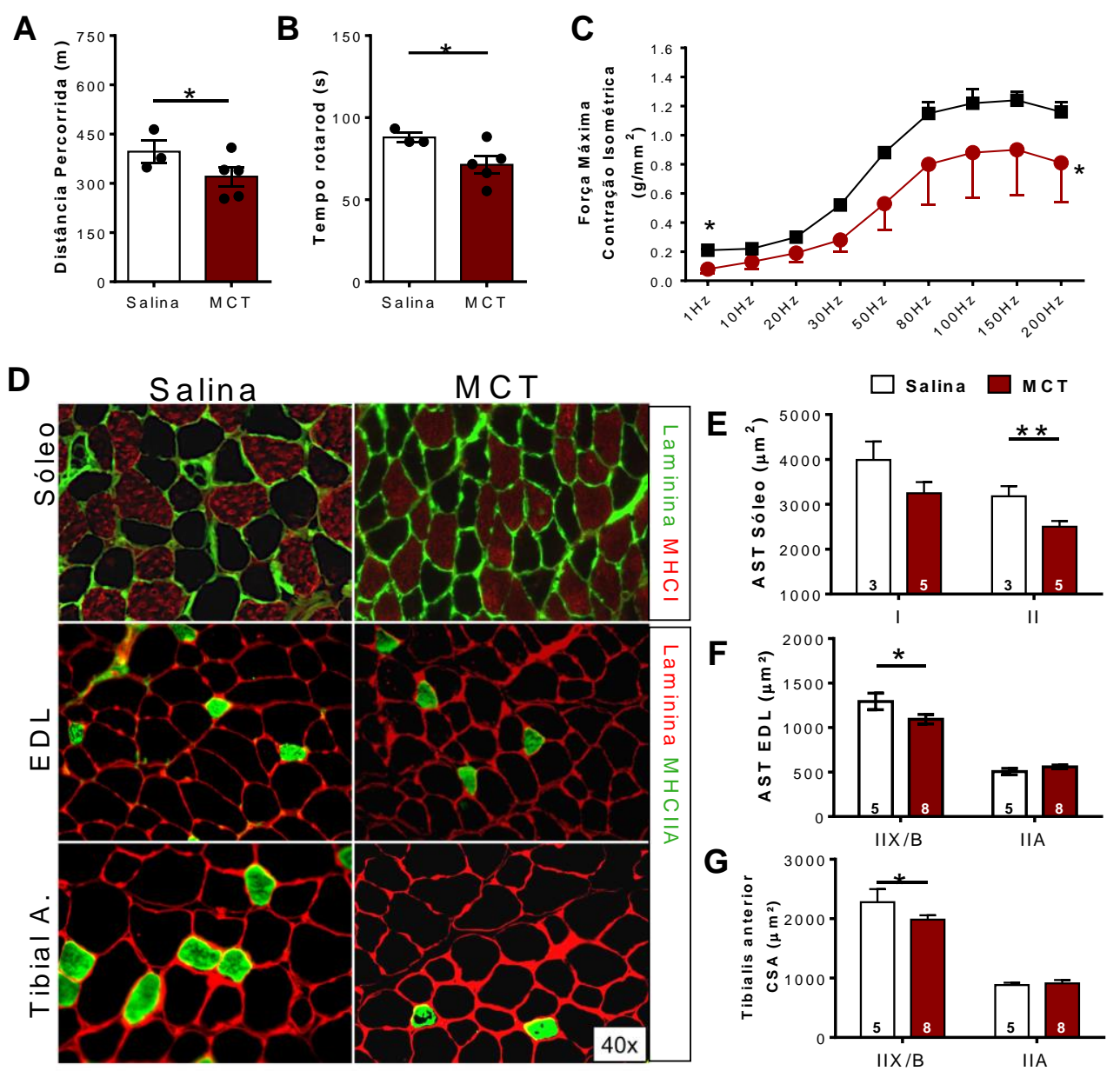

Figura 8. Alterações funcionais e estruturais desencadeadas pelo tratamento com monocrotalina no músculo esquelético. Distância percorrida em teste de tolerância ao esforço (A), tempo até a queda no teste de rotarod (B) e força máxima de contração isométrica (C). Painel representativo com as marcações por imunofluorescência para fibras do tipo I (MHC I, vermelho) no músculo sóleo, fibras do tipo IIA (MHC IIa, verde) nos músculos EDL e tibial anterior, e laminina (marcação do sarcolema, verde no sóleo e vermelha no EDL e tibial anterior) (D). Área de secção transversa (AST) das fibras do tipo I e II do músculo sóleo (E) e AST fibras do tipo II e IIA dos músculos EDL (F) e tibial anterior (G) em camundongos tratados com salina (barras brancas) ou monocrotalina (doses a cada 20 dias de $80 \mathrm{mg} / \mathrm{kg}$, representados pelas barras vermelhas). Os dados estão representados na forma de média \pm erro padrão da média. Os dados foram analisados pelo teste $t$ de Student para dados não pareados. * diferença significante vs. salina, $\mathrm{p}<0.05$; ** diferença significante vs. salina, $\mathrm{p}<0,01$. AST, área de secção transversa; EDL, extensor digitorum longus; MCT, monocrotalina.

Além da atrofia muscular, outras alterações na musculatura esquelética estão associadas ao estabelecimento do quadro de intolerância aos esforços físicos na IC. De fato, após 4 meses de tratamento com MCT, concomitante à menor AST das fibras do Tipo II, no músculo EDL observou-se também tendência ao aumento no percentual de fibras mais glicolíticas (Tipo IIA $\rightarrow$ II, $\uparrow$ de 3,5 \%) (Figura 9C e D, p=0,06) e rarefação vascular (Figura 9A e B, $\downarrow$ 13,6 \%). No músculo sóleo não foram observadas diferenças na distribuição de fibras entre os grupos estudados (\% Fibra Tipo II; 47,17 $\pm 0,85$ vs 47,27 $\pm 0,48$ - salina e MCT; respectivamente). 
Esses resultados se fazem importantes, pois o comprometimento da perfusão da musculatura ativa (Wilson et al., 1984; Sullivan et al., 1989; Vescovo et al., 2001b; Schulze et al., 2002b; Roveda et al., 2003), bem como o aumento no percentual de fibras do Tipo II (predomínio glicolítico, menos resistentes à fadiga) (Mancini et al., 1989; Sullivan et al., 1990; Drexler et al., 1992; Mancini et al., 1992), contribuem em parte para o acionamento precoce do metabolismo anaeróbio e ao maior acúmulo de lactato para uma determinada intensidade de esforço (Vescovo, 2002). No entanto, o potencial efeito dessas alterações sobre prejuízo funcional de pacientes com IC, depende do grau de comprometimento de cada variável. Dessa forma, é crucial a compreensão do estágio da doença visto que as adaptações na musculatura esquelética são sempre mais tardias do que as observadas no tecido cardíaco (Lunde et al., 2001).

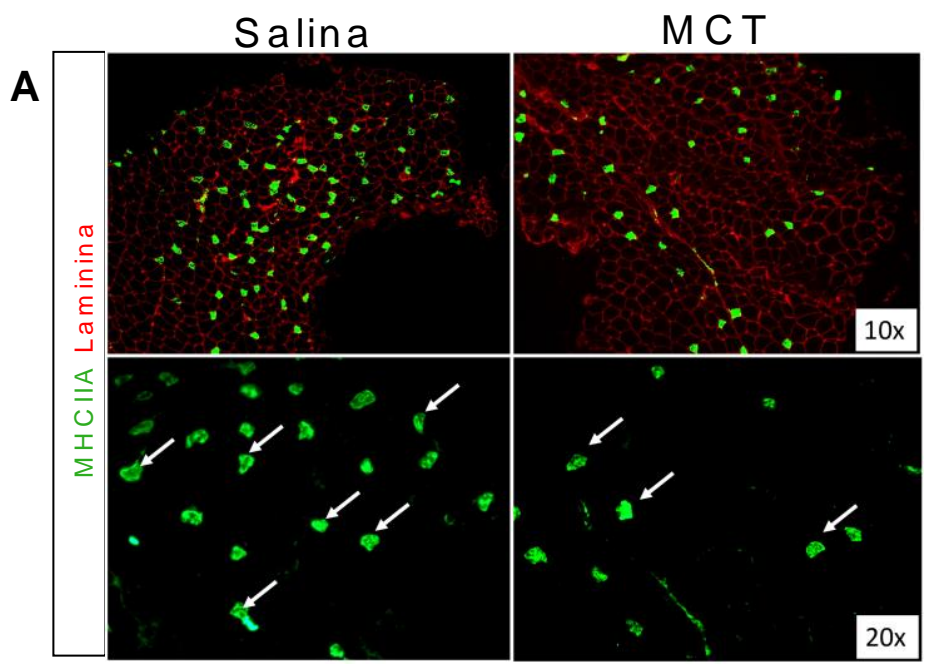

B
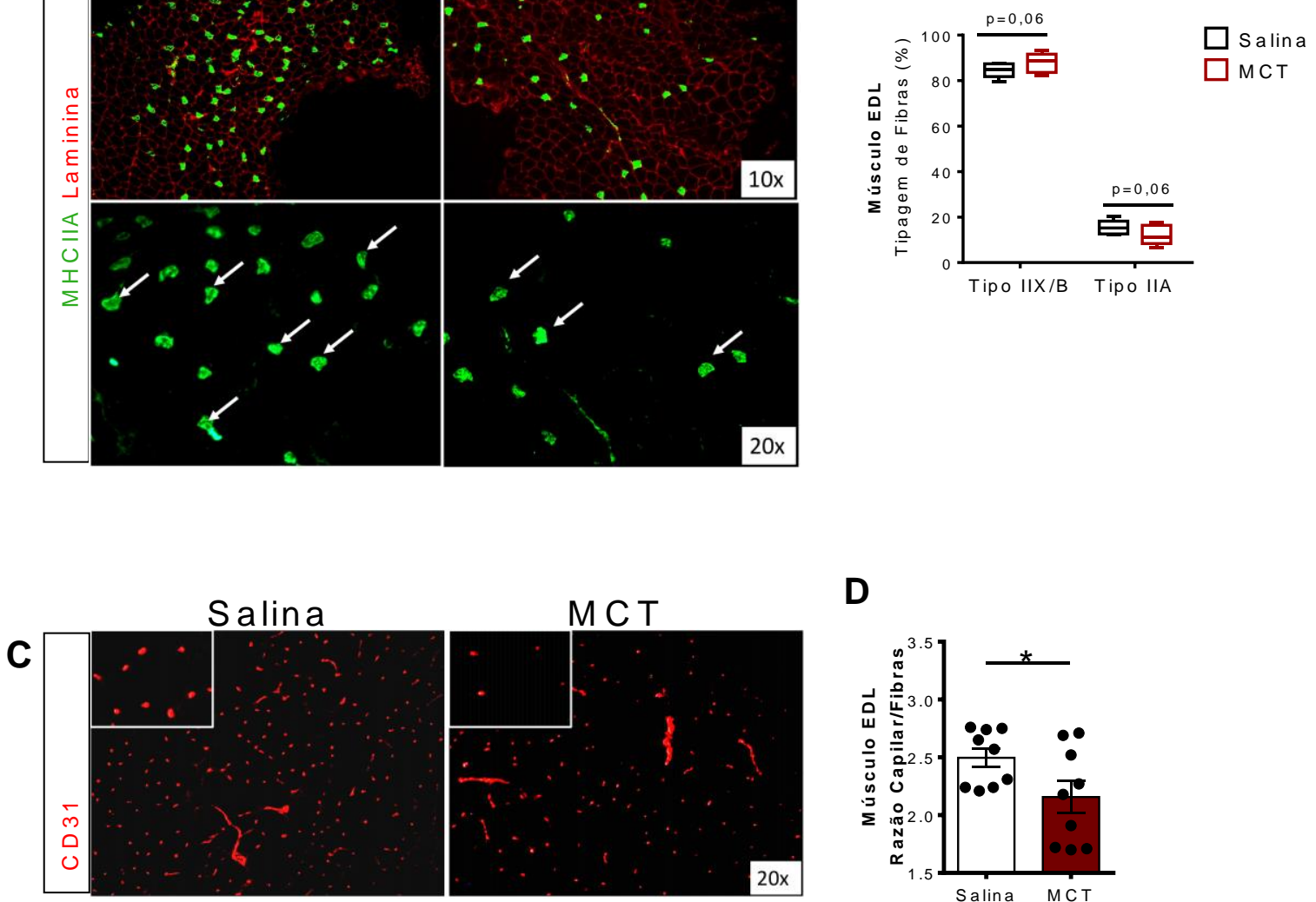

D

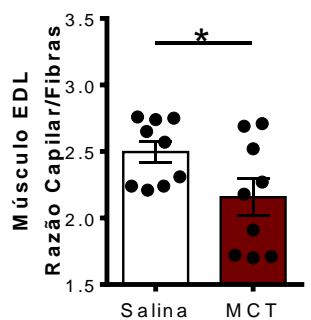

Figura 9. Tipagem de fibras e Razão capilar por fibra do músculo EDL de animais tratados com monocrotalina. Painel representativo com as marcações por imunofluorescência para fibras do tipo IIA (MHC IIa, verde) e laminina (marcação do sarcolema, vermelha) (A). Percentual de fibras tipo I e IIA do músculo EDL (B). Painel representativo com as marcações por imunofluorescência para marcação de vasos (CD31, vermelho) e laminina (marcação do sarcolema, verde) (C). Razão capilar por fibra do músculo EDL (D) de camundongos tratados com salina (círculos ou barras pretas) ou monocrotalina (doses a cada 20 dias de $80 \mathrm{mg} / \mathrm{kg}$, representados 
pelos quadrados ou barras cinzas). Os dados estão representados na forma de média \pm erro padrão da média. Os dados foram analisados pelo teste $t$ de Student para dados não pareados. *diferença significante vs. salina, $\mathrm{p}<0.05$. As setas brancas indicam as fibras positivas para MHC IIA. EDL, extensor digitorum longus. MCT, monocrotalina.

Portanto, o modelo de IC induzida por MCT em camundongos, parece ser apropriado para estudar a miopatia esquelética nesta síndrome. Com base nos resultados obtidos após 4 meses de tratamento com MCT, o potencial efeito dessa droga nas alterações observadas segue a seguinte ordem: $1^{\circ}$ Pulmão; $2^{\circ}$ Ventrículo Direito; $3^{\circ}$ Ventrículo Esquerdo; e $4^{\circ}$ Músculo Esquelético. Sendo este último, caracterizado como início do quadro de miopatia esquelética.

Uma vez caracterizado o modelo de IC induzida por MCT e determinado os diferentes "tempos" relacionados com a progressão da doença, com base nos resultados obtidos determinamos que o período de treinamento físico aeróbico (TF) compreenderia entre o $3^{\circ} \mathrm{e} \mathrm{o}$ $4^{\circ}$ mês após tratamento com MCT, ou seja, o TF foi iniciado após estabelecimento da IC, e antes do desenvolvimento da miopatia esquelética. Portanto, o TF foi uma intervenção de caráter terapêutico para os tecidos pulmonar e cardíaco, e de caráter preventivo para o tecido muscular esquelético. 


\subsection{Efeito do treinamento físico aeróbico nos sistemas cardiovascular e muscular esquelético em modelo de IC induzida por MCT}

Nos últimos anos, dados convincentes foram publicados destacando os benefícios do TFA no tratamento da IC (Zurlo et al., 1990; Cunha et al., 2012; Bacurau et al., 2016; Cunha et al., 2017), melhorando os sistemas neuro-humorais, função endotelial, efeitos antiinflamatórios, efeitos cardiovasculares e alterações do músculo esquelético (Babu et al., 2017). Considerando esses efeitos observados na IC, espera-se que o treinamento físico também seja benéfico para os pacientes com HP. De fato, estudos em pacientes com IC são utilizados para direcionar hipóteses para o treinamento físico em HP (Zurlo et al., 1990).

O efeito do TF foi muito pouco explorado em modelo de IC induzida por MCT. Além de poucos estudos, a maioria deles foi conduzida com ratos, cuja a mortalidade é alta em curto período de estudo (aproximadamente 30 dias) (Doggrell e Brown, 1998). Neste contexto, os estudos que realizaram o TF, ou efetuaram essa intervenção antes do desenvolvimento do quadro de IC, como um pré-condicionamento físico (Nogueira-Ferreira et al., 2016), ou realizam o TF em estágios mais avançados da doença, em períodos curto de intervenção (Brown et al., 2017; Enache et al., 2017). Dessa forma, o pouco conhecimento que existe sobre TF em modelo de IC por MCT ainda é bastante controverso.

Como observado na Figura 10 (painéis, B e C), animais tratados com MCT, após 4 semanas de TFA não apresentaram melhoras no quadro de edema pulmonar, que caracteriza a hipertensão pulmonar nesses animais, corroborando outros estudos já publicados na literatura (Natali et al., 2015). De fato, diversos estudos mostram que os benefícios advindos do exercício físico em indivíduos com hipertensão pulmonar são resultado de melhora na função cardíaca e muscular, e não pulmonar (Handoko et al., 2009; Natali et al., 2015).

Similar ao resultado observado no tecido pulmonar, o TFA não apresentou benefício na função e remodelamento do VD (Figura 10D e E). De fato, os benefícios diretos do treinamento físico moderado para o tecido pulmonar e a função do VD são muito modestos (La Gerche e Claessen 2015, Natali, Fowler et al. 2015, Moreira-Gonçalves, Ferreira-Nogueira et al. 2017)

Diferente do VD, animais treinados tratados com MCT mostraram maior fração de encurtamento e ejeção (Figura 10F e G), sem hipertrofia dos cardiomiócitos do VE (Figura 10H) quando comparados ao animais sedentários tratados com MCT. Em conjunto, esses dados 
mostram que o treinamento físico parece ser eficaz para retardar a progressão da HP, retardando o remodelamento cardíaco esquerdo.
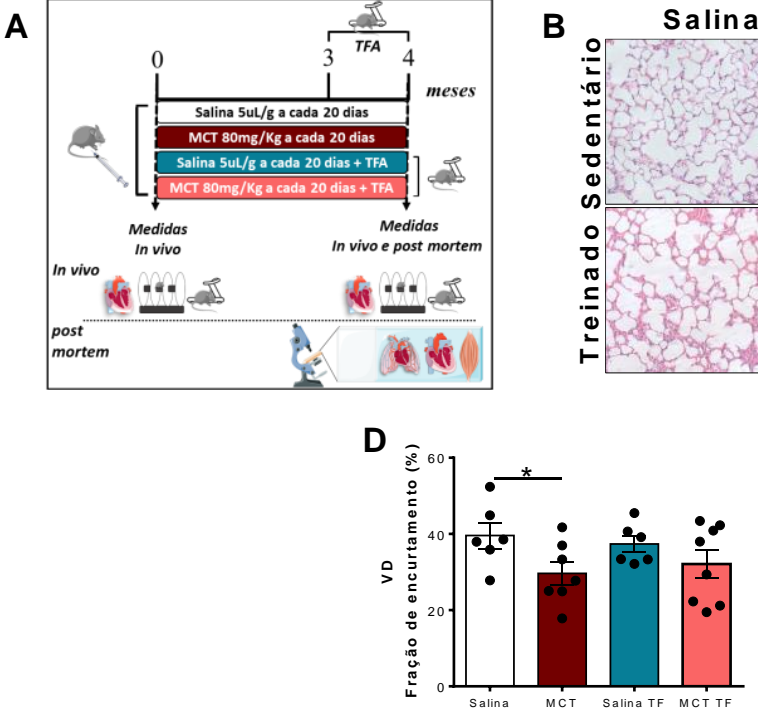

$\mathbf{F}$

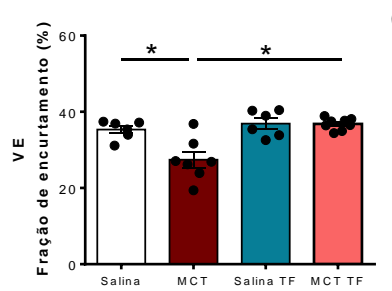

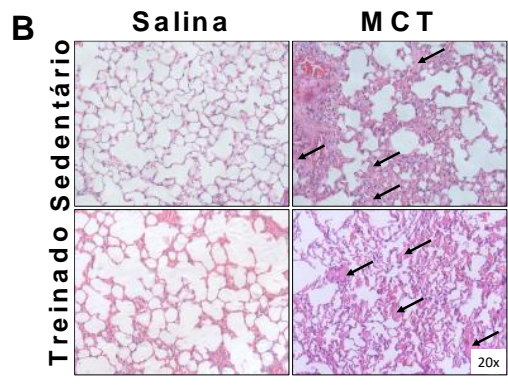

C

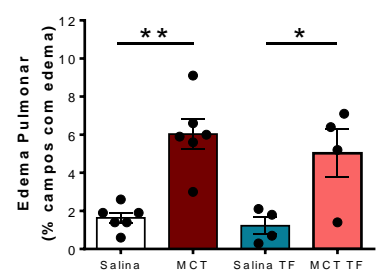

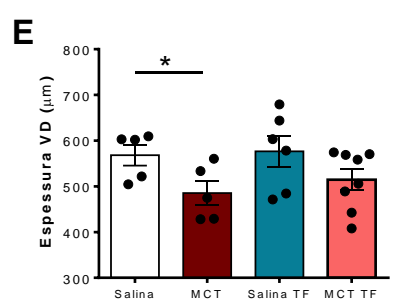

G

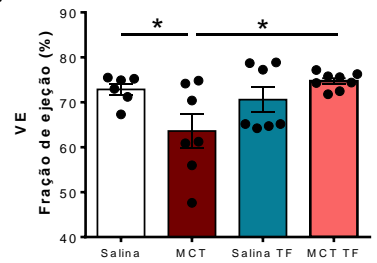

$\mathbf{H}$

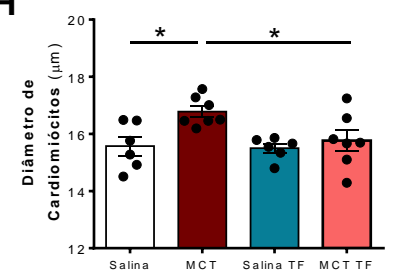

Figura 10. Efeito do treinamento físico aeróbico nas mudanças funcionais e estruturais desencadeadas pelo tratamento com monocrotalina no músculo cardíaco e tecido pulmonar. Esquema do desenho experimental (A), coloração por hematoxilina eosina em cortes transversais do pulmão (as setas indicam área de edema pulmonar) (B) e o número de eventos de edema pulmonar (C). Fração de encurtamento por ecocardiograma (D) e espessura da parede livre por histologia do VD (E). Fração de encurtamento (F), fração de ejeção (G) e diâmetro de cardiomiócitos $(\mathrm{H})$ do ventrículo esquerdo de camundongos tratados com salina (barras brancas) ou monocrotalina (doses a cada 20 dias de $80 \mathrm{mg} / \mathrm{kg}$, representados pelas barras vermelhas), sedentários (barras brancas e vermelhas) e após 1 mês de treinamento físico aeróbico (barras azuis e salmão) (do 3o ao 4o mês do período experimental). Os dados foram comparados pela ANOVA de dois caminhos. * diferença significante vs. grupo indicado pelo traço, $\mathrm{p}<0.05$. MCT, monocrotalina; TF, treinamento físico; VD, ventrículo direito; VE, ventrículo esquerdo.

Apesar de nenhum benefício no quadro de edema pulmonar, e da discreta melhora morfofuncional no coração, o período de 1 mês de TF foi eficaz em aumentar a tolerância ao esforço físico $(P<0,05$; Figura 11A) e o tempo de queda no teste rotarod ( $p<0,05$; Figura 11B) em animais tratados como MCT. Essa melhora foi acompanhada pelo aumento da área de secção transversa das fibras do tipo IIX/B do músculo tibial anterior, quando comparado ao grupo MCT sedentário ( $P<0,05$; Figuras $11 \mathrm{C}$ e D). Esse resultado merece destaque, pois mesmo com discreta melhora do TF nos tecidos associados a "origem da doença", essa resposta do tecido muscular ao TF amenizou o quadro de intolerância ao esforço físico, sinal clássico da 
IC. De fato, o TF é considerado a intervenção mais significativa em contrapor os efeitos da IC no tecido muscular esquelético, principalmente no que concerne a manutenção da massa muscular (Anker et al., 2013). Portanto, o modelo de IC induzida por MCT em camundongos, se faz uma importante ferramenta para o estudo das alterações musculares advindas da ICD induzida por HP, bem como o efeito do TFA em contrapor essas alterações.

A

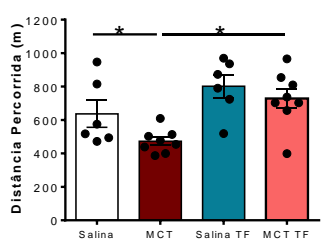

D

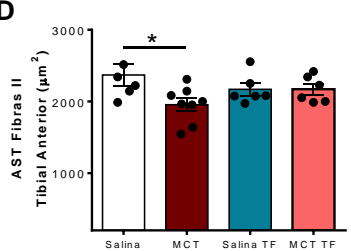

B

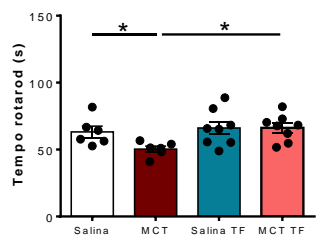

E

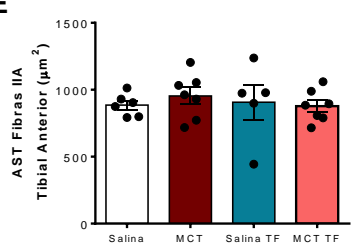

c

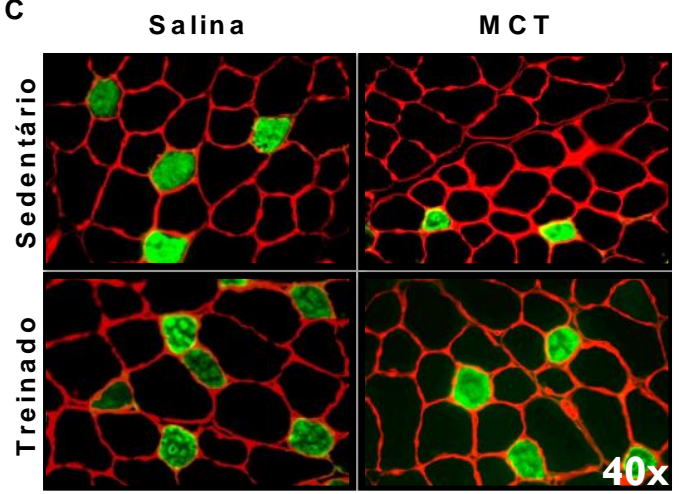

Figura 11. Efeito do treinamento físico aeróbico nas mudanças funcionais e estruturais desencadeadas pelo tratamento com monocrotalina no músculo esquelético. Distância percorrida em teste de tolerância ao esforço (A). Painel representativo com as marcações por imunofluorescência para fibras do tipo IIA (MHC IIa, verde) e laminina (marcação do sarcolema, vermelha) no músculo tibial anterior (C). Área de secção transversa (AST) das fibras do tipo IIX/B (D) e IIA (E) do músculo tibial anterior em camundongos tratados com salina (barras brancas) ou monocrotalina (doses a cada 20 dias de $80 \mathrm{mg} / \mathrm{kg}$, representados pelas barras vermelhas), sedentários (barras brancas e vermelhas) e após 1 mês de treinamento físico aeróbico (barras azuis e salmão) (do 3o ao 4o mês do período experimental). Os dados foram comparados pela ANOVA de dois caminhos. * diferença significante vs. grupo indicado pelo traço, $\mathrm{p}<0.05$. AST, área de secção transversa; MCT, monocrotalina; TF, treinamento físico.

\subsection{Papel do treinamento físico aeróbico na modulacão de marcadores de lesão/regeneração durante a miopatia esquelética em modelo de IC por monocrotalina}

A importância da força e da massa muscular para a manutenção da saúde já estão bem descritas na literatura. Por sua vez, a perda de massa e a redução de força muscular estão diretamente ligados ao aumento da mortalidade, especialmente em doenças crônicodegenerativas (Anker et al., 1997; Metter et al., 2002). Uma vez que padronizamos o modelo de IC induzido por MCT, nosso próximo objetivo foi buscar compreender melhor os processos celulares que são responsáveis pelo estabelecimento do quadro de miopatia esquelética.

Parte da regulação funcional do músculo esquelético está relacionada à sua capacidade de se regenerar frente a um processo lesivo. Esse processo "orquestrado" por diferentes fases, permite que o músculo esquelético se regenere e recupere sua funcionalidade, por meio do 
remodelamento vascular e neuromotor, voltando ao seu estado basal (Sartore et al., 1982; Carlson, 2003).

A regeneração muscular foi descrita pela primeira vez no meio do século XIX em estudos de Valentin e Schwann (G, 1835; T, 1839), entretanto, durante muitos anos esse fato foi negado e acreditava-se que o músculo esquelético era um tecido com baixa capacidade regenerativa (Carlson, 2003). Essa visão só foi mudada quase um século depois com a descoberta das células satélites por Mauro em 1961 (Mauro, 1961). A partir disso, o processo de regeneração muscular tornou-se um tema científico de grande relevância na expectativa de que a manipulação terapêutica dos mecanismos que regem a manutenção desse tecido, pudessem melhorar a qualidade de vida de indivíduos em diferentes doenças (Charge e Rudnicki, 2004).

Embora estudos tenham demonstrado a associação da menor capacidade regenerativa no desenvolvimento da atrofia muscular em doenças crônico-degenerativas ou no envelhecimento (Mehl et al., 2005; Carlson et al., 2009), pouco se sabe sobre a contribuição desses mecanismos para o desenvolvimento e progressão do quadro de miopatia esquelética na IC. Além disso, também é desconhecido se o treinamento físico aeróbico, uma efetiva estratégia terapêutica na IC esquerda pode, ao menos em parte, exercer seus efeitos por meio da regulação desses processos envolvidos na homeostasia muscular. Assim, justifica-se o estudo dos mecanismos por meio dos processos envolvidos na regulação da regeneração muscular, e se na síndrome da ICD, os efeitos positivos do TFA sobre a musculatura esquelética são também devido à modulação do processo regenerativo.

Para isso, procuramos identificar alterações morfológicas e gênicas no músculo tibial anterior que indicariam uma maior incidência de lesão e/ou regeneração muscular, ou uma disfunção no processo regenerativo. Nessa etapa do projeto avaliamos também o potencial efeito do TFA em contrapor essas possíveis alterações.

Na Figura 12, podemos notar que o grupo MCT apresentou maior número de eventos de infiltrado inflamatório quando comparado ao grupo controle, sendo esse aumento abolido pelo TFA (Figura 12A). De fato, estudos demonstram que tanto em humanos (Anker et al., 1999) quanto em modelos animais com IC (Lopes et al., 2010), há um aumento nos processos inflamatórios. O desequilíbrio entre citocinas pró-inflamatórias (que induzem o catabolismo proteico) e citocinas anti-inflamatórias (evitam o catabolismo proteico) vem sendo observado em músculos durante a progressão da síndrome da IC. Essas evidências sugerem que, durante 
o desenvolvimento da miopatia esquelética da IC, ocorra uma maior incidência de dano muscular. Por sua vez, o TFA vem sendo apontado como uma importante intervenção para restaurar o desequilibro entre citocinas pró-inflamatórias e anti-inflamatórias (Gielen et al., 2003). Esse benefício do TFA em reduzir a inflamação e prevenir a atrofia muscular, pode estar associado em parte, ao menor índice de lesão muscular. De fato, como podemos observar na Figura 12B, o grupo MCT apresentou maior número de fibras com núcleo centralizado quando comparado ao grupo controle. No entanto, o grupo MCT após período de TFA apresentou redução de $24,7 \%$ dessas fibras que estão em processo regenerativo (Figura 12B).

Durante as quantificações, também foram realizadas análises qualitativas dos músculos estudados. Um fenômeno frequentemente observado foi o aparecimento de fibras divididas, que é comumente chamado de "splitting de fibras". Na Figura 12C, podemos observar um aumento no percentual de fibras divididas no grupo MCT após o TFA quando comparado ao grupo MCT sedentário. O fenômeno da divisão de fibras está bem documentado em resposta a vários estímulos de sobrecarga muscular em animais (Hall-Craggs, 1970; Gonyea et al., 1977; Gonyea et al., 1986; Murach et al., 2017). Em condições patológicas, como a distrofia muscular de Duchenne, já foi demonstrado que o estímulo de contração, associado à doença muscular, pode levar ao aumento do número de fibras divididas \{Kiriaev, 2018 \#7702\}. Sendo assim, as contrações musculares realizadas durante o período de treinamento, associadas à ICD, podem ter induzido a divisão das fibras musculares desses animais (Figura 12C).

Outra análise realizada foi a porcentagem de células satélites por fibra. As CS em sua forma quiescente podem ser identificadas pela expressão de Pax7 (paired box transcription factors), um fator de transcrição importante para a especificação da população de CS, pois sua inativação no genoma de camundongos, levou à ausência de CS, associada a uma deficiência muscular grave e letalidade (Seale et al., 2000). Em sua forma ativa, as CS passam a expressar fatores de transcrição Myf-5 e MyoD e, uma vez diferenciadas, expressam Miogenina e MRF4. CS que mantêm a expressão de Pax7, reduzem a expressão de $\mathrm{MyoD}$, reconstituem o compartimento de células satélites, promovendo sua autorrenovação (Zammit et al., 2006). Durante o envelhecimento, a diminuição do pool de CS bem como o menor potencial de ativação proliferação e diferenciação dessas células estão associados à diminuição da capacidade regenerativa, e consequentemente, ao menor número e calibre das fibras musculares. No envelhecimento essa condição é chamada de "sarcopenia" (Collins et al., 2007; Wang et al., 2013). Até o momento, um único estudo associou a atrofia muscular da IC esquerda a uma menor população de CS (Yoshida et al., 2014). Nossos resultados mostram que essa 
alteração também ocorre na ICD, apresentando diminuição de 10,3\% das CS do músculo tibial

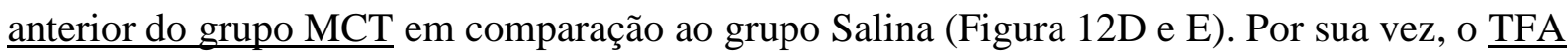
promoveu um aumento de $15,4 \%$ nas CS do grupo MCT em comparação ao grupo MCT que permaneceu sedentário. Já o grupo Salina TFA apresentou aumento de 27,6\% de CS quando comparado ao grupo Salina sedentário (Figura 12D e E). Esses resultados demonstram o potencial miogênico do TFA em aumentar o pool de CS, sendo esse efeito mais impactante em músculo de animais saudáveis. 
A
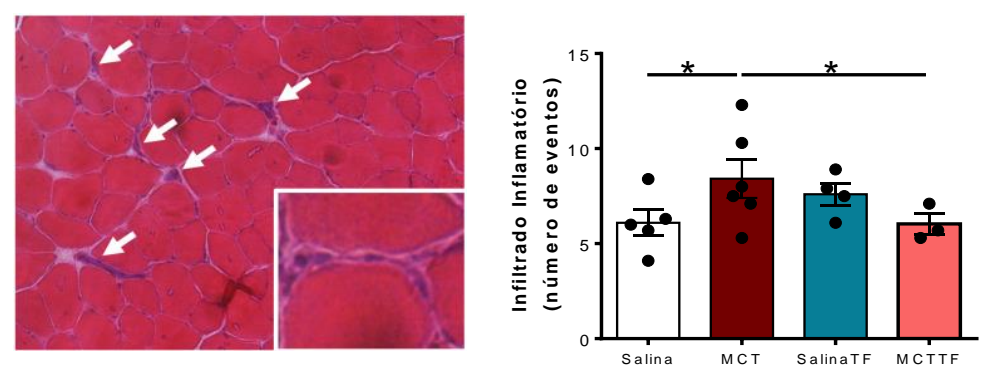

B
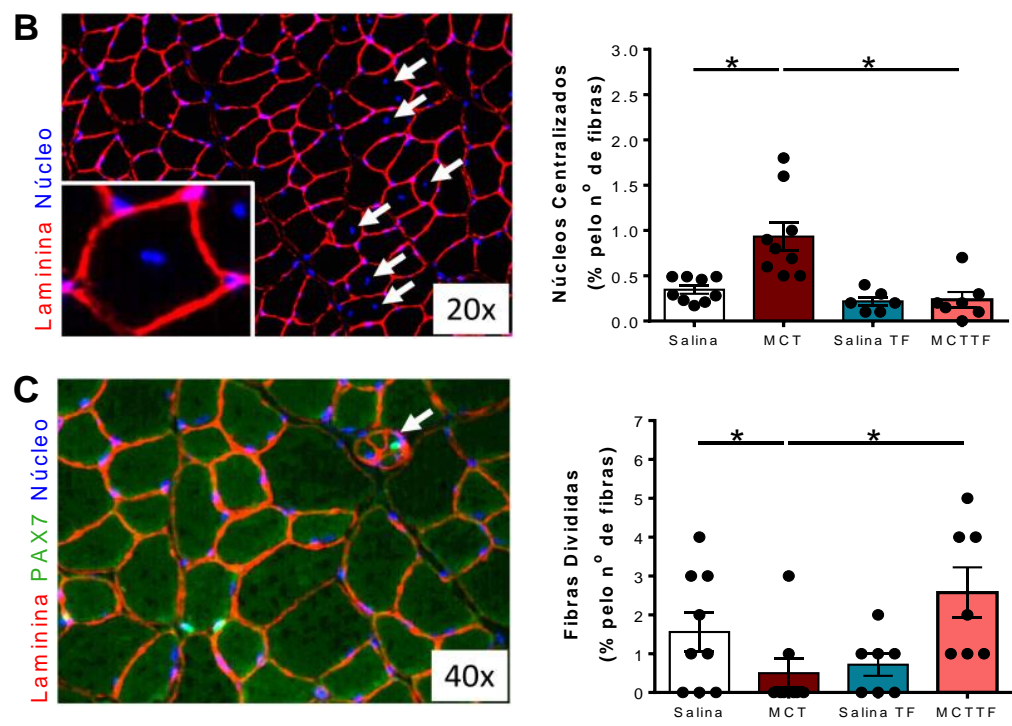

D
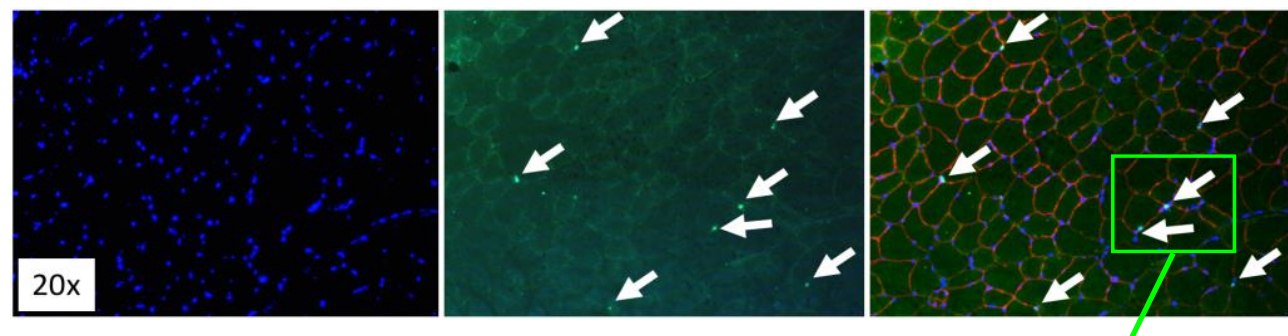

E
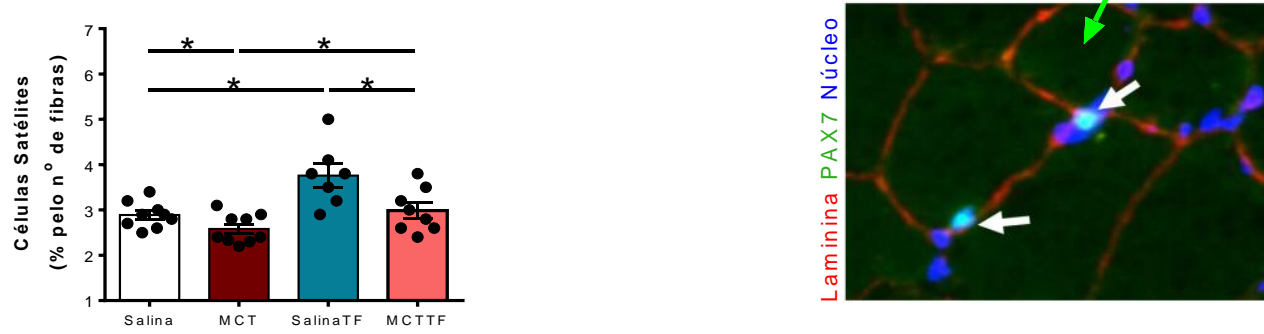

Figura 12. Efeito do treinamento físico aeróbico nas células satélites e nos indicadores de lesão/regeneração do músculo tibial anterior no quadro de miopatia muscular após tratamento com monocrotalina. Coloração por hematoxilina-eosina para análise do número de eventos de infiltrado inflamatório (A; indicado pelas setas); Imunofluorescência para laminina (vermelha) e mionúcleo (azul) para quantificação do percentual de células com núcleo centralizado (B; indicado pelas setas); Imunofluorescência para laminina (vermelha), mionúcleo (azul) e Pax7 (verde) para quantificação do percentual de fibras divididas (C; indicado pela seta); Painel ilustrativo para imunofluorescência para mionúcleo (azul), Pax7 (verde), e merge de laminina (vermelha) núcleo e Pax7 (D; indicado pelas setas) e quantificação do percentual de células satélites (E) no músculo tibial anterior anterior em camundongos tratados com salina (barras brancas) ou monocrotalina (doses a cada 20 dias de $80 \mathrm{mg} / \mathrm{kg}$, representados pelas barras vermelhas), sedentários (barras brancas e vermelhas) e após 1 mês de treinamento físico aeróbico (barras azuis e salmão) (do 30 ao 40 mês do período experimental). Os dados foram comparados pela ANOVA de dois caminhos. * diferença significante vs. grupo indicado pelo traço, $p<0.05$. MCT, monocrotalina; PAX7, Paired box protein 7, TF, treinamento físico. 
Como complemento das avaliações morfológicas, foi quantificada a expressão de genes reguladores miogênicos, atrogenes e de genes indicadores de lesão/regeneração muscular nos grupos estudados. Contudo, não obtivemos diferença significativa na expressão desses genes (Figura 13). Uma possível explicação para tais resultados é o baixo nível de expressão de tais genes, tornando mais difícil a análise por RT-qPCR. Outro ponto é o fato de a expressão gênica ser um processo dinâmico, sendo assim os genes tem um pico de expressão, que pode não ter coincidido com o momento de coleta dos nossos dados, sendo essa uma limitação do nosso estudo.

A
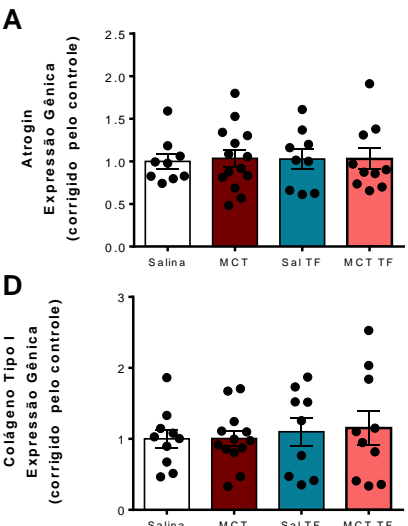

G
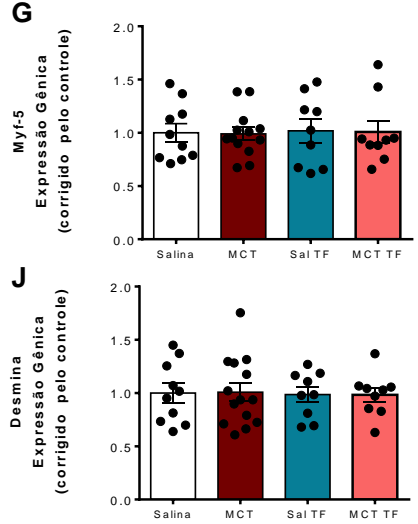

B

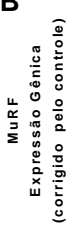

E

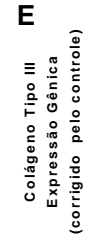

H

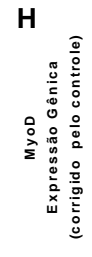

K

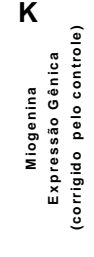

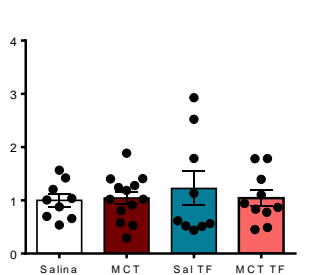
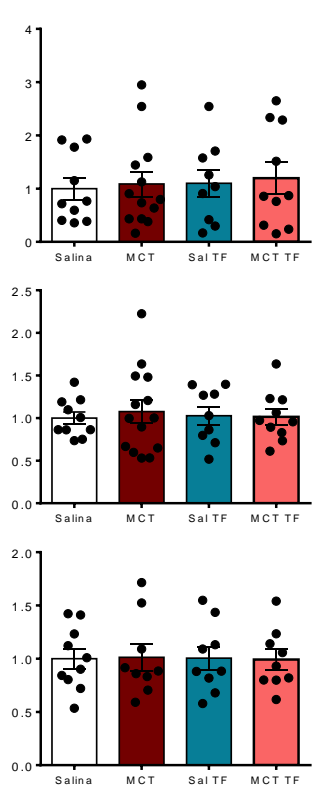

C

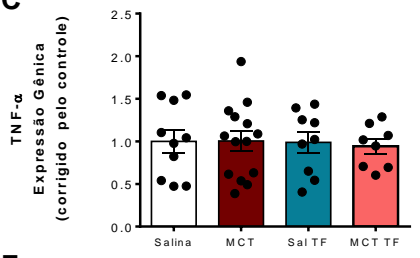

$\mathbf{F}$

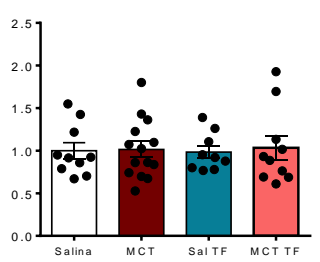

I

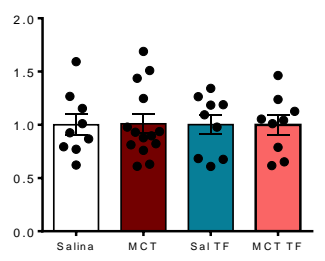

$\mathbf{L}$

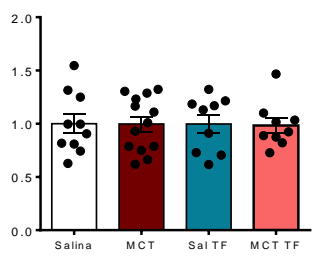

Figura 13. Efeito do treinamento físico aeróbico na expressão gênica de reguladores miogênicos, atrogenes e indicadores de lesão/regeneração muscular. Expressão dos genes para Atrogin (A), MuRF (B), TNF- $\alpha$ (C), Colágeno tipo I (D), Colágeno tipo III (E), Miostatina (F), Myf-5 (G), MyoD (H), Pax7 (I), Desmina (J), Miogennina (K), MRF4 (L) do músculo tibial anterior anterior em camundongos tratados com salina (barras brancas) ou monocrotalina (doses a cada 20 dias de $80 \mathrm{mg} / \mathrm{kg}$, representados pelas barras vermelhas), sedentários (barras brancas e vermelhas) e após 1 mês de treinamento físico aeróbico (barras azuis e salmão) (do 3o ao 4o mês do período experimental). Os resultados são expressos utilizando o método de limiar comparativo de ciclos (2$\Delta \Delta \mathrm{Ct}$ ) como descrito pelo produtor do sistema. Os dados foram comparados entre os grupos pela ANOVA de dois caminhos com medidas repetidas. TNF- $\alpha$, Tumor Necrosis Factor $\alpha$; Myf-5, Myogenic Factor 1; MyoD, Myoblast Determination Protein 1; Pax7, Paired box protein 7; MRF4, Myogenic factor 6; MCT, monocrotalina. 
A Figura 14 reúne os principais resultados da padronização do modelo de IC induzida por MCT, bem como o efeito do TF nos tecidos pulmonar, cardíaco e muscular esquelético até o momento.

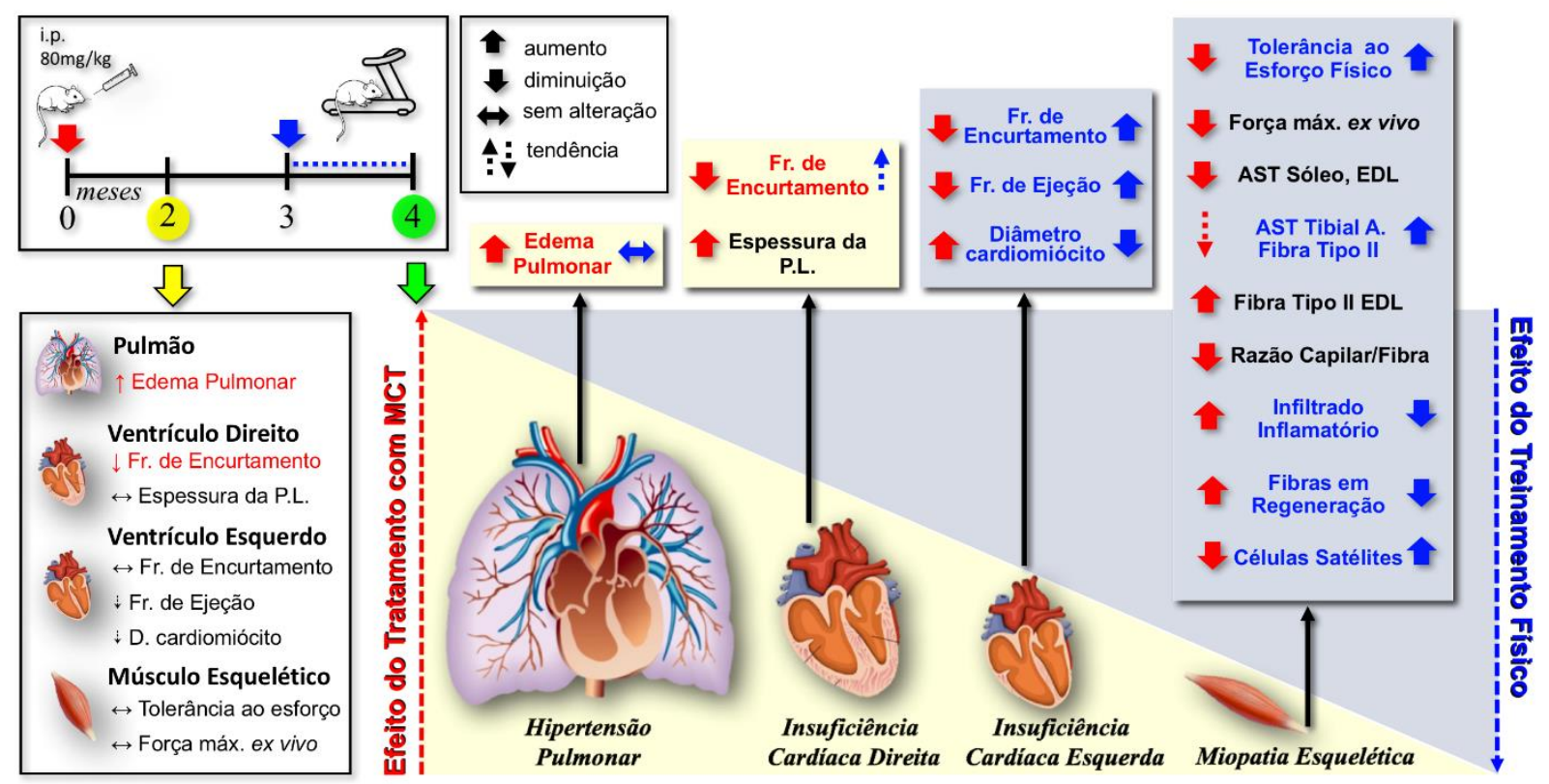

Figura 14. Sumário dos resultados da padronização do modelo de IC induzida por MCT em camundongos, bem como o efeito do TF nos tecidos pulmonar, cardíaco e muscular esquelético. Diferentes fases do tratamento com MCT, 2 meses (seta amarela) e 4 meses (seta verde). O TFA teve duração de 1 mês, do $3^{\circ}$ ao $4^{\circ}$ mês do período experimental. A variáveis e setas em vermelho indicam o efeito do tratamento com MCT. As variáveis e setas em azul indicam o efeito contrarregulador do TFA. MCT, monocrotalina; TF, treinamento físico; P.L., parede livre; EDL, extensor digitorum longus; Fr., fração; 


\section{CONCLUSÃO}

Em suma, os resultados deste projeto sugerem que o modelo de IC induzido por MCT é de grande valia para estudo da miopatia esquelética desencadeada pela ICD. Além disso, nosso modelo também se mostrou semelhante a outros em relação a resposta ao TFA, o que o torna também uma boa alternativa para estudo dos efeitos terapêuticos e preventivos do TFA.

Nosso trabalho se faz importante em mostrar que a perda de massa muscular ocorre em fases avançadas da doença pulmonar, no momento em que já há disfunção cardíaca direita e esquerda. O TFA foi eficaz em reverter a intolerância ao esforço físico e a atrofia muscular, ressaltando seu papel na terapia e prevenção da miopatia esquelética associada à ICD induzida por HP.

Além disso, nosso trabalho mostra, pela primeira vez, que o desenvolvimento da miopatia esquelética na ICD está associado a alterações nas células satélites e que o TFA é capaz de restaurar o número dessas células em animais tratados com MCT. 


\section{MATERIAIS E MÉTODOS}

\subsection{Amostra}

Foram utilizados camundongos machos da linhagem C57BL/6J na faixa etária compreendida entre três (início do protocolo) e sete (fim do protocolo) meses de idade, os quais foram mantidos no biotério da Escola de Educação Física e Esporte da Universidade de São Paulo (EEFE-USP), com temperatura controlada entre 22 e $25^{\circ} \mathrm{C}$, em ciclo claro-escuro invertido em 12:12 horas, com início do período escuro às 7 horas da manhã e início do período claro às 19 horas, com um total máximo de 5 animais por caixa. Água e comida foram administradas ad libitum. Após a anestesia com isoflurano, os camundongos foram mortos por deslocamento cervical seguindo os preceitos éticos do Guia brasileiro de produção, manutenção ou utilização de animais em atividades de ensino ou pesquisa científica do Conselho Nacional de Controle de Experimentação Animal (1 ${ }^{a}$ edição, 3/02/2016). Os tecidos de interesse foram adequadamente coletados e armazenados conforme as análises a que foram submetidos. Em cada procedimento, utilizamos um número amostral entre 3 e 11 animais por grupo. O projeto foi aprovado pela Comissão de Ética no Uso de Animais (CEUA) da EEFE-USP (nº 2014/03). Além disso, esse trabalho segue os princípios éticos na experimentação animal seguindo a Diretriz Brasileira para o Cuidado e a Utilização de Animais para fins Científicos e Didáticos do Conselho Nacional de Controle de Experimentação Animal.(CONCEA-MCTIC).

\subsection{Acompanhamento ponderal da massa corporal}

O controle da massa corporal foi realizado semanalmente em balança $G E H A K A^{\circledR}$ durante o período experimental.

\subsection{Modelo de IC por monocrotalina}

Foram administradas injeções intraperitoneais de $80 \mathrm{mg} / \mathrm{kg}$ de MCT, no volume de $5 \mathrm{ul} / \mathrm{g}$, a cada 20 dias, durante 2 ou 4 meses (de acordo com o período de análise), como descrito por Li e colaboradores (Li et al., 2014). A MCT foi diluída em solução $1.0 \mathrm{M} \mathrm{HCl}$ e seu pH ajustado para 7,4-7,6 com 0.1 M NaOH. Os animais do grupo controle receberam 150uL de solução salina nas mesmas condições. 


\subsection{Treinamento físico aeróbico}

O TFA foi utilizado como uma estratégia preventiva para o quadro de miopatia esquelética observada nos animais com IC. Realizamos o TFA em intensidade moderada com predomínio de metabolismo aeróbio, conforme padronizado anteriormente em nosso laboratório (Ferreira et al., 2007). Mais especificamente, realizamos 4 semanas de TFA em esteira rolante, com sessões de exercício com duração de 60 minutos, 5 vezes por semana a $60 \%$ da velocidade máxima atingida no teste de exercício físico progressivo até a exaustão, que corresponde a intensidade de máxima fase estável do lactato. Para verificarmos a eficácia do TFA avaliamos a tolerância ao esforço por meio de teste progressivo até a exaustão antes e após o período de TFA.

\subsection{Avaliação da função cardíaca}

Existem diversas formas de se avaliar a função cardíaca do VD in vivo, como tomografia, ressonância magnética, cateterização, entre outros. Neste estudo foi utilizada a avaliação da função cardíaca por meio de ecocardiografia, que pode ser realizada com anestesia volátil, apresentando baixo custo (Kossaify, 2015). Além disso, é um método não invasivo, reduzindo as chances de morte experimental. Apesar de ser uma técnica limitada para avaliação da função do VD, uma vez que grande parte da câmara desse ventrículo se encontra atrás do esterno, este método nos permite obter informações importantes quanto à função e estrutura do VD (Foale et al., 1986).

A avaliação da função ventricular foi realizada de acordo com as recomendações da Sociedade Americana de Ecocardiografia (Sahn et al., 1978). Antes do procedimento, os pelos dos animais foram removidos com creme depilatório de forma que toda a área do peitoral ficasse exposta. Sobre o precórdio do animal foi aplicado um gel de transmissão para ultrassom de viscosidade média/alta (General Imaging Gel, ATL. Reedsville, EUA). O exame ecocardiográfico foi realizado utilizando o equipamento Vevo 2100 High Resolution Ultrasound Imaging System (VisualSonics Inc, Toronto, Canada) (Figura 15) equipado com transdutor MS550D de 22-55 MHz, em animal anestesiado com isofluorano com fluxo de 2,5L/min Para a medida das estruturas cardíacas, foram utilizadas imagens em modo M com o feixe de ultrassom orientado pela imagem bidimensional com o transdutor na posição paraesternal no eixo menor. 
Durante o exame foram analisados o diâmetro sistólico final do ventrículo direito (DSFVD) e o diâmetro diastólico final do ventrículo direito (DDFVD). A fração de encurtamento do VD (\%FE = ((DDFVD-DSFVD)/DDFVD)x100) foi calculada após a realização das medidas. A fração de encurtamento e ejeção do VE foi calculada de forma automática pelo aparelho. O exame foi realizado no Instituto do Coração (InCor-FMUSP), por ecocardiografista experiente e especialista em animais de pequeno porte, cego para os grupos de animais.

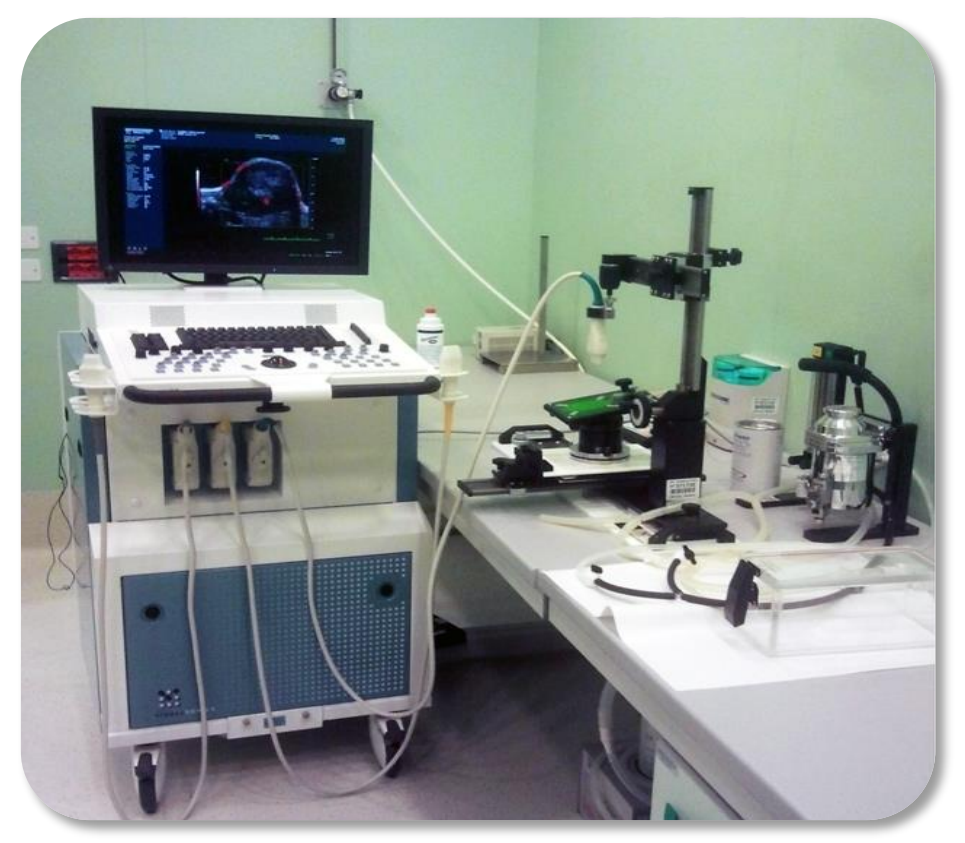

Figura 15. Aparelho Vevo 2100 utilizado para avaliação ecocardiográfica de roedores de pequeno porte.

\subsection{Avaliação da capacidade física e função muscular}

\subsubsection{A tolerância ao esforço}

A redução da tolerância ao esforço é um dos sinais clínicos de IC e apresenta uma forte correlação com o estabelecimento do quadro de miopatia esquelética. Foi avaliada por meio de teste progressivo até a exaustão, onde os animais realizaram um teste de protocolo escalonado de exercício físico com velocidade inicial de $6 \mathrm{~m} / \mathrm{min}$ (sem inclinação) e incrementos na velocidade da esteira de $3 \mathrm{~m} / \mathrm{min}$ a cada 3 minutos até a exaustão do animal de acordo com protocolo desenvolvido por Ferreira et al (Figura 16). (Ferreira et al., 2007). Antes de realizar o teste, os animais passaram por um período de adaptação nas esteiras, para que se familiarizassem com o aparelho e as alterações de velocidade similares às que foram utilizadas 
no teste. Os resultados foram apresentados pela distância total percorrida, em metros. Este teste foi realizado antes do início do tratamento, ao início e ao final do treinamento físico.

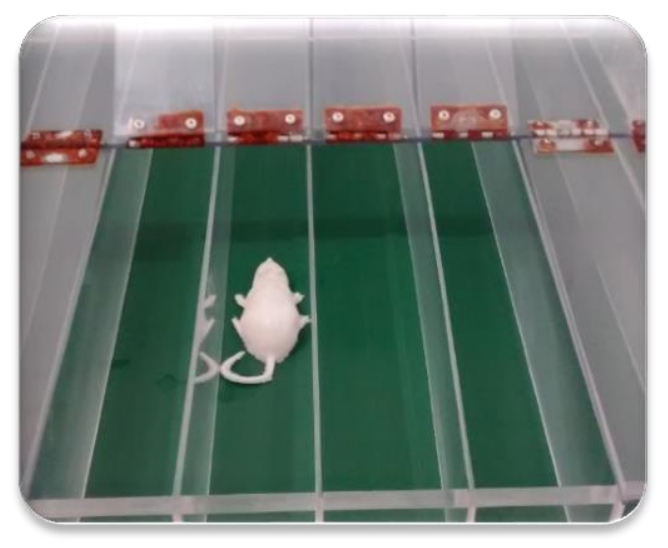

Figura 16. Esteira rolante para determinar tolerância ao esforço e treinamento físico.

\subsubsection{Função muscular em teste Rotarod}

O teste de Rotarod foi desenvolvido para avaliar função motora de roedores, sendo um dos mais sensíveis e mais utilizados para esse fim (Brooks e Dunnett, 2009). Este teste foi realizado em aparelho AVS Projetos (Figura 17) constituído de cilindros programados para apresentar velocidade inicial de $1 \mathrm{rpm}$ e velocidade final de $40 \mathrm{rpm}$, com duração máxima de até 300 segundos, sendo a aceleração constante durante todo o experimento. A avaliação consistiu em três tentativas por animal, onde o tempo (em segundos) alcançado até a queda foi anotado e o resultado do teste foi considerado como o maior tempo alcançado nas três tentativas (Turgeman et al., 2008). Este teste foi realizado na segunda e na quarta semana de tratamento após a administração de MCT/salina.

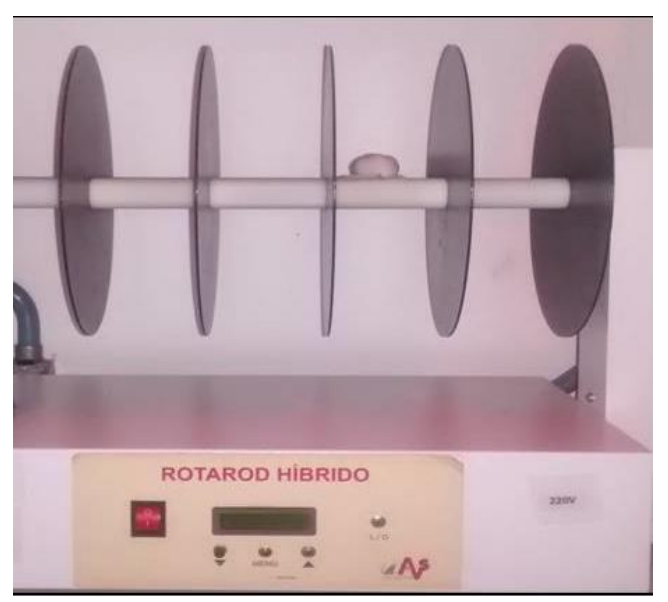

Figura 17. Aparelho Rotarod AVS Projetos (C) para determinar função muscular. 


\subsubsection{Avaliação da função contrátil "ex vivo” do músculo EDL}

Há anos o estudo de músculos isolados tem contribuído para o conhecimento dos mecanismos de contração, as bases da fadiga e outras alterações que afetem a função muscular (Barclay, 2005; Allen et al., 2008). Entre as vantagens desse método está a retirada do componente neurológico da contração muscular e a possibilidade de intervenção farmacológica diretamente no tecido muscular (Allen et al., 2008). Entre as limitações estão o tempo que o músculo passa sem suprimento sanguíneo durante sua retirada (aproximadamente 20 minutos), afetando em parte a sua capacidade de contração, porém todos os músculos passam por esse processo, logo, todos estariam sem suprimento sanguíneo por um mesmo período, fazendo com que os resultados sejam comparáveis. Outra limitação é o acúmulo de metabólitos produzidos pelo músculo na cuba do aparelho (Barclay, 2005). Para minimizar esse efeito, a cada novo protocolo o conteúdo da cuba foi trocado. Além disso, na cuba do aparelho foi colocada a solução de Krebs, que tem por objetivo manter a viabilidade do músculo, bem como mimetizar as condições fisiológicas e as propriedades físico-químicas do plasma sanguíneo.

Para análise da função contrátil, foi utilizado o protocolo de força x frequência. Nesse protocolo são realizados estímulos progressivos $(0-200 \mathrm{~Hz})$ até que a capacidade de produzir força do músculo comece a reduzir, possibilitando assim, estimar a capacidade máxima de produção de força do músculo.

A avaliação contrátil foi realizada após o músculo ser cuidadosamente dissecado e suas duas extremidades (tendões) amarradas com linha cirúrgica e montadas em banho de órgãos (AVS, Solução Integrada Ltda., Brasil) para análise do protocolo Curva força $\mathrm{x}$ frequência (Figura 18). A extremidade distal foi fixada num gancho dentro de uma cuba de vidro $(25 \mathrm{~mL})$, contendo solução de Krebs aerada com solução carbogênica $\left(95 \%\right.$ de $\mathrm{O}_{2}$ e $5 \%$ de $\left.\mathrm{CO}_{2}\right)$, e a extremidade proximal foi fixada a um transdutor de força isométrica, conectado a um sistema computadorizado para aquisição e registro dos dados (AQCAD AVS, Solução Integrada Ltda., Brasil). O músculo foi estimulado eletricamente por eletrodos inseridos dentro da cuba, utilizando-se um estimulador elétrico e um amplificador, controlado por um sistema computadorizado. Após definido o comprimento muscular inicial as tensões absolutas aos estímulos foram corrigidas pelo valor da área de secção transversa (AST) do músculo, resultando no valor da força específica. A AST foi calculada pela seguinte fórmula: AST = Massa do músculo (g) / Comprimento ótimo das fibras musculares (mm, obtido pelo produto do valor do comprimento ótimo do músculo por 0,48 para o EDL) $x$ densidade do músculo esquelético. Os resultados foram registrados pelo software AQCAD (AVS, 
Solução Integrada Ltda., Brasil) com taxa de aquisição de $2500 \mathrm{~Hz}$ e foram analisados por meio do software ANCAD (AVS, Solução Integrada Ltda., Brasil).
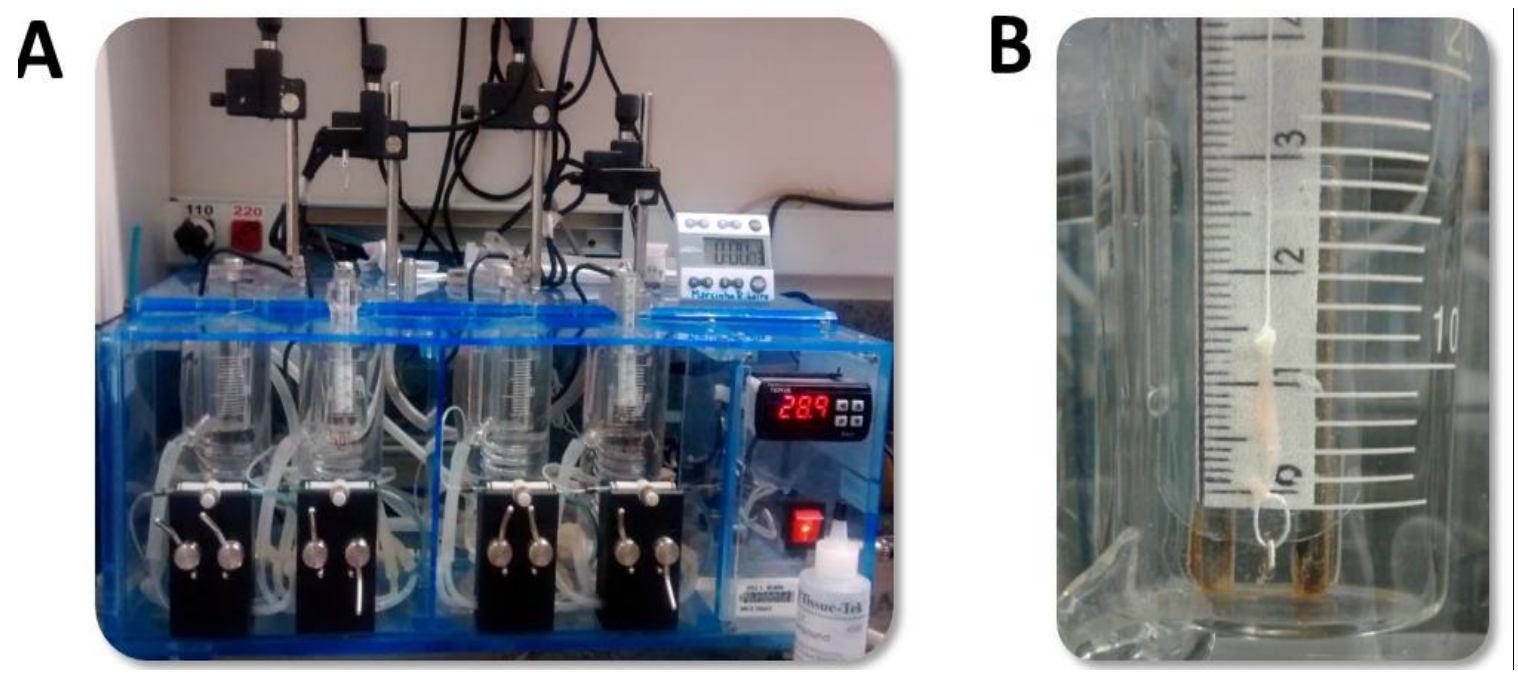

Figura 18. Sistema de banho de órgãos (A) e cuba com o músculo EDL (B) para avaliação de função contrátil.

\subsection{Avaliação da ingestão alimentar em gaiola metabólica}

Para verificarmos se o quadro de IC desenvolvido pelos camundongos do grupo MCT seria acompanhado de redução na ingestão alimentar, característica observada em outros modelos de IC, os animais tratados com MCT e com salina foram mantidos em gaiolas metabólicas para camundongos (Beiramar ${ }^{\circledR}$ ) onde era controlada a ingestão de ração e água, bem como a excreção de urina e fezes destes animais (Figura 19). Antes do período de avaliação de $24 \mathrm{~h}$ em gaiola metabólica, os animais realizaram um dia de adaptação, com o objetivo de ambientá-los à gaiola. 


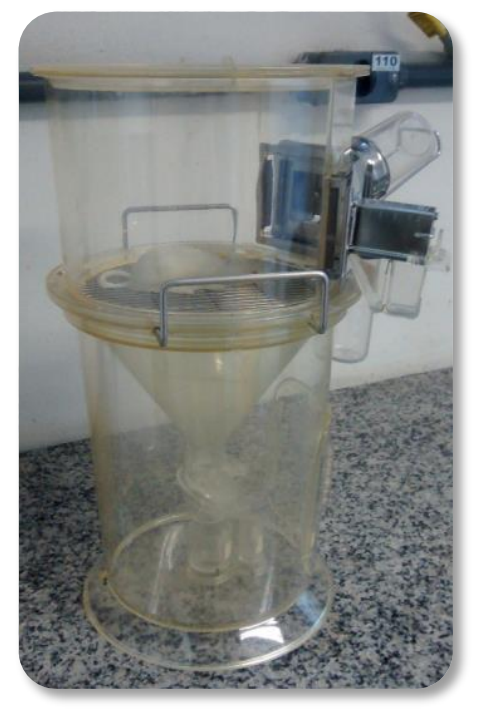

Figura 19. Gaiola metabólica para avaliação da ingestão alimentar de camundongos.

\subsection{Coleta dos tecidos}

Após o final do período experimental, os animais foram anestesiados e mortos por deslocamento cervical, método rápido e livre de sofrimentos prolongados como mencionado anteriormente. Para a avaliação de edema pulmonar e ascite, foram coletadas partes dos pulmões e fígados, para posterior aferição de suas massas (massa úmida) e colocados em estufa a $65^{\circ} \mathrm{C}$, após $24 \mathrm{~h}$ a massa dos tecidos fio novamente aferida (massa seca). A retenção hídrica, sugestiva de congestão hepática e pulmonar foi estimada a partir da razão da massa dos órgãos úmidos/secos. Para avaliação da hipertrofia cardíaca, os corações foram retirados e pesados, em seguida os ventrículos direito e esquerdo mais o septo tiveram suas massas aferidas separadamente. Em seguida o pulmão direito e as câmaras cardíacas foram mantidas em formalina $4 \%$ por $24 \mathrm{~h}$ e então armazenados em álcool $70 \%$ até a realização das análises histológicas. Para a avaliação da massa muscular, os músculos da pata direita: sóleo, vasto lateral, tibial anterior e EDL foram pesados e os resultados normalizados pela massa corporal. Após aferição da massa, os músculos foram em seguida colocados em barcas de alumínio com Tissue-Tek $^{\circledR}$, pré-congelados em isopentano e rapidamente acondicionados em nitrogênio líquido, onde foram mantidos até a realização dos cortes histológicos. Para a avaliação da função muscular "ex vivo", o músculo EDL da pata esquerda foi retirado. Os demais músculos da pata esquerda foram congelados em nitrogênio e mantidos a $-80^{\circ} \mathrm{C}$ para análise da expressão gênica. 


\subsection{Análises histológicas}

\subsection{1. Área de secção transversa das fibras do tipo I e II}

Os músculos sóleo e EDL foram seccionados transversalmente em criostato (Leica CM1850, Alemanha) na espessura de 5 a $8 \mu \mathrm{m}$. As secções foram previamente fixadas com formalina (Sigma-Aldrich, HT501128, Brasil) 4\% por 10 minutos em temperatura ambiente, permeabilizadas em 0,2\% de Triton X-100 (Bio-rad, 01-0407, EUA) e 1\% albumina sérica bovina (BSA; Amresco, E588, EUA) diluídos em PBS (Phosphate Buffered Saline; Tampão Fosfato Salino; Sigma-Aldrich, P4417, Brasil) por 10 minutos. O bloqueio foi feito em 10\% goat serum (Sigma-Aldrich, G9023, Brasil) em PBS por 45 minutos. As lâminas foram incubadas com solução contendo os anticorpos primários contra: 1) MHCI (diluição 1:6000 Developmental Studies Hybridoma Bank, BA-D5) ou MHC IIa (diluição 1:200, Developmental Studies Hybridoma Bank, SC-71) para a diferenciação da fibra muscular do tipo I; e 2) Laminina (diluição 1:100, Sigma-Aldrich, L9393) para a marcação das demais fibras musculares, negativas para tipo I, ou seja, fibras do tipo II; com 1,5\% de soro de cabra em PBS por 1 h e 30 minutos em temperatura ambiente. Após a lavagem com 0,2\% Triton X-100 e 1\% albumina sérica bovina em PBS (3 vezes de 10 minutos cada), os cortes foram incubados por 40 minutos em sala escura com uma solução PBS contendo os respectivos anticorpos secundários fluorescentes para MHCI (diluição 1:500; Alexa Fluor 568 goat anti-mouse, Life Technologies, A11004, EUA) e Laminina (diluição 1:500; Alexa Fluor 488 goat anti-rabbit, Life Technologies, A11008, EUA) e Hoechst (diluição 1:1000, para visualização dos núcleos). Após 30 minutos de lavagem em 0,2\% Triton X-100 e 1\% albumina sérica bovina em PBS, as lâminas foram cobertas com lamínulas utilizando-se glicerol tamponado (60\% Glicerol, 40\% Tris- $\mathrm{HCl} 0.1 \mathrm{M} \mathrm{pH} 9.3$ ).

A captura das imagens obtidas pelas duas técnicas de coloração foi realizada com aumento de 200x e objetiva de 20x. O registro das imagens foi realizado em computador acoplado a um microscópio fluorescente e conectado a um sistema fotográfico (magnificação de 200x) (Leica Qwin, Leica Microsystems, Alemanha). A quantificação da AST dos diferentes tipos de fibras dos músculos sóleo e plantar foi realizada por meio do programa ImageJ. Os resultados foram expressos em $\mu \mathrm{m}^{2}$.

\subsubsection{Imunofluorescência para células satélites}

O músculo tibial anterior foi seccionado transversalmente em criostato (Leica CM1850, Alemanha) na espessura de 5 a $8 \mu \mathrm{m}$. As secções foram previamente fixadas com formalina 
(Sigma-Aldrich, HT501128, Brasil) $4 \%$ por 10 minutos em temperatura ambiente, permeabilizadas em 0,2\% de Triton X-100 (Bio-rad, 01-0407, EUA) e 1\% albumina sérica bovina (BSA; Amresco, E588, EUA) diluídos em PBS (Phosphate Buffered Saline; Tampão Fosfato Salino; Sigma-Aldrich, P4417, Brasil) por 10 minutos. O bloqueio foi feito em 10\% goat serum (Sigma-Aldrich, G9023, Brasil) em PBS por 45 minutos. As lâminas foram incubadas com solução contendo os anticorpos primários contra 1) Pax7 (diluição 1:50, Developmental Studies Hybridoma Bank, PAX7-C) para marcação de células satélites; e 2) Laminina (diluição 1:100, Sigma-Aldrich, L9393) para a marcação das demais fibras musculares overnight em temperatura ambiente. Após a lavagem com 0,2\% Triton X-100 e 1\% albumina sérica bovina em PBS (3 vezes de 10 minutos cada), os cortes foram incubados por 40 minutos em sala escura com uma solução PBS contendo os respectivos anticorpos secundários fluorescentes para Pax7 (diluição 1:500; Alexa Fluor 568 goat anti-mouse, Life Technologies, A11004, EUA) e Laminina (diluição 1:500; Alexa Fluor 488 goat anti-rabbit, Life Technologies, A11008, EUA) e Hoechst (diluição 1:1000, para visualização dos núcleos). Após 30 minutos de lavagem em 0,2\% Triton X-100 e 1\% albumina sérica bovina em PBS, as lâminas foram cobertas com lamínulas utilizando-se glicerol tamponado (60\% Glicerol, 40\% Tris- $\mathrm{HCl} 0.1 \mathrm{M} \mathrm{pH} \mathrm{9.3).}$

A captura das imagens obtidas pelas duas técnicas de coloração foi realizada com aumento de 200x e objetiva de 20x. O registro das imagens foi realizado em computador acoplado a um microscópio fluorescente e conectado a um sistema fotográfico (magnificação de 200x) (Leica Qwin, Leica Microsystems, Alemanha). O número de células satélites foi dado pela marcação de Pax7+Hoescht, como indicado na Figura 12E.

\subsubsection{Inflamação muscular}

Os tecidos foram corados por hematoxilina-eosina. A análise das imagens foi realizada em microscópio óptico associado a um sistema de análise de imagens Quantimet Leica® (Leica, Reino Unido) com aumento de 200x e objetiva de 10x. Todas as imagens foram divididas em pequenos campos e eram assinalados todos os campos que apresentassem acúmulo de núcleos.

\subsubsection{Diâmetro de cardiomiócitos}

Os tecidos foram enviados para o Instituto do Coração (InCor) para serem processados e corados por hematoxilina-eosina. A análise das imagens foi realizada em microscópio óptico 
associado a um sistema de análise de imagens Quantimet Leica ${ }^{\circledR}$ (Leica, Reino Unido) com aumento de 200x e objetiva de 40x. Todos os cardiomiócitos com núcleos visíveis e membrana celular intacta foram selecionados para análise.

\subsubsection{Edema pulmonar}

Os tecidos foram enviados para o Instituto do Coração (InCor) para serem processados e corados por hematoxilina-eosina. A análise das imagens foi realizada em microscópio óptico associado a um sistema de análise de imagens Quantimet Leica ${ }^{\circledR}$ (Leica, Reino Unido) com aumento de 200x e objetiva de 10x. Todas as imagens foram divididas em pequenos campos e eram assinalados todos os campos que fossem positivos para edema pulmonar. Foi considerado como edema pulmonar os campos que apresentavam acúmulo de água no espaço intersticial, visíveis pela cor rosa claro.

\subsection{Expressão gênica}

A expressão dos genes de interesse foram avaliados por meio da técnica de reação em cadeia da polimerase quantitativa em tempo real (qRT-PCR). Para isso, foi realizado o isolamento do RNA total utilizando método de trizol. As concentrações e a pureza do RNA são determinadas por espectrofotometria (NanoDrop 2000, Thermo Scientific, EUA) e por gel de agarose 1\% marcado com Nancy-520 (Sigma-Aldrich, SP, Brasil). A transcrição reversa do RNA (síntese de cDNA) é realizada utilizando RevertaidTM First Strand cDNA Synthesis Kit (Fermentas, EUA) seguindo as instruções do fabricante. A expressão gênica foi avaliada por qRT-PCR (ABI Prism 7500, Applied Biosystems, EUA) utilizando primers específicos e Maxima ${ }^{\circledR}$ SYBR Green/ROX qPCR Master Mix (Fermentas, EUA). Os resultados são expressos utilizando o método de limiar comparativo de ciclos $\left(2^{-\Delta \Delta C t}\right)$ como descrito pelo produtor do sistema.

Os oligonucleotídeos iniciadores (primers) específicos de cada gene foram desenhados de acordo com as sequências disponíveis no GenBank (http://www.ncbi.nlm.nih.gov/gene) utilizando a ferramenta Primer-BLAST (http://www.ncbi.nlm.nih.gov/tools/primer-blast). O gene normalizador foi determinado a partir de padronizações no laboratório (Tabela 2). 
Tabela 2 - Sequência dos oligonucleotídeos iniciadores (primers) utilizados na expressão gênica por meio de qRT-PCR.

\begin{tabular}{|c|c|c|}
\hline PRIMER & SENSE & ANTI-SENSE \\
\hline$P A X 7$ & 5'GACTCCGGATGTGGAGAAAA3' & 5'GAGCACTCGGCTAATCGAAC3' \\
\hline Myf5 & 5'AGGAAAAGAAGCCCTGAAGC3' & 5'GCAAAAAGAACAGGCAGAGG3' \\
\hline MyoD & 5'AGTGAATGAGGCCTTCGAGA3' & 5'GCATCTGAGTCGCCACTGTA3' \\
\hline MyoG & 5'TCCCAACCCAGGAGATCATT3' & 5’AGTTGGGCATGGTTTCGTCT3' \\
\hline MRF4 & 5'ATGGTACCCTATCCCCTTGC3' & 5'ATCTTGGGGGCAGATTTTCT3' \\
\hline Miostatina & 5'CTGTAACCTTCCCAGGACCA3' & 5'TCTTTTGGGTGCGATAATCC3' \\
\hline Desmina & 5'AGGCTCAAGGCCAAACTACA3' & 5'TCTGCGCTCCAGGTCAATAC3' \\
\hline $\begin{array}{c}\text { Colágeno } \\
\text { tipo I }\end{array}$ & 5'TGACTGGAAGAGCGGAGAGT3' & 5'AGACGGCTGAGTAGGGAACA3' \\
\hline $\begin{array}{c}\text { Colágeno } \\
\text { tipo III }\end{array}$ & 5'CGAATTCAAGGCTGAAGGA3' & 5'TTGCTGGGGTTTCAGAGAG3' \\
\hline MurF & 5'GTGTGAGGTGCCTACTTGCT3' & 5'ACTCAGCTCCTCCTTCACCT3' \\
\hline Atrogin & 5'TACTAAGGAGCGCCATGGATAC3' & 5'GTTGAATCTTCTGGAATCCAGG3' \\
\hline Ciclofilina & 5'TGGCAAGCATGTGGTCTTTGGGAAG3' & 5'GGTGATCTTCTTGCTGGTCTTGCCATTC3' \\
\hline
\end{tabular}

\subsection{Análise estatística}

Inicialmente, a distribuição dos dados foi testada por meio do teste de Shapiro-Wilk. Como os dados apresentaram distribuição normal e variâncias homogêneas, utilizamos análises paramétricas. Conforme o desenho experimental apresentado, foi utilizada análise de variância (ANOVA) para um ou dois caminhos ou teste $t$ de Student unicaudal para amostras não pareadas. No caso de interação significante, foi aplicado o teste post-hoc de Sidak. Para todas as análises, foi adotado como nível de significância um $p<0,05$. Os dados estão apresentados como média \pm erro padrão. 


\section{REFERÊNCIAS}

ADAMOPOULOS, S.; PARISSIS, J. T.; KREMASTINOS, D. T. New aspects for the role of physical training in the management of patients with chronic heart failure. Int J Cardiol, v. 90, n. 1, p. 1-14, Jul 2003.

ADAMOPOULOS, S. et al. Circadian pattern of heart rate variability in chronic heart failure patients. Effects of physical training. Eur Heart J, v. 16, n. 10, p. 1380-6., 1995.

AHN, B. et al. Diaphragm atrophy and contractile dysfunction in a murine model of pulmonary hypertension. PLoS One, v. 8, n. 4, p. e62702, 2013.

ALLEN, D. G.; LAMB, G. D.; WESTERBLAD, H. Skeletal muscle fatigue: cellular mechanisms. Physiol Rev, v. 88, n. 1, p. 287-332, Jan 2008.

ALLEN, D. L.; ROY, R. R.; EDGERTON, V. R. Myonuclear domains in muscle adaptation and disease. Muscle Nerve, v. 22, n. 10, p. 1350-60, Oct 1999.

ANKER, M. S. et al. Highlights of mechanistic and therapeutic cachexia and sarcopenia research 2010 to 2012 and their relevance for cardiology. Arch Med Sci, v. 9, n. 1, p. 166-71, Feb 212013.

ANKER, S. D.; COATS, A. J. Cardiac cachexia: a syndrome with impaired survival and immune and neuroendocrine activation. Chest, v. 115, n. 3, p. 836-47, Mar 1999.

ANKER, S. D. et al. Wasting as independent risk factor for mortality in chronic heart failure. Lancet, v. 349, n. 9058, p. 1050-3, Apr 121997.

ANKER, S. D. et al. Cytokines and neurohormones relating to body composition alterations in the wasting syndrome of chronic heart failure. Eur Heart J, v. 20, n. 9, p. 683-93, May 1999.

ANKER, S. D.; SHARMA, R. The syndrome of cardiac cachexia. Int J Cardiol, v. 85, n. 1, p. 51-66, Sep 2002. 
ARENA, R. et al. The effect of exercise training on the pulmonary arterial system in patients with pulmonary hypertension. Prog Cardiovasc Dis, v. 57, n. 5, p. 480-8, Mar-Apr 2015.

ARTHUR, P. G.; GROUNDS, M. D.; SHAVLAKADZE, T. Oxidative stress as a therapeutic target during muscle wasting: considering the complex interactions. Curr Opin Clin Nutr Metab Care, v. 11, n. 4, p. 408-16, Jul 2008.

ASAKURA, A. et al. Myogenic specification of side population cells in skeletal muscle. J Cell Biol, v. 159, n. 1, p. 123-34, Oct 142002.

BABU, A. S.; ARENA, R.; MORRIS, N. R. Evidence on Exercise Training in Pulmonary Hypertension. Adv Exp Med Biol, v. 1000, p. 153-172, 2017.

BACURAU A.V., C. T. F., SOUZA R.W. VOLTARELLI V.A., GABRIEL, D., BRUM PC. Aerobic Exercise and Pharmacological Therapies for Skeletal Myopathy in Heart Failure: Similarities and Differences. Oxidative Medicine and Cellular Longevity, v. 16, p. 16, 2015.

BACURAU, A. V., CUNHA, T. F., SOUZA R.W., VOLTARELLI, V.A., GABRIEL-COSTA, D., BRUM, P.C. Aerobic Exercise and Pharmacological Therapies for Skeletal Myopathy in Heart Failure: Similarities and Differences. Oxidative Medicine and Cellular Longevity, 2015 .

BACURAU, A. V. et al. Akt/mTOR pathway contributes to skeletal muscle anti-atrophic effect of aerobic exercise training in heart failure mice. Int J Cardiol, v. 214, p. 137-47, Jul 12016.

BACURAU, A. V. et al. Sympathetic hyperactivity differentially affects skeletal muscle mass in developing heart failure: role of exercise training. J Appl Physiol, v. 106, n. 5, p. 1631-40, May 2009.

BARCLAY, C. J. Modelling diffusive $\mathrm{O}(2)$ supply to isolated preparations of mammalian skeletal and cardiac muscle. J Muscle Res Cell Motil, v. 26, n. 4-5, p. 225-35, 2005.

BATT, J. et al. Skeletal muscle dysfunction in idiopathic pulmonary arterial hypertension. Am J Respir Cell Mol Biol, v. 50, n. 1, p. 74-86, Jan 2014. 
BOCCHI, E. ATUALIZAÇÃO DA DIRETRIZ BRASILEIRA DE INSUFICIÊNCIA CARDÍACA

CRÔNICA. SOCIEDADE BRASILEIRA DE CARDIOLOGIA, v. 98, 2012.

BREDA, A. P. et al. Skeletal muscle abnormalities in pulmonary arterial hypertension. PLoS One, v. 9, n. 12, p. e114101, 2014.

BREITBART, A. et al. Myostatin from the heart: local and systemic actions in cardiac failure and muscle wasting. Am J Physiol Heart Circ Physiol, v. 300, n. 6, p. H1973-82, Jun 2011.

BROOKS, S. P.; DUNNETT, S. B. Tests to assess motor phenotype in mice: a user's guide. Nat Rev Neurosci, v. 10, n. 7, p. 519-29, Jul 2009.

BROWN, M. B. et al. High-intensity interval training, but not continuous training, reverses right ventricular hypertrophy and dysfunction in a rat model of pulmonary hypertension. Am J Physiol Regul Integr Comp Physiol, v. 312, n. 2, p. R197-R210, Feb 012017.

BRUM, P. C. et al. Aerobic exercise training in heart failure: impact on sympathetic hyperactivity and cardiac and skeletal muscle function. Braz J Med Biol Res, v. 44, n. 9, p. 827-35, Sep 2011.

BRUM, P. C. et al. Abnormal cardiac function associated with sympathetic nervous system hyperactivity in mice. American Journal of Physiology Heart Circulatory Physiology, v. 283, n. 5, p. H1838-45, Nov 2002.

CARLSON, B. M. Muscle regeneration in amphibians and mammals: passing the torch. Dev Dyn, v. 226, n. 2, p. 167-81, Feb 2003.

CARLSON, M. E. et al. Molecular aging and rejuvenation of human muscle stem cells. EMBO Mol Med, v. 1, n. 8-9, p. 381-91, Nov 2009.

CHARGE, S. B.; RUDNICKI, M. A. Cellular and molecular regulation of muscle regeneration. Physiol Rev, v. 84, n. 1, p. 209-38, Jan 2004. 
CICILIOT, S. et al. Muscle type and fiber type specificity in muscle wasting. Int J Biochem Cell Biol, v. 45, n. 10, p. 2191-9, Oct 2013.

COLLINS, C. A. et al. A population of myogenic stem cells that survives skeletal muscle aging. Stem Cells, v. 25, n. 4, p. 885-94, Apr 2007.

CUNHA, T. F. et al. Exercise training prevents oxidative stress and ubiquitin-proteasome system overactivity and reverse skeletal muscle atrophy in heart failure. PLoS One, v. 7, n. 8, p. e41701, 2012.

CUNHA, T. F. et al. Exercise training decreases NADPH oxidase activity and restores skeletal muscle mass in heart failure rats. J Appl Physiol (1985), p. jap 00182 2016, Jan 192017.

DOGGRELL, S. A.; BROWN, L. Rat models of hypertension, cardiac hypertrophy and failure. Cardiovasc Res, v. 39, n. 1, p. 89-105, Jul 1998.

DREXLER, H. et al. Alterations of skeletal muscle in chronic heart failure. Circulation, v. 85, n. 5, p. 1751-9, May 1992.

ENACHE, I. et al. Downhill exercise training in monocrotaline-injected rats: Effects on echocardiographic and haemodynamic variables and survival. Arch Cardiovasc Dis, v. 110, n. 2, p. 106-115, Feb 2017.

ERBS, S. et al. Exercise training in patients with severe chronic heart failure: impact on left ventricular performance and cardiac size. A retrospective analysis of the Leipzig Heart Failure Training Trial. Eur J Cardiovasc Prev Rehabil, v. 10, n. 5, p. 336-44, Oct 2003.

FERREIRA, J. C. et al. Maximal lactate steady state in running mice: effect of exercise training. Clin Exp Pharmacol Physiol, v. 34, n. 8, p. 760-5, Aug 2007.

FIELDING, R. A. et al. Acute phase response in exercise. III. Neutrophil and IL-1 beta accumulation in skeletal muscle. Am J Physiol, v. 265, n. 1 Pt 2, p. R166-72, Jul 1993. 
FOALE, R. et al. Echocardiographic measurement of the normal adult right ventricle. Br Heart J, v. 56, n. 1, p. 33-44, Jul 1986.

FOLLAND, J. P.; WILLIAMS, A. G. The adaptations to strength training : morphological and neurological contributions to increased strength. Sports Med, v. 37, n. 2, p. 145-68, 2007.

FOX, B. D. et al. Ambulatory rehabilitation improves exercise capacity in patients with pulmonary hypertension. J Card Fail, v. 17, n. 3, p. 196-200, Mar 2011.

FRAGA, R. et al. Exercise training reduces sympathetic nerve activity in heart failure patients treated with carvedilol. Eur J Heart Fail, v. 9, n. 6-7, p. 630-6, Jun-Jul 2007.

FRIEDBERG, M. K.; REDINGTON, A. N. Right versus left ventricular failure: differences, similarities, and interactions. Circulation, v. 129, n. 9, p. 1033-44, Mar 42014.

G, V. Handbuch der Entwicklungsgeschichte des Menschen. 1835.

GAINE, S. Pulmonary hypertension. JAMA, v. 284, n. 24, p. 3160-8, Dec 272000.

GHIO, S. et al. Independent and additive prognostic value of right ventricular systolic function and pulmonary artery pressure in patients with chronic heart failure. J Am Coll Cardiol, v. 37, n. 1, p. 183-8, Jan 2001.

GIELEN, S. et al. Anti-inflammatory effects of exercise training in the skeletal muscle of patients with chronic heart failure. J Am Coll Cardiol, v. 42, n. 5, p. 861-8, Sep 32003.

GONYEA, W.; ERICSON, G. C.; BONDE-PETERSEN, F. Skeletal muscle fiber splitting induced by weight-lifting exercise in cats. Acta Physiol Scand, v. 99, n. 1, p. 105-9, Jan 1977.

GONYEA, W. J. et al. Exercise induced increases in muscle fiber number. Eur J Appl Physiol Occup Physiol, v. 55, n. 2, p. 137-41, 1986.

HAIDARA, M. A. et al. Heart Failure Models: Traditional and Novel Therapy. Curr Vasc Pharmacol, v. 13, n. 5, p. 658-69, 2015. 
HALL-CRAGGS, E. C. The longitudinal division of fibres in overloaded rat skeletal muscle. J Anat, v. 107, n. Pt 3, p. 459-70, Nov 1970.

HAMBRECHT, R. et al. Effects of endurance training on mitochondrial ultrastructure and fiber type distribution in skeletal muscle of patients with stable chronic heart failure. J Am Coll Cardiol, v. 29, n. 5, p. 1067-73, Apr 1997.

HAMBRECHT, R. et al. Physical training in patients with stable chronic heart failure: effects on cardiorespiratory fitness and ultrastructural abnormalities of leg muscles. J Am Coll Cardiol, v. 25, n. 6, p. 1239-49, May 1995.

HAMBRECHT, R. et al. Reduction of insulin-like growth factor-I expression in the skeletal muscle of noncachectic patients with chronic heart failure. Journal of the American College of Cardiology, v. 39, n. 7, p. 1175-81, Apr 32002.

HANDOKO, M. L. et al. Opposite effects of training in rats with stable and progressive pulmonary hypertension. Circulation, v. 120, n. 1, p. 42-9, Jul 72009.

HARRINGTON, D. et al. Skeletal muscle function and its relation to exercise tolerance in chronic heart failure. J Am Coll Cardiol, v. 30, n. 7, p. 1758-64, Dec 1997.

HAWKE, T. J.; GARRY, D. J. Myogenic satellite cells: physiology to molecular biology. J Appl Physiol (1985), v. 91, n. 2, p. 534-51, Aug 2001.

HAWKE, T. J.; JIANG, N.; GARRY, D. J. Absence of p21CIP rescues myogenic progenitor cell proliferative and regenerative capacity in Foxk1 null mice. J Biol Chem, v. 278, n. 6, p. 4015-20, Feb 72003.

JACKMAN, R. W.; KANDARIAN, S. C. The molecular basis of skeletal muscle atrophy. American Journal of Physiology Cell Physiology, v. 287, n. 4, p. C834-43, Oct 2004.

KANNEL, W. B.; GORDON, T.; OFFUTT, D. Left ventricular hypertrophy by electrocardiogram. Prevalence, incidence, and mortality in the Framingham study. Ann Intern Med, v. 71, n. 1, p. 89-105, Jul 1969. 
KATO, A. Muscle wasting is associated with reduced exercise capacity and advanced disease in patients with chronic heart failure. Future Cardiol, v. 9, n. 6, p. 767-70, Nov 2013.

KOSSAIFY, A. Echocardiographic Assessment of the Right Ventricle, from the Conventional Approach to Speckle Tracking and Three-Dimensional Imaging, and Insights into the "Right Way" to Explore the Forgotten Chamber. Clin Med Insights Cardiol, v. 9, p. 65-75, 2015.

LI, L. et al. Inhibition of nuclear factor-kappaB in the lungs prevents monocrotaline-induced pulmonary hypertension in mice. Hypertension, v. 63, n. 6, p. 1260-9, Jun 2014.

LOPES, R. D. et al. Changes in the production of IL-10 and TNF-alpha in skeletal muscle of rats with heart failure secondary to acute myocardial infarction. Arq Bras Cardiol, v. 94, n. 3, p. 293-300, 313-20, Mar 2010.

LOURENCO, A. P. et al. A Western-type diet attenuates pulmonary hypertension with heart failure and cardiac cachexia in rats. J Nutr, v. 141, n. 11, p. 1954-60, Nov 2011.

LUNDE, P. K. et al. Skeletal muscle disorders in heart failure. Acta Physiologica Scandinavica, v. 171, n. 3, p. 277-94, Mar 2001.

MAHMUD, M.; CHAMPION, H. C. Right ventricular failure complicating heart failure: pathophysiology, significance, and management strategies. Curr Cardiol Rep, v. 9, n. 3, p. 200-8, May 2007.

MAINGUY, V. et al. Effects of a rehabilitation program on skeletal muscle function in idiopathic pulmonary arterial hypertension. J Cardiopulm Rehabil Prev, v. 30, n. 5, p. 31923, Sep-Oct 2010a.

Peripheral muscle dysfunction in idiopathic pulmonary arterial hypertension. Thorax, v. 65 , n. 2, p. 113-7, Feb 2010b.

MANCINI, D. M. et al. Contribution of intrinsic skeletal muscle changes to 31P NMR skeletal muscle metabolic abnormalities in patients with chronic heart failure. Circulation, v. 80, n. 5, p. 1338-46, Nov 1989. 
MANCINI, D. M. et al. Contribution of skeletal muscle atrophy to exercise intolerance and altered muscle metabolism in heart failure. Circulation, v. 85, n. 4, p. 1364-73, Apr 1992.

MANDIC, S. et al. Resistance versus aerobic exercise training in chronic heart failure. Curr Heart Fail Rep, v. 9, n. 1, p. 57-64, Mar 2012.

MANSUR ADE, P., FAVARATO, D. Mortalidade por Doenças Cardiovasculares no Brasil e na Região Metropolitana de São Paulo: Atualização 2011. Arquivos Brasileiros de Cardiologia, 2012.

MARRA, A. M. et al. Pulmonary arterial hypertension-related myopathy: an overview of current data and future perspectives. Nutr Metab Cardiovasc Dis, v. 25, n. 2, p. 131-9, Feb 2015.

MATHEW, J. et al. Reduction of cardiovascular risk by regression of electrocardiographic markers of left ventricular hypertrophy by the angiotensin-converting enzyme inhibitor ramipril. Circulation, v. 104, n. 14, p. 1615-21, Oct 022001.

MATSUDA, R.; NISHIKAWA, A.; TANAKA, H. Visualization of dystrophic muscle fibers in mdx mouse by vital staining with Evans blue: evidence of apoptosis in dystrophin-deficient muscle. J Biochem, v. 118, n. 5, p. 959-64, Nov 1995.

MAURO, A. Satellite cell of skeletal muscle fibers. J Biophys Biochem Cytol, v. 9, p. 493-5, Feb 1961.

MCKENNA, S. P. et al. The Cambridge Pulmonary Hypertension Outcome Review (CAMPHOR): a measure of health-related quality of life and quality of life for patients with pulmonary hypertension. Qual Life Res, v. 15, n. 1, p. 103-15, Feb 2006.

MCLAUGHLIN, V. V.; MCGOON, M. D. Pulmonary arterial hypertension. Circulation, v. 114, n. 13, p. 1417-31, Sep 262006. 
MEDEIROS, A. et al. Exercise Training Delays Cardiac Dysfunction and Prevents Calcium Handling Abnormalities in Sympathetic Hyperactivity-Induced Heart Failure Mice. J Appl Physiol, Nov 12007.

MEHL, K. A. et al. Myofiber degeneration/regeneration is induced in the cachectic ApcMin/+ mouse. J Appl Physiol (1985), v. 99, n. 6, p. 2379-87, Dec 2005.

METTER, E. J. et al. Skeletal muscle strength as a predictor of all-cause mortality in healthy men. J Gerontol A Biol Sci Med Sci, v. 57, n. 10, p. B359-65, Oct 2002.

MEYRICK, B.; GAMBLE, W.; REID, L. Development of Crotalaria pulmonary hypertension: hemodynamic and structural study. Am J Physiol, v. 239, n. 5, p. H692-702, Nov 1980.

MORLEY, J. E.; THOMAS, D. R.; WILSON, M. M. Cachexia: pathophysiology and clinical relevance. The American Journal of Clinical Nutrition, v. 83, n. 4, p. 735-43, Apr 2006a.

Cachexia: pathophysiology and clinical relevance. Am J Clin Nutr, v. 83, n. 4, p. 73543, Apr 2006b.

MURACH, K. A. et al. Differential requirement for satellite cells during overload-induced muscle hypertrophy in growing versus mature mice. Skelet Muscle, v. 7, n. 1, p. 14, Jul 10 2017.

NATALI, A. J. et al. Voluntary exercise delays heart failure onset in rats with pulmonary artery hypertension. Am J Physiol Heart Circ Physiol, v. 309, n. 3, p. H421-4, Aug 12015.

NOGUEIRA-FERREIRA, R. et al. Exercise preconditioning prevents MCT-induced right ventricle remodeling through the regulation of TNF superfamily cytokines. Int J Cardiol, v. 203, p. 858-66, Jan 152016.

PATTEN, R. D.; HALL-PORTER, M. R. Small animal models of heart failure: development of novel therapies, past and present. Circ Heart Fail, v. 2, n. 2, p. 138-44, Mar 2009. 
PIEPOLI, M. F.; COATS, A. J. The 'skeletal muscle hypothesis in heart failure' revised. Eur Heart J, v. 34, n. 7, p. 486-8, Feb 2013.

PITTMAN, J. G.; COHEN, P. The Pathogenesis of Cardiac Cachexia. N Engl J Med, v. 271, p. 453-60 CONCL, Aug 271964.

ROLIM, N. P. et al. Exercise training improves the net balance of cardiac $\mathrm{Ca} 2+$ handling protein expression in heart failure. Physiol Genomics, v. 29, n. 3, p. 246-52, May 112007.

ROVEDA, F. et al. The effects of exercise training on sympathetic neural activation in advanced heart failure: a randomized controlled trial. Journal of American College Cardiology, v. 42, n. 5, p. 854-60, Sep 32003.

RYAN, J. J. et al. Right ventricular adaptation and failure in pulmonary arterial hypertension. Can J Cardiol, v. 31, n. 4, p. 391-406, Apr 2015.

SAHN, D. J. et al. Recommendations regarding quantitation in M-mode echocardiography: results of a survey of echocardiographic measurements. Circulation, v. 58, n. 6, p. 1072-83, Dec 1978.

SARTORE, S.; GORZA, L.; SCHIAFFINO, S. Fetal myosin heavy chains in regenerating muscle. Nature, v. 298, n. 5871, p. 294-6, Jul 151982.

SCHIAFFINO, S. et al. Mechanisms regulating skeletal muscle growth and atrophy. FEBS J, v. 280, n. 17, p. 4294-314, Sep 2013.

SCHULZE, P. C. et al. Chronic heart failure and skeletal muscle catabolism: effects of exercise training. Int J Cardiol, v. 85, n. 1, p. 141-9, Sep 2002a.

Chronic heart failure and skeletal muscle catabolism: effects of exercise training. International Journal of Cardiology, v. 85, n. 1, p. 141-9, Sep 2002 b.

SEALE, P. et al. Pax7 is required for the specification of myogenic satellite cells. Cell, v. 102, n. 6, p. 777-86, Sep 152000. 
ST PIERRE, B. A.; TIDBALL, J. G. Differential response of macrophage subpopulations to soleus muscle reloading after rat hindlimb suspension. J Appl Physiol (1985), v. 77, n. 1, p. 290-7, Jul 1994.

STENMARK, K. R. et al. Animal models of pulmonary arterial hypertension: the hope for etiological discovery and pharmacological cure. Am J Physiol Lung Cell Mol Physiol, v. 297, n. 6, p. L1013-32, Dec 2009.

SULLIVAN, M. J.; GREEN, H. J.; COBB, F. R. Skeletal muscle biochemistry and histology in ambulatory patients with long-term heart failure. Circulation, v. 81, n. 2, p. 518-27, Feb 1990.

Altered skeletal muscle metabolic response to exercise in chronic heart failure. Relation to skeletal muscle aerobic enzyme activity. Circulation, v. 84, n. 4, p. 1597-607, Oct 1991.

SULLIVAN, M. J. et al. Relation between central and peripheral hemodynamics during exercise in patients with chronic heart failure. Muscle blood flow is reduced with maintenance of arterial perfusion pressure. Circulation, v. 80, n. 4, p. 769-81, Oct 1989.

\section{T, S. Mikroskopische Untersuchungen über die Uebereinstimmung in der Struktur und dem Wachstume der Thiere und Pflanzen. 1839.}

TIDBALL, J. G.; VILLALTA, S. A. Regulatory interactions between muscle and the immune system during muscle regeneration. Am J Physiol Regul Integr Comp Physiol, v. 298, n. 5, p. R1173-87, May 2010.

TRAN, D. L. et al. Pathophysiology of exercise intolerance in pulmonary arterial hypertension. Respirology, v. 23, n. 2, p. 148-159, Feb 2018.

TURGEMAN, T. et al. Prevention of muscle fibrosis and improvement in muscle performance in the mdx mouse by halofuginone. Neuromuscul Disord, v. 18, n. 11, p. 857-68, Nov 2008. 
VELEZ-ROA, S. et al. Increased sympathetic nerve activity in pulmonary artery hypertension. Circulation, v. 110, n. 10, p. 1308-12, Sep 72004.

VESCOVO, G. Skeletal muscle response to exercise and treatment: another sibyl in the heart failure syndrome? International Journal of Cardiology, v. 83, n. 1, p. 33-4, Apr 2002.

VEScovo, G.; AMBrosiO, G. B.; DALlA LIBERA, L. Apoptosis and changes in contractile protein pattern in the skeletal muscle in heart failure. Acta Physiol Scand, v. 171, n. 3, p. 305-10, Mar 2001a.

Apoptosis and changes in contractile protein pattern in the skeletal muscle in heart failure. Acta Physiologica Scandinavica, v. 171, n. 3, p. 305-10, Mar 2001 b.

VON HAEHLING, S.; ANKER, S. D. Treatment of cachexia: An overview of recent developments. Int J Cardiol, v. 184, p. 736-42, Apr 12015.

VON HAEHLING, S. et al. Muscle wasting in heart failure: An overview. Int J Biochem Cell Biol, v. 45, n. 10, p. 2257-65, Oct 2013.

VONK-NOORDEGRAAF, A. et al. Right heart adaptation to pulmonary arterial hypertension: physiology and pathobiology. J Am Coll Cardiol, v. 62, n. 25 Suppl, p. D22-33, Dec 242013.

WANG, $X$. et al. Transient systemic mtDNA damage leads to muscle wasting by reducing the satellite cell pool. Hum Mol Genet, v. 22, n. 19, p. 3976-86, Oct 12013.

WILSON, J. R. et al. Exercise intolerance in patients with chronic heart failure: role of impaired nutritive flow to skeletal muscle. Circulation, v. 69, n. 6, p. 1079-87, Jun 1984.

WING, S. S.; GOLDBERG, A. L. Glucocorticoids activate the ATP-ubiquitin-dependent proteolytic system in skeletal muscle during fasting. Am J Physiol, v. 264, n. 4 Pt 1, p. E66876, Apr 1993.

WING, S. S.; HAAS, A. L.; GOLDBERG, A. L. Increase in ubiquitin-protein conjugates concomitant with the increase in proteolysis in rat skeletal muscle during starvation and atrophy denervation. Biochem J, v. 307 ( Pt 3), p. 639-45, May 11995. 
WUST, R. C. et al. Regional skeletal muscle remodeling and mitochondrial dysfunction in right ventricular heart failure. Am J Physiol Heart Circ Physiol, v. 302, n. 2, p. H402-11, Jan 2012.

YAO, J. et al. Hepatic cytochrome P450s play a major role in monocrotaline-induced renal toxicity in mice. Acta Pharmacol Sin, v. 35, n. 2, p. 292-300, Feb 2014.

YOSHIDA, T.; HUQ, T. S.; DELAFONTAINE, P. Angiotensin type 2 receptor signaling in satellite cells potentiates skeletal muscle regeneration. J Biol Chem, v. 289, n. 38, p. 2623948, Sep 192014.

ZAMMIT, P. S. et al. Pax7 and myogenic progression in skeletal muscle satellite cells. J Cell Sci, v. 119, n. Pt 9, p. 1824-32, May 12006.

ZARAGOZA, C. et al. Animal models of cardiovascular diseases. J Biomed Biotechnol, v. 2011, p. 497841, 2011.

ZONG, P.; TUNE, J. D.; DOWNEY, H. F. Mechanisms of oxygen demand/supply balance in the right ventricle. Exp Biol Med (Maywood), v. 230, n. 8, p. 507-19, Sep 2005.

ZURLO, F. et al. Skeletal muscle metabolism is a major determinant of resting energy expenditure. J Clin Invest, v. 86, n. 5, p. 1423-7, Nov 1990. 
ANEXOS

ANEXO I: Aprovação do projeto de pesquisa na Comissão de Ética no Uso de Animais (CEUA) da Escola de Educação Física e Esporte da USP.

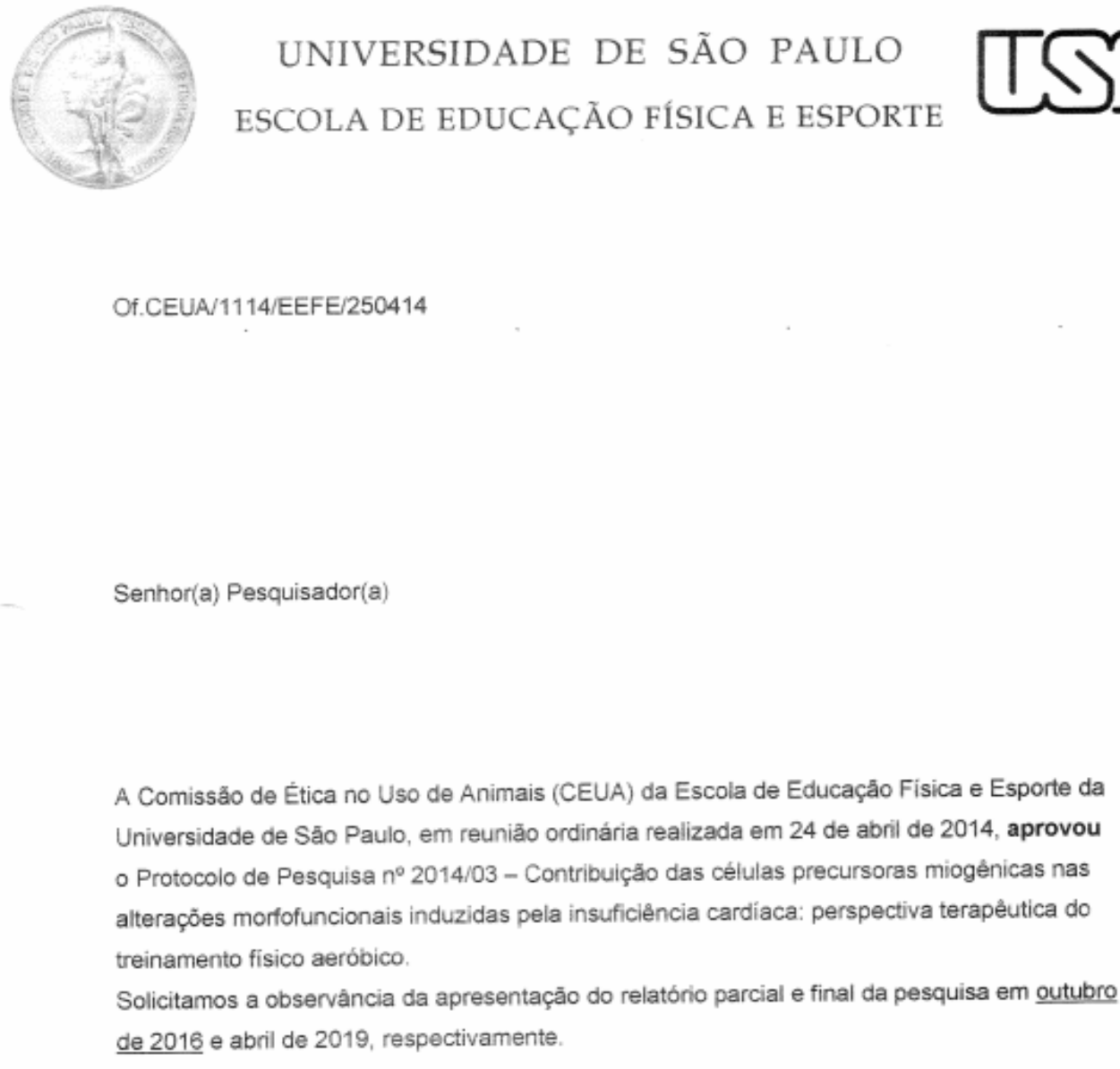

Atenciosamente,

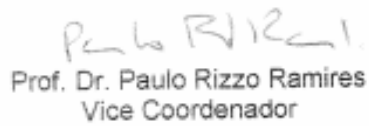

IImo(a). Sr(a).

Prof(a). Dr(a). Patricia Chakur Brum Av. Professor Mello Moraes, 65
CEP 05508-030 - Sio Paulo - 5P - Brasil
Fone/fax: 55113091.3097 